\title{
Integrative Analysis of Disease Signatures Shows Inflammation Disrupts Juvenile Experience- Dependent Cortical Plasticity
}

\author{
Milo R. Smith ${ }^{1,2,3,4,5,6,7,8}$, Poromendro Burman ${ }^{1,3,4,5,8}$, ${ }^{-}$Masato Sadahiro ${ }^{1,3,4,5,6,8}$, ${ }^{\text {Brian A. Kidd, }}$, ${ }^{2,7}$ Joel \\ T. Dudley, ${ }^{2,7}$ and ${ }^{(0 H i r o f u m i}$ Morishita ${ }^{1,3,4,5,8}$
}

\section{DOI:http://dx.doi.org/10.1523/ENEURO.0240-16.2016}

${ }^{1}$ Department of Neuroscience, Icahn School of Medicine at Mount Sinai, New York, New York 10029, ${ }^{2}$ Department of Genetics and Genomic Sciences, Icahn School of Medicine at Mount Sinai, New York, New York 10029, ${ }^{3}$ Department of Psychiatry, Icahn School of Medicine at Mount Sinai, New York, New York 10029, ${ }^{4}$ Department of Ophthalmology, Icahn School of Medicine at Mount Sinai, New York, New York 10029, ${ }^{5}$ Mindich Child Health and Development Institute, Icahn School of Medicine at Mount Sinai, New York, New York 10029, ${ }^{6}$ Graduate School of Biomedical Sciences, Icahn School of Medicine at Mount Sinai, New York, New York 10029, ${ }^{7}$ Icahn Institute for Genomics and Multiscale Biology, Icahn School of Medicine at Mount Sinai, New York, New York 10029, and ${ }^{8}$ Friedman Brain Institute, Icahn School of Medicine at Mount Sinai, New York, New York 10029

\section{Visual Abstract}

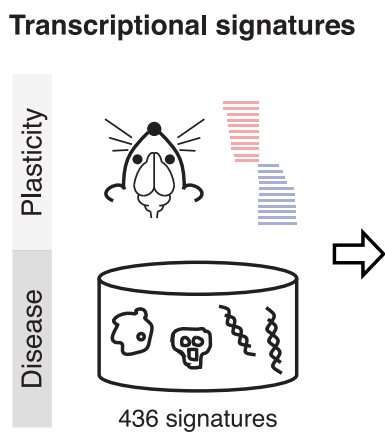

\section{Molecular matching}

Plasticity Disease signature signature

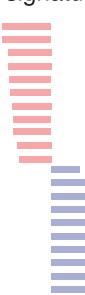

Disease Leverage

Molecular
Experimental validation

Inflammation disrupts developmental plasticity

Throughout childhood and adolescence, periods of heightened neuroplasticity are critical for the development of healthy brain function and behavior. Given the high prevalence of neurodevelopmental disorders, such as autism, identifying disruptors of developmental plasticity represents an essential step for developing strategies for prevention and intervention. Applying a novel computational approach that systematically assessed connections between 436 transcriptional signatures of disease and multiple signatures of neuroplasticity, we identified inflammation as a common pathological process central to a diverse set of diseases predicted to dysregulate

\section{Significance Statement}

During childhood and adolescence, heightened neuroplasticity allows the brain to reorganize and adapt to its environment. Disruptions in these malleable phases can result in permanent neurodevelopmental disorders. To identify pathological mechanisms that disrupt developmental neuroplasticity, we applied a systematic computational screen of hundreds of diseases for their impact on neuroplasticity. We discovered that inflammation would putatively disrupt neuroplasticity and validated this hypothesis in an in vivo experimental mouse model of developmental cortical plasticity. This work suggests that inflammation during the childhood period could have unrecognized negative consequences on the neurodevelopmental trajectory. 
plasticity signatures. We tested the hypothesis that inflammation disrupts developmental cortical plasticity in vivo using the mouse ocular dominance model of experience-dependent plasticity in primary visual cortex. We found that the administration of systemic lipopolysaccharide suppressed plasticity during juvenile critical period with accompanying transcriptional changes in a particular set of molecular regulators within primary visual cortex. These findings suggest that inflammation may have unrecognized adverse consequences on the postnatal developmental trajectory and indicate that treating inflammation may reduce the burden of neurodevelopmental disorders.

Key words: bioinformatics; critical period; inflammation; plasticity; transcriptome; visual cortex

\section{Introduction}

During childhood and adolescence, the human brain undergoes tremendous reorganization during windows of heightened neuroplasticity. These windows of plasticity are critical periods that allow brain circuits to be refined by sensory and social experiences, which help to establish normal perception and higher cognitive function (Johnson and Newport, 1989; Nikolopoulos et al., 1999; Lewis and Maurer, 2005; Schorr et al., 2005; Nelson et al., 2007; Fox et al., 2010). Disruption of these critical periods can alter neural circuits that shape function and behavior, which may, in turn, contribute to a wide range of psychiatric and neurodevelopmental disorders, such as autism (Weinberger, 1987; LeBlanc and Fagiolini, 2011; Takesian and Hensch, 2013; Lee et al., 2014). Previous studies focused on several genes relevant to autism spectrum disorders (MeCP2, Ube3a, Fmr1) and identified marked disruptions in developmental cortical plasticity (Tropea et al., 2009; Yashiro et al., 2009; Harlow et al., 2010). To our knowledge, no studies have conducted a systematic evaluation of pathological mechanisms that may disrupt developmental plasticity. The goal of this study was to leverage the growing repository of publically available transcriptome data from diverse disease states to identify pathological

Received August 9, 2016; accepted November 12, 2016; First published December 15, 2016.

Authors declare no competing financial interests.

Author contributions: M.R.S., B.A.K., J.T.D., and H.M. designed research; M.R.S., P.B., M.S., and H.M. performed research; M.R.S., B.A.K., and H.M. analyzed data; and M.R.S., B.A.K., J.T.D., and H.M. wrote the paper.

This research was funded by a Traineeship, National Institute of Child Health and Human Development-Interdisciplinary Training in Systems and Developmental Biology and Birth Defects Grant T32H-D0-75735 (to M.R.S.); the Mindich Child Health and Development Institute Pilot Fund (to J.T.D. and H.M.); National Institute of Environmental Health Sciences Grant P30-ES-023515 (to J.T.D. and H.M.), the Knights Templar Eye Foundation (to H.M.); the March of Dimes (to H.M.); the Whitehall Foundation (to H.M.); and National Institutes of Health Grants R01-DK-098242 and U54-CA-189201 (to J.T.D.), R01-EY024918, R01-EY-026053, and R21 MH106919 (to H.M.).

Acknowledgments: We thank Dr. N. Bukhari for assistance with the gene expression experiments, Dr. B. Readhead for helpful discussions, and Dr. Nathaniel Heintz (Rockefeller University) for providing the $L y n \times 1^{-1-}$ mice.

Address correspondence to either Joel T. Dudley or Hirofumi Morishita, 1 Gustave L Levy Place, New York, NY 10029, E-mail: joel.dudley@mssm.edu or hirofumi.morishita@mssm.edu.

DOI:http://dx.doi.org/10.1523/ENEURO.0240-16.2016

Copyright (C) 2016 Smith et al.

This is an open-access article distributed under the terms of the Creative Commons Attribution 4.0 International, which permits unrestricted use, distribution and reproduction in any medium provided that the original work is properly attributed. processes with the capacity to disrupt developmental cortical plasticity.

To identify pathological processes that disrupt developmental plasticity, we designed an integrative bioinformatics approach that identifies disruptive pathways through systematic evaluation of molecular profiles of disease states in humans and animals. Our approach adapts molecular matching algorithms from computational drug repurposing (for review, see Hodos et al., 2016) to match transcriptional signatures of disease to those of neuroplasticity. To model plasticity, we leveraged the paradigmatic ocular dominance model of in vivo developmental plasticity (Wiesel and Hubel, 1963) and generated transcriptional signatures from primary visual cortex (V1). We matched plasticity and disease signatures to produce a diverse list of diseases ranked by their likelihood to dysregulate developmental plasticity. Across this ranked list, we sought to identify shared pathophysiology, rather than generate hypotheses about individual disease matches. To quantify shared pathophysiology, we developed and applied a novel Disease Leverage Analysis (DLA) that identifies shared molecular patterns of disease signatures to reveal novel disruptors of developmental plasticity. By examining shared pathophysiology, DLA identified a strong relationship between the molecular signatures of inflammation and developmental plasticity. We tested the hypothesis that inflammation disrupts developmental plasticity in the ocular dominance model of developmental V1 plasticity and found that functional, experience-dependent plasticity in vivo was suppressed by systemic inflammation. Our study demonstrates the utility of an integrative bioinformatics approach for identifying disruptors of developmental neuroplasticity and suggests that inflammation may be an unrecognized risk factor for neurodevelopmental disorders.

\section{Materials and Methods}

\section{Animals}

Male C57BL/6 mice (Charles River Laboratories) and Lyn $\times 1^{-1-}$ mice (Miwa et al., 2006; a gift from Dr. Nathaniel Heintz, Rockefeller University, New York, NY) were group housed (three to five animals per cage) under a standard $12 \mathrm{~h}$ light/dark cycle (lights on at 7:00 A.M., lights off at 7:00 P.M.) with constant temperature $\left(23^{\circ} \mathrm{C}\right)$ and ad libitum access to food and water. The Institutional Animal Care and Use Committee at the 
Icahn School of Medicine at Mount Sinai approved all procedures involving animals.

\section{Substances}

Lyophilized Escherichia coli lipopolysaccharide (LPS; 600,000 endotoxin units/mg; serotype 0127:B8, catalog \#L5024, lot 073M4024V, Sigma-Aldrich) was reconstituted in sterile saline $(0.9 \% \mathrm{NaCl})$ to yield a stock solution of $2 \mathrm{mg} / \mathrm{ml}$, which was diluted with saline on the day of injection to yield a working concentration of $0.03 \mathrm{mg} / \mathrm{ml}$.

\section{Plasticity signature generation}

Transcriptomes were profiled with microarray to generate plasticity signatures. Experiment-naive juvenile C57BL/6 mice at postnatal day 29 (P29), adult $L y n \times 1^{-/-}$ mice (>P60), and adult C57BL/6 mice (>P60; $n=3$ each group) were anesthetized with isoflurane and cervically dislocated; bilateral V1 was removed, immediately frozen on dry ice, and stored at $-80^{\circ} \mathrm{C}$ until processed. Total RNA was extracted from V1 using RNeasy Lipid Tissue Mini kit (Qiagen) and stored at $-80^{\circ} \mathrm{C}$. A total of $4.5 \mu \mathrm{g}$ of $\mathrm{CRNA}$ was hybridized to Illumina WG-6 2.0 microarrays (750 ng/subarray). A juvenile plasticity signature was generated via differential expression analyses of juvenile versus adult V1 transcriptomes by first quantile normalizing probe-level data with limma (Smyth, 2005) and then computing rank-based differential expression with RankProd (Hong et al., 2006; both R packages available through the Bioconductor repository) to yield 193 unique mouse Entrez IDs. For downstream analysis, mouse Entrez IDs were mapped to human orthologs using the Mouse Genome Informatics homology reference to yield a 176 gene juvenile plasticity signature. We generated a Lyn $\times 1^{-1-}$ signature in an analogous manner to juvenile, to yield a $L y n \times 1^{-1-}$ plasticity signature of 98 genes. Raw data for plasticity signatures is freely available at the Gene Expression Omnibus under accession number GSE89757.

\section{Molecular matching algorithm}

To identify diseases that are predicted to dysregulate plasticity signature genes, we developed a molecular matching score, which is the sum of the absolute value of the rank-difference gene expression measure of disease signatures (for details of this expression measure, see Dudley et al., 2009) that intersect with neuroplasticity signature genes. The absolute value was chosen to simplify downstream interpretation. This score is similar in spirit to the approach taken by Zhang and Gant (2008), except in our implementation high scores indicate significant overlap between disease and plasticity signatures, whereas low scores indicate little or no overlap. To compare match scores (M) across diseases, we normalized the scores with $n=10,000$ permutations of scores using $\frac{\mathrm{M}_{\text {actual }}-\overline{\mathrm{M}}_{\text {perm }}}{\sqrt{\frac{\sum_{i=1}^{n}\left(\mathrm{M}_{\text {perm }}-\overline{\mathrm{M}}_{\text {perm }}\right)^{2}}{n-1}}} \cdot p$ Values were estimated using the Generalized Pareto Distribution (Knijnenburg et al., 2009) on $n$ permutations and were multiple test corrected using the method of Benjamini and Hochberg (1995).

\section{Disease Leverage Analysis}

We developed DLA to infer pathological processes that are shared across diseases and predicted to dysregulate plasticity signature genes. For pathological processes, we used the 50 "hallmark" gene sets (MSigDb; Subramanian et al., 2005). We computed a pathology score for each hallmark gene set for each disease signature, for a total of $50 \times 436=21,800$ scores. A pathology score is the sum of the absolute value of the normalized disease signature gene expression that is shared with a hallmark gene set. The absolute value was chosen because the direction of effect for gene sets is not necessarily known. We next calculated a linear regression between the pathology scores for a specific gene set and the plasticity-disease molecular match scores. We estimated the $p$ value for the association between the pathology scores and disease-plasticity scores (the $\beta_{1}$ coefficient) by computing 20,000 permutations of pathology scores using gene sets the same length as the input gene set and then calculating the regression on the permuted scores. If $\sum_{i=1}^{n}\left[\mathbb{1}_{\left[\left|\beta 1_{\text {perm }}\right|>\left|\beta 1_{\text {actual }}\right|\right]}\right]>10$, where $\mathbb{1}$ is the indicator function (i.e., the value is 1 when the conditional is satisfied and 0 otherwise) and $n=$ the number of permutations, the $p$ value was the empirical estimate: $\frac{\sum_{i=1}^{n}\left|\beta 1_{\text {perm }}\right|>\left|\beta 1_{\text {actual }}\right|}{n}$; otherwise, the Generalized Pareto Distribution was used to estimate the $p$ value (Knijnenburg et al., 2009). Bonferroni's method was used to correct for multiple hypothesis tests (denoted $p_{\text {corrected }}$ in the text). To account for the probability of a large coefficient by chance, actual $\beta_{1}$ coefficients were normalized by the permutated distribu-

$$
\text { tion of } \beta_{1} \text { according to } \frac{\beta 1_{\text {actual }}-\overline{\beta 1}_{\text {perm }}}{\sqrt{\frac{\sum_{i=1}^{n}\left(\beta 1_{\text {perm }}-\overline{\beta 1_{\text {perm }}}\right)^{2}}{n-1}}} \text {. }
$$

Positive $\beta$ values are pathological processes associated with diseases that were predicted to disrupt plasticity signatures. Negative $\beta$ values are pathological processes associated with diseases that are predicted to not disrupt plasticity signatures. To calculate enrichments of top DLA gene sets, we chose a conservative cutoff of $p_{\text {corrected }}<5$ $\times 10^{-5}$ and then calculated the over-representation of inflammation gene sets among positive DLA associations. To do so, we used the hypergea (Bönn, 2016) R package, which uses a conditional maximum likelihood estimate to compute the odds ratio (OR) on adjusted cell counts (to avoid empty cells) and obtains two-sided $p$ values from the hypergeometric distribution. 
Table 1: Statistics

\begin{tabular}{|c|c|c|c|}
\hline Subscript & Data structure & Type of test & Power \\
\hline a & Hypergeometric & Fisher's exact & $95 \% \mathrm{Cl}=1.4-491.2$ \\
\hline b & Hypergeometric & Fisher's exact & $95 \% \mathrm{Cl}=23.8-58.0$ \\
\hline c & Hypergeometric & Fisher's exact & $95 \% \mathrm{Cl}=3.2-1229.8$ \\
\hline d & Approximately normal & Welch $t$ test & $\begin{array}{l}95 \% \mathrm{Cl}=-3.3 \text { to }-1.6 \text {, alternative hypothesis: } \\
\text { true difference in means is not equal to } 0\end{array}$ \\
\hline e & Non-normal & Empirical $p$ value & NA \\
\hline$f$ & Non-normal & Spearman rank correlation & NA \\
\hline g & Approximately normal & Welch $t$ test & $\begin{array}{l}\text { NA; no specific } p \text { values reported, rather a group of } \\
\text { genes under a specified } p \text { value threshold }\end{array}$ \\
\hline h & Approximately normal & Welch $t$ test & $\begin{array}{l}95 \% \mathrm{Cl}=-3.0 \text { to }-0.1 \text {, alternative hypothesis: true } \\
\text { difference in means is not equal to } 0\end{array}$ \\
\hline i & Approximately normal & Welch $t$ test & $\begin{array}{l}95 \% \mathrm{Cl}=-1.3 \text { to }-0.1 \text {, alternative hypothesis: true } \\
\text { difference in means is not equal to } 0\end{array}$ \\
\hline j & Approximately normal & Welch $t$ test & $\begin{array}{l}95 \% \mathrm{Cl}=0.3-1.6 \text {, alternative hypothesis: true } \\
\text { difference in means is not equal to } 0\end{array}$ \\
\hline $\mathrm{k}$ & Approximately normal & Welch $t$ test & $\begin{array}{l}\text { NA; no specific } p \text { values reported, rather a group } \\
\text { of genes above a specified } p \\
\text { value threshold (e.g., not significant) }\end{array}$ \\
\hline I & Approximately normal & $\begin{array}{l}\text { Welch } t \text { test, one-sided (due to specific } \\
\text { prior hypothesis as to direction } \\
\text { of effect; results still significant } \\
\text { using a two-sided test at a threshold } \\
\text { of } \alpha=0.05 \text { ) }\end{array}$ & $\begin{array}{l}95 \% \mathrm{Cl}=0.1 \text { to } \infty] \text {, alternative hypothesis: true } \\
\text { difference in means is not equal to } 0\end{array}$ \\
\hline $\mathrm{m}$ & Non-normal & $\chi^{2}$ test of ODS counts & NA \\
\hline
\end{tabular}

\section{Quantitative PCR}

Experiment-naive juvenile mice (P26; $n=5 /$ group) were lightly anesthetized with isoflurane to avoid additional stressors and injected intraperitoneally before 12:00 noon eastern standard time with a dose of LPS that does not cross the blood-brain barrier (Banks and Robinson, 2010; $300 \mu \mathrm{g} / \mathrm{kg}$, $\sim 4.5 \mu \mathrm{g} /$ mouse) or vehicle (150 $\mu$ l of saline). Four hours later, mice were deeply anesthetized with isoflurane and decapitated, and bilateral V1 was removed under RNAsefree conditions, briefly rinsed in sterile saline $(0.9 \% \mathrm{NaCl})$, immediately frozen on dry ice, and transferred to $-80^{\circ} \mathrm{C}$ storage until processed. Total RNA was extracted from V1 using the RNeasy Lipid Tissue Mini Kit (Qiagen) and stored at $-80^{\circ} \mathrm{C}$. RNA yields ranged from 4.5 to $10 \mu \mathrm{g} / \mathrm{sample}$ and RNA integrity numbers ranged from 8.7 to 10 (mean, 9.8; SD, 0.32). Total V1 RNA was converted to cDNA using a HighCapacity cDNA Reverse Transcription Kit (Life Technologies). Quantitative PCR (qPCR) was performed by the Mount Sinai Quantitative PCR core facility using TaqMan probes (catalog numbers: NogoR: 00445861, Lynx1: 01204957_g1, S100a8: 00496696_g1, Lrg1: 01278767_m1, Lcn2: 01324470_m1, PirB: 01700366_m1, Cldn5: 00727012_s1, Egr2: 00456650_m1, Npas4:01227866_g1, ll1:00434228_m1, Agmat: 01348862_m1, Ch25h: 00515486_s1, Alox12b: 01325300_gH, Evpl: 01700609_m1, S/c40a1: 00489835_g1, Arc: 01204954_g1, S100a9: 00656925_m1, H2D1/H2K1: 04208017_mH, BDNF: 04230607_s1, Nptx2: 00479438_m1, and Ppp3ca: 01317678_m1, Applied Biosystems). Quantification of the fold change was derived via the $-\Delta \Delta$ CT method (equivalent to a log2 fold change) and significance was computed with parametric $t$ tests of the $\Delta$ CTs, given the approximately normal distribution of $\Delta \mathrm{CTs}$. To prioritize qPCR validations, we identified the most differentially dysregulated juvenile neuroplasticity genes by an independent LPS brain study (GSE3253) by subsetting with the LPS brain expression whose absolute expression statistic was $\geq 2$ after conversion to $z$-score.

\section{In vivo electrophysiology}

Under light isoflurane anesthesia, the contralateral eye of experiment-naive P26 mice was sutured, and the animal was immediately injected intraperitoneally with LPS $(300 \mu \mathrm{g} / \mathrm{kg}, \sim 4.5 \mu \mathrm{g} /$ mouse) or vehicle $(150 \mu \mathrm{l}$ saline). Three days later, single-unit electrophysiological recordings were taken in binocular zone of $\mathrm{V} 1$ in response to visual stimuli presented to each eye separately (Gordon and Stryker, 1996). Briefly, recording was conducted under nembutal/chlorprothixene anesthesia. Visually evoked single-unit responses were recorded with 16-channel silicone probes (NeuroNexus) in response to a high-contrast single bar generated by visage system (Cambridge Research Systems). The signal was amplified and thresholded (OmniPlex, Plexon). To ensure single-unit isolation, the waveforms of recorded units were further examined off-line (Offline Sorter, Plexon). For each animal, approximately 3-10 single units were recorded in each of the four to six vertical penetrations spaced evenly (250 $\mu \mathrm{m}$ intervals) across the mediolateral extent of $\mathrm{V} 1$ to map the monocular and binocular zones and to avoid sampling bias. Monocular zone was identified when three consecutive units solely registered contralateral responses within a single penetration [ocular dominance score (ODS) of 1 , see below for definition of ODS]. Secondary visual cortex was identified by the reversal of retinotopy seen as the electrode was moved into the secondary visual cortex (Gordon and Stryker, 1996). Mice that experienced opening of the sutured eye or had poor record- 
a

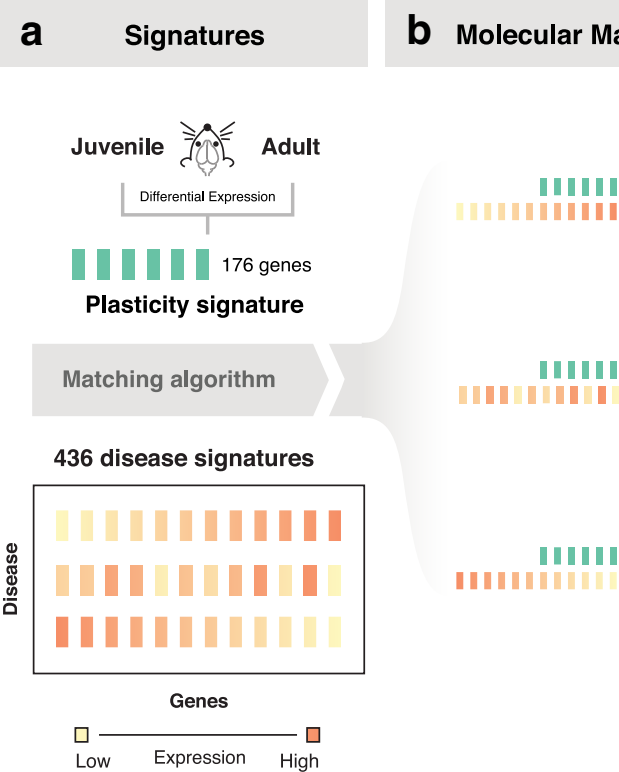

C Disease Leverage Analysis

Figure 1. Diseases that dysregulate the juvenile plasticity signature are associated with inflammatory processes. $\boldsymbol{a}, \boldsymbol{b}, \mathrm{Juvenile}$ plasticity signature of 176 genes (represented by green bars) generated by differential expression of P29 vs >P60 C57BL/6 male mice primary visual cortex was computationally matched to 436 disease signatures (represented by orange bars; a) using rank-based molecular matching where large scores indicate shared transcriptional phenotype (b). c, DLA systematically identified processes associated to diseases that dysregulate the plasticity signature. Seven of the 14 largest associations were inflammation-related gene sets, and 7 of 7 of inflammation-related gene sets were strongly associated with plasticity (all at $p_{\text {corrected }}<5 \times 10^{-5}$ : OR $=25.8,95 \% \mathrm{Cl}=1.4-491.2, p=2.7 \times 10^{-3}$, Fisher's exact test). See Figure 1-1 for source DLA data.

ings $(<10$ cells/mouse or $<3$ penetrations/mouse or lack of positive identification of monocular zone and secondary visual cortex) were excluded from further study. To analyze the electrophysiology data, normalized ocular dominance index (ODI) of single neurons was computed by a custom-made MATLAB code by peristimulus time histogram analysis of peak to baseline spiking activity in response to each eye: $\{[$ Peak(ipsi) - baseline(ipsi)] - [Peak(contra) - baseline(contra)]\}/ $\{[$ Peak(ipsi) - baseline(ipsi $)]+[$ Peak(contra) - baseline(contra) $]\}$, which produces a range of $[-1,+1]$ where -1 is a completely contralateral dominated cell and +1 is a completely ipsilateral dominated cell. ODI is linearly transformed by assigning $[-1.0,-0.5)=\mathbf{1},[-0.5,-0.3)$ $=2,[-0.3,-0.1)=\mathbf{3},[-0.1,+0.1]=\mathbf{4},(+0.1,+0.3]=\mathbf{5}$, $(+0.3,+0.5]=6,(+0.5,+1.0]=7$ to produce the ODS. Finally, the contralateral bias index (CBI), a monocular weighted, animal-level summary statistic, is computed from the ODS, as follows: $[(n 1-n 7)+2 / 3(n 2-n 6)+$ $1 / 3(n 3-n 5)+N] / 2 N$, where $N=$ total number of cells and $n \mathbf{x}=$ number of cells corresponding to ODS of $\mathbf{x}$. Thus, a CBI value of 0.7 is contralateral dominant, and a $\mathrm{CBI}$ value of 0.4 is ipsilateral dominant. For statistical comparison of ocular dominance, ODSs of single neurons were plotted as a proportion histogram and compared via a nonparametric $\chi^{2}$ test, and CBI values of single animals were compared via a $t$ test. Saline-treated juvenile animals (age P26) were the comparison group. The experimenter was blind to the sample group. Sample sizes were statistically estimated prior to undertaking experimental work to be $n=6$ per group, assuming the effect sizes seen in previous relevant work.

\section{Statistical analysis}

All statistical and computational analyses conducted with $\mathrm{R}$ (version 3.2.2) and Python (version 2.7.10). Parametric Welch $t$ tests were two sided, unless otherwise noted. Sample sizes (denoted $n$ ) always indicate the number of mice. The influenza $95 \%$ confidence interval $(\mathrm{Cl})$ for the incidence rate ratio was estimated using the Katz log approach (Fagerland et al., 2015) $\left(e^{\left.\log (I R R) \pm \sqrt{\frac{1}{a}+\frac{1}{b}-\frac{1}{m}-\frac{1}{n}}\right)}\right.$, where $a$ and $b$ are the successes and $m$ and $n$ are the totals (totals determined by dividing the successes by the published incidence rates. The detail of statistical analysis is shown in Table 1.

\section{Results}

\section{Molecular matching between plasticity and disease signatures}

To enable molecular matching between plasticity and disease, we compared V1 transcriptomes of juvenile wild-type mice, during the critical period of elevated ocular dominance plasticity in V1 (Gordon and Stryker, 1996), with adult wild-type mice with reduced plasticity, to identify a differential expression signature of 176 genes (Fig. 1a; Table 2). We computationally matched this signature to 436 disease signatures derived from public microarray data using a previously described method 


\begin{tabular}{|c|c|c|c|c|c|}
\hline & Name & Normalized_effect & Betas & Pval & Bonferroni \\
\hline HALLMARK_EPITHELIAL_MESENCHYMAL_TRANSITION & epithelial mesenchymal transition & 22.89 & 7.44 & $5.7 \mathrm{E}-15$ & $2.8 \mathrm{E}-13$ \\
\hline HALLMARK_KRAS_SIGNALING_UP & kras signaling up & 17.05 & 5.49 & $0.0 \mathrm{E}+00$ & $0.0 \mathrm{E}+00$ \\
\hline HALLMARK_TNFA_SIGNALING_VIA_NFKB & tnfa signaling via nfkb & 16.57 & 5.35 & $6.0 \mathrm{E}-13$ & 3.0E-11 \\
\hline HALLMARK_INTERFERON_GAMMA_RESPONSE & interferon gamma response & 13.40 & 4.33 & $5.3 E-18$ & 2.6E-16 \\
\hline HALLMARK_HYPOXIA & hypoxia & 11.11 & 3.52 & $3.9 \mathrm{E}-10$ & $2.0 \mathrm{E}-08$ \\
\hline HALLMARK_ESTROGEN_RESPONSE_LATE & estrogen response late & 10.68 & 3.39 & $6.8 \mathrm{E}-10$ & 3.4E-08 \\
\hline HALLMARK_INFLAMMATORY_RESPONSE & inflammatory response & 10.42 & 3.33 & $1.4 \mathrm{E}-14$ & $6.8 \mathrm{E}-13$ \\
\hline HALLMARK_COMPLEMENT & complement & 10.08 & 3.18 & $0.0 \mathrm{E}+00$ & $0.0 \mathrm{E}+00$ \\
\hline HALLMARK_E2F_TARGETS & e2f targets & 9.94 & 3.14 & $2.2 \mathrm{E}-09$ & $1.1 \mathrm{E}-07$ \\
\hline HALLMARK_ANGIOGENESIS & angiogenesis & 9.85 & 1.39 & $3.2 \mathrm{E}-07$ & $1.6 \mathrm{E}-05$ \\
\hline HALLMARK_IL2_STAT5_SIGNALING & il2 stat5 signaling & 9.78 & 3.09 & $2.8 \mathrm{E}-09$ & $1.4 \mathrm{E}-07$ \\
\hline HALLMARK_INTERFERON_ALPHA_RESPONSE & interferon alpha response & 9.38 & 2.09 & 4.6E-12 & 2.3E-10 \\
\hline HALLMARK_G2M_CHECKPOINT & g2m checkpoint & 9.00 & 2.85 & $2.2 \mathrm{E}-12$ & $1.1 \mathrm{E}-10$ \\
\hline HALLMARK_IL6_JAK_STAT3_SIGNALING & il6 jak stat3 signaling & 7.98 & 1.70 & 2.6E-09 & $1.3 E-07$ \\
\hline HALLMARK_ESTROGEN_RESPONSE_EARLY & estrogen response early & 7.72 & 2.40 & $1.2 \mathrm{E}-07$ & $6.0 \mathrm{E}-06$ \\
\hline HALLMARK_UV_RESPONSE_DN & uv response dn & 7.11 & 1.90 & $3.1 \mathrm{E}-11$ & $1.6 \mathrm{E}-09$ \\
\hline HALLMARK_ALLOGRAFT_REJECTION & allograft rejection & 6.63 & 2.04 & 4.1E-09 & $2.1 \mathrm{E}-07$ \\
\hline HALLMARK_TGF_BETA_SIGNALING & tgf beta signaling & 6.30 & 1.06 & 1.1E-06 & $5.5 \mathrm{E}-05$ \\
\hline HALLMARK_COĀEULATION & coagulation & 5.82 & 1.51 & $6.3 \mathrm{E}-07$ & $3.2 \mathrm{E}-05$ \\
\hline HALLMARK_APOPTOSIS & apoptosis & 5.81 & 1.62 & $8.2 \mathrm{E}-07$ & $4.1 \mathrm{E}-05$ \\
\hline HALLMARK_APICAL_JUNCTION & apical junction & 5.50 & 1.66 & $1.0 \mathrm{E}-06$ & $5.2 \mathrm{E}-05$ \\
\hline HALLMARK_MYOGENESIS & myogenesis & 5.33 & 1.61 & $2.3 \mathrm{E}-06$ & $1.1 \mathrm{E}-04$ \\
\hline HALLMARK_P53_PATHWAY & p53 pathway & 4.93 & 1.47 & $9.8 \mathrm{E}-05$ & $4.9 \mathrm{E}-03$ \\
\hline HALLMARK_CHOLESTEROL_HOMEOSTASIS & cholesterol homeostasis & 4.66 & 0.89 & $6.8 \mathrm{E}-05$ & $3.4 \mathrm{E}-03$ \\
\hline HALLMARK_X̄XENOBIOTIC_M̄METABOLISM & xenobiotic metabolism & 4.14 & 1.21 & $1.3 \mathrm{E}-03$ & $6.3 \mathrm{E}-02$ \\
\hline HALLMARK_UV_RESPONSE_UP & uv response up & 4.02 & 1.06 & $6.5 \mathrm{E}-04$ & $3.3 \mathrm{E}-02$ \\
\hline HALLMARK_MTORC1_SIGNALING & mtorc1 signaling & 2.87 & 0.79 & $3.3 \mathrm{E}-02$ & $1.0 \mathrm{E}+00$ \\
\hline HALLMARK_MITOTIC_SPINDLE & mitotic spindle & 2.81 & 0.76 & $3.5 \mathrm{E}-02$ & $1.0 \mathrm{E}+00$ \\
\hline HALLMARK_GLYCOLYSIS & glycolysis & 2.80 & 0.77 & $3.8 \mathrm{E}-02$ & $1.0 \mathrm{E}+00$ \\
\hline HALLMARK_ANDROGEN_RESPONSE & androgen response & 2.27 & 0.45 & 7.4E-02 & $1.0 \mathrm{E}+00$ \\
\hline HALLMARK_KRAS_SIGNALING_DN & kras signaling dn & 2.21 & 0.56 & $1.3 \mathrm{E}-01$ & $1.0 \mathrm{E}+00$ \\
\hline HALLMARK_BILE_ACID_METABOLISM & bile acid metabolism & 2.16 & 0.44 & $1.0 \mathrm{E}-01$ & $1.0 \mathrm{E}+00$ \\
\hline HALLMARK_HEDGEHOG_SIGNALING & hedgehog signaling & 1.99 & 0.25 & $8.2 \mathrm{E}-02$ & $1.0 \mathrm{E}+00$ \\
\hline HALLMARK_PANCREAS_BETA_CELLS & pancreas beta cells & 1.73 & 0.22 & $1.5 \mathrm{E}-01$ & $1.0 \mathrm{E}+00$ \\
\hline HALLMARK_WNT_BETA_CATENIN_SIGNALING & wnt beta catenin signaling & 1.71 & 0.23 & $1.5 \mathrm{E}-01$ & $1.0 \mathrm{E}+00$ \\
\hline HALLMARK_NOTCH_SIGNALING & notch signaling & 1.50 & 0.17 & $2.1 \mathrm{E}-01$ & $1.0 \mathrm{E}+00$ \\
\hline HALLMARK_APICAL_SURFACE & apical surface & 0.79 & 0.09 & $6.0 \mathrm{E}-01$ & $1.0 \mathrm{E}+00$ \\
\hline HALLMARK_UNFOLDED_PROTEIN_RESPONSE & unfolded protein response & 0.21 & -0.04 & $8.8 \mathrm{E}-01$ & $1.0 \mathrm{E}+00$ \\
\hline HALLMARK_MYC_TARGETS_V2 & myc targets $v 2$ & 0.15 & -0.02 & $9.1 \mathrm{E}-01$ & $1.0 \mathrm{E}+00$ \\
\hline HALLMARK_PEROXISOME & peroxisome & 0.13 & -0.06 & $8.3 \mathrm{E}-01$ & $1.0 \mathrm{E}+00$ \\
\hline HALLMARK_FATTY_ACID_METABOLISM & fatty acid metabolism & -0.21 & -0.20 & $5.6 \mathrm{E}-01$ & $1.0 \mathrm{E}+00$ \\
\hline HALLMARK_SPERMATTOGENESIS & spermatogenesis & -0.34 & -0.21 & 4.9E-01 & $1.0 \mathrm{E}+00$ \\
\hline HALLMARK_ADIPOGENESIS & adipogenesis & -0.90 & -0.47 & 2.1E-01 & $1.0 \mathrm{E}+00$ \\
\hline HALLMARK_REACTIVE_OXIGEN_SPECIES_PATHWAY & reactive oxigen species pathway & -1.02 & -0.21 & $2.2 \mathrm{E}-01$ & $1.0 \mathrm{E}+00$ \\
\hline HALLMARK_PI3K_AKT_MTOR_SIGNALING & pi3k akt mtor signaling & -1.45 & -0.45 & 8.7E-02 & $1.0 \mathrm{E}+00$ \\
\hline HALLMARK_HEME_METABOLISM & heme metabolism & -3.18 & -1.24 & $2.0 \mathrm{E}-04$ & 1.0E-02 \\
\hline HALLMARK_PROTEIN_SECRETION & protein secretion & -4.56 & -1.15 & $0.0 \mathrm{E}+00$ & $0.0 \mathrm{E}+00$ \\
\hline HALLMARK_DNA_REPAIR & dna repair & -4.90 & -1.52 & $0.0 \mathrm{E}+00$ & $0.0 \mathrm{E}+00$ \\
\hline HALLMARK_MYC_TARGETS_V1 & myc targets $\mathrm{v} 1$ & -7.83 & -2.78 & $0.0 \mathrm{E}+00$ & $0.0 \mathrm{E}+00$ \\
\hline HALLMARK_OXIDATTIVE_PHŌSPHORYLATION & oxidative phosphorylation & -17.22 & -5.92 & $0.0 \mathrm{E}+00$ & $0.0 E+00$ \\
\hline
\end{tabular}

Figure 1-1. DLA identifies biological processes common to diseases that perturb the juvenile plasticity signature. To identify shared pathophysiology across the diverse list of diseases predicted to dysregulate the juvenile plasticity signature, we applied DLA. This approach calculates the association between diseases that dysregulate the plasticity signature genes and 50 well defined and distinct biological pathways. To do so, it computes a regression between the molecular match score (a measure that indicates the strength of association between the disease and plasticity signatures; see Table 3 and Materials and Methods) and the pathology score (a measure of activity of the biological pathway in that disease; see Materials and Methods). Large regression coefficients indicate that the biological pathway may disrupt juvenile plasticity. Using a multiple test-corrected, empirical $p<5 \times 10^{-5}$, seven of the 14 largest DLA associations were inflammation-related gene sets, and every inflammationrelated gene set in the hallmark library was strongly associated with diseases that dysregulate plasticity genes (seven of seven inflammation gene sets at $p_{\text {corrected }}<5 \times 10^{-5}$ : $\mathrm{OR}=25.8,95 \% \mathrm{Cl}=1.4-491.2, p=2.7 \times 10^{-3}$, Fisher's exact test). A total of 20,000 permutations of the gene sets was used to estimate $p$ values and to normalize the regression coefficients to allow comparison between effect sizes for different biological pathways. Inflammation-related gene sets: TNF- $\alpha$ signaling via NF- $\kappa \mathrm{B}$, IFN- $\gamma$ response, inflammatory response, complement, IL-2-Stat5 signaling, IFN- $\alpha$ response, IL-6-Jak-Stat3 signaling.

(Dudley et al., 2009; Fig. 1a). This systematic method applies a rank-based molecular matching algorithm to determine the molecular concordance between the plasticity signature and a given disease signature, where high scores indicate plasticity genes are significantly dysregulated by the disease and low scores indicate that the disease has no impact on plasticity genes (for details, see Materials and Methods; Fig. 1b). The molecular matching procedure produced a list of 436 diseases ordered by their prediction to disrupt the plasticity signature. Interestingly, highly ranked diseases included not only brain disorders known to disrupt plasticity, such as Huntington's disease (Usdin et al., 1999; Murphy et al., 2000; Milnerwood et al., 
2006), but also non-neurologic disorders (e.g., bacterial infections, inflammatory bowel disease, metabolic diseases), suggesting that a broad range of disease states may impact molecular pathways involved in plasticity.

\section{Disease Leverage Analysis (DLA) identifies inflammatory processes as putative disruptors of plasticity}

We sought to identify shared pathophysiology across the diverse list of diseases predicted to dysregulate plasticity signatures. To do so, we developed DLA. This approach calculates the association between diseases that dysregulate the plasticity signature genes and the 50 gene sets in the hallmark library (Subramanian et al., 2005 ) that represent well defined and distinct biological pathways. Specifically, DLA computes a linear regression between the molecular match score (a measure of strength of association between disease and plasticity signatures) and the pathology score (a measure of activity of the biological pathway in a given disease). Large regression coefficients indicate that a given biological pathway is highly active in diseases that dysregulate plasticity gene signatures and may be pathological to developmental plasticity. Using a multiple test-corrected, empirical $p$ value threshold of $p<$ $5 \times 10^{-5}$, we found that 7 of 14 largest DLA associations were inflammation-related gene sets and that every inflammation-related gene set in the hallmark library was strongly associated with diseases that dysregulate the plasticity signature ( 7 of 7 inflammation gene sets at a threshold of $p_{\text {corrected }}<5 \times 10^{-5}$ : OR $=25.8,95 \% \mathrm{Cl}$ $=1.4-491.2, p=2.7 \times 10^{-3}$ a, Fisher's exact test; Figs. 1c, 1-1). Moreover, two of these gene sets, tumor necrosis factor- $\alpha$ (TNF- $\alpha$ ) signaling via nuclear factor $-\kappa \mathrm{B}(\mathrm{NF}-\kappa \mathrm{B})$ and interferon- $\gamma(\mathrm{IFN}-\gamma)$ response, reflect pathways involved in critical period plasticity (Kaneko et al., 2008; Nagakura et al., 2014).

To control for nonplasticity aspects of age, we repeated the entire analysis using a $L y n \times 1^{-1-}$ plasticity signature of 98 genes, which was identified by computing the differential expression between adult $L y n \times 1^{-1-}$ and adult wild-type V1 (Table 4). By releasing the Lynx1 brake on plasticity, Lynx $1^{-/-}$mice have juvenile-like plasticity in adulthood (Morishita et al., 2010; Bukhari et al., 2015). Indeed, functional similarity is reflected in signature similarity, as juvenile and $L y n \times 1^{-1-}$ plasticity signatures significantly overlap (35 genes shared, OR = $\left.37.1,95 \% \mathrm{Cl}=23.8-58.0, p<2.2 \times 10^{-16} \mathrm{~b}\right)$. Applying DLA to the $L y n \times 1^{-1-}$ molecular matches, we found a strong association between diseases predicted to disrupt $L y n \times 1^{-1-}$ plasticity and inflammation-related gene sets ( 7 of 7 inflammation gene sets at a threshold of $p_{\text {corrected }}<5 \times 10^{-5}$ : OR $=63.0,95 \% \mathrm{Cl}=3.2-1229.8$, $p=7.6 \times 10^{-5}{ }_{c}$ Fisher's exact test; Figs. 2, 2-1). Together, the bioinformatics analyses indicate that inflammation is a process central to diseases predicted to dysregulate plasticity gene expression, suggesting that inflammation may disrupt developmental plasticity.

\section{Lynx1-KO Disease Leverage}

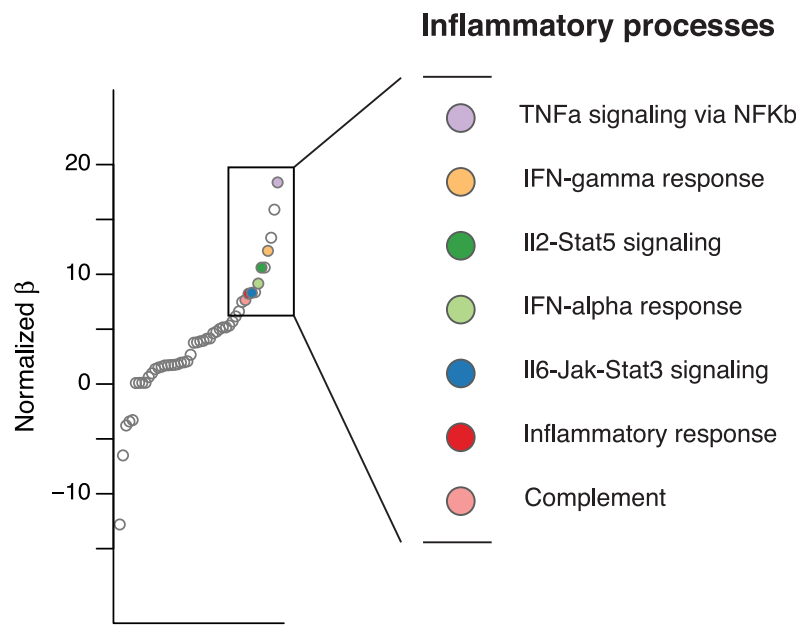

50 Hallmark Gene Sets

Figure 2. Diseases that dysregulate the adult $L y n \times 1^{-/-}$plasticity signature are associated with inflammatory processes. Using an adult $L y n \times 1^{-1-}$ plasticity signature of 98 genes (generated by differential expression of primary visual cortex from >P60 $\mathrm{Lyn} 1^{-/-}$vs >P60 C57BL/6 male mice), DLA systematically identified biological processes associated with diseases that dysregulate the adult $L y n \times 1^{-/-}$plasticity signature genes. Using adult $L y n \times 1^{-/-}$animals controls for age, as these adult animals have elevated plasticity similar to that of juvenile animals. Seven of the 11 largest associations were inflammation-related gene sets, and every inflammation-related gene set was strongly associated with plasticity ( 7 of 7 inflammation gene sets at $p_{\text {corrected }}<5 \times 10^{-5}$ : OR $=63.0,95 \% \mathrm{Cl}=$ $3.2-1229.8, p=7.6 \times 10^{-5}$, Fisher's exact test). See Figure 2-1 for source DLA data.

\section{Lipopolysaccharide model of inflammation suppresses developmental cortical plasticity}

Based on the DLA findings, we hypothesized that inflammatory processes disrupt developmental cortical plasticity. To test this hypothesis, we induced a systemic inflammatory response via LPS and measured the impact on developmental plasticity and related gene expression. We injected a low dose of LPS $(300 \mu \mathrm{g} / \mathrm{kg}$, intraperitoneal) at the peak of juvenile ocular dominance plasticity at P26 and found a strong inflammatory response in V1, as indicated by a $2.4 \log _{2}$ fold increase of interleukin (IL)-1 $\beta$ compared with vehicle control $(p=$ $3.4 \times 10^{-4}$ d, $t$ test of $\Delta$ CTs, $n=5 \mathrm{mice} /$ group). To identify a focused subset of plasticity genes likely to be regulated by LPS (regardless of age or specific brain region) to test in vivo, we investigated a highly significant molecular match between the juvenile plasticity signature and an adult brain-derived LPS transcriptome (GSE3253; rank \#14, $p=7.9 \times 10^{-4}$; ; empirical $p$ value calculated using molecular match algorithm; Fig. 3a; Table 3). Next, we identified a subset of genes from GSE3253 that is likely to play a larger role in the under- 
lying biology (the genes in the extremes using a z-score cutoff) and intersected it with the plasticity signature to identify 16 shared genes (Fig. 3b). Notably, among these shared genes, we identified a negative correlation in their expression pattern (cor $=-0.77, p=0.0007_{\mathrm{f}}$, Spearman's correlation). Among these 16 shared genes, the adult LPS data indicated the direction of expression of 13 genes would be reversed by LPS. Indeed, the majority $(61.5 \%)$ of the 13 genes showed a complete reversal in their differential expression pattern in V1 after peripheral LPS administration during the critical period (qPCR, all reversed genes $p<5 \times 10^{-4}$, $t$ test of $\Delta$ CTs, $n=5$ mice per group; Fig. 3c). These data indicate that genes in the plasticity signature that are also regulated by LPS act in an antagonistic fashion and naturally led us to the hypothesis that inflammation may suppress plasticity. Consistent with this logic, the established brakes of plasticity, PirB (Syken et al., 2006) and H2K1 and H2D1 (Datwani et al., 2009), showed increased expression compared with vehicle $p$ $=0.04_{\mathrm{h}}$ and $p=0.03_{\mathrm{i}}$, respectively, $t$ test of $\Delta$ CTs, $n=$ 5 mice per group; Fig. 4a,b). In addition, a trigger of plasticity that increases across development, BDNF (Huang et al., 1999), which we predicted in silico to decrease after LPS (Fig. 3b), showed decreased expression compared with vehicle $\left(p=0.009_{\mathrm{j}}, t\right.$ test of $\Delta$ CTs, $n=5$ mice/group; Fig. 4b). In contrast, other known plasticity effectors (Takesian and Hensch, 2013) were not changed relative to vehicle (Nptx2, Lynx1, NogoR, Ppp3ca; $p>0.1_{\mathrm{k}}$, $t$ test of $\Delta$ CTs, $n=5$ mice per group), indicating that LPS may act through a specific subset of known and novel plasticity effectors (Fig. $4 b)$.

Finally, we tested whether inflammation suppresses experience-dependent developmental cortical plasticity in vivo. We administered LPS (300 $\mu \mathrm{g} / \mathrm{kg}$, intraperitoneal) or saline on P26 immediately after suturing one eye to induce ocular dominance plasticity via monocular deprivation (MD; Fig. 4a). After $3 \mathrm{~d}$ of MD, we conducted in vivo single-unit recordings of activitydriven changes in the eye preference of single neurons (ocular dominance) in binocular V1 in response to light (Gordon and Stryker, 1996). In mice treated with saline, we observed the expected shift in cortical responsivity to light stimulation from the deprived contralateral to nondeprived ipsilateral eye, as quantified by a decrease in the animal-level $\mathrm{CBI}(\mathrm{CBI}=0.49 \pm 0.04$; six mice; 135 cells), indicating the presence of developmental plasticity (Fig. 4c, right-hand plot). In contrast, LPS significantly suppressed the shift in cortical responsivity from the deprived contralateral eye to the nondeprived ipsilateral eye, which was quantified by an increase in $\mathrm{CBI}$ and an elimination of the right shift in the distribution of ODSs of single neurons $(\mathrm{CBI}=0.64$ \pm 0.02 , seven mice, 129 cells; one-sided $t$ test of CBIs: $p=0.006 ; \chi^{2}$ test of ODS distribution: $p=2.6 \times$ $10^{-6} \mathrm{~m}$ ), indicating impaired plasticity during the critical period in V1 (Fig. 4c, left-hand plot). Together, these data are consistent with our informatics-derived hypothesis by demonstrating that peripheral injection of
LPS induces an inflammatory response in the brain and suppresses developmental cortical plasticity in vivo.

\section{Discussion}

Using an integrative bioinformatics approach, we found that inflammation disrupts developmental cortical plasticity. Our study demonstrates the utility of this approach for both identifying diseases that may disrupt plasticity and generating hypotheses on the molecular mechanisms underlying these disruptions. Moreover, our novel Disease Leverage Analysis facilitates novel hypothesis generation, because seemingly unrelated phenotypes, such as neuroplasticity and inflammation, can be connected based on apparently disparate tissues and diseases. Previous work indicating that the disease signal harmonizes across tissues (Dudley et al., 2009) supports this approach and in the present study suggests that the molecular pathways underlying plasticity are shared in diverse tissues and are dysregulated in many disease states, including apparently nonneurological phenotypes (e.g., bacterial infections, inflammatory bowel disease, metabolic diseases). Importantly, the biological relevance of any given molecular match between plasticity and disease must be interpreted with care. In all cases, molecular matches indicate that plasticity and the disease phenotype share underlying molecular machinery. However, a given disease state in a specific tissue may or may not have an impact on functional plasticity or related gene expression if the disease state or tissue is sufficiently localized and segregated from neural tissue. Consequently, we developed Disease Leverage Analysis to use the information of all matches collectively to identify common disease processes and simultaneously shrink the hypothesis space to a manageable set of disease process-oriented hypotheses that bind together the diverse matches. This approach facilitated the unbiased and systematic use of apparently disparate disease signatures to generate novel hypotheses about shared disease mechanisms that may dysregulate plasticity. We find here that a common theme among these dysregulations is inflammation, a biological process that is well suited to communicate peripheral signals to the brain, disrupting plasticity.

We demonstrate several lines of evidence supporting a hypothesis that plasticity and inflammatory processes share components of underlying molecular networks. We computationally predicted associations between plasticity signature-perturbing diseases and TNF- $\alpha$ and IFN- $\gamma$ pathways (Figs. 1, 2) and also experimentally identified associations between systemic inflammation and increases in the plasticity brakes PirB and MHC-1 in the brain (Fig. 4). These predictions and observations confirm the known role of pathways involving TNF- $\alpha$, IFN- $\gamma$, Pirb, and MHC-I on regulating developmental plasticity (Syken et al., 2006; Kaneko et al., 2008; Datwani et al., 2009; Nagakura et al., 2014) and extend them to the context of inflammation. We also showed that $B D N F$, a neurotrophic factor essential to the 


\begin{tabular}{|c|c|c|c|c|c|}
\hline & Name & Normalized_effect & Betas & Pval & Bonferroni \\
\hline HALLMARK_TNFA_SIGNALING_VIA_NFKB & tnfa signaling via $n f k b$ & 18.38 & 6.60 & $0.0 \mathrm{E}+00$ & $0.0 \mathrm{E}+00$ \\
\hline HALLMARK_EPITHËEIAL_MESEN̄CHȲMAL_TRANSITION & epithelial mesenchymal transition & 15.90 & 5.66 & $2.6 \mathrm{E}-17$ & $1.3 \mathrm{E}-15$ \\
\hline HALLMARK_KRAS_SIGNALING_UP & kras signaling up & 13.34 & 4.70 & $0.0 \mathrm{E}+00$ & $0.0 \mathrm{E}+00$ \\
\hline HALLMARK_INTERFERON_GAMMA_RESPONSE & interferon gamma response & 12.15 & 4.28 & $6.1 E-13$ & 3.1E-11 \\
\hline HALLMARK_HYPOXIA & hypoxia & 10.62 & 3.65 & $5.6 \mathrm{E}-12$ & $2.8 \mathrm{E}-10$ \\
\hline HALLMARK_IL2_STAT5_SIGNALING & il2 stat5 signaling & 10.62 & 3.65 & $1.4 \mathrm{E}-12$ & 7.1E-11 \\
\hline HALLMARK_INTERFERON_ALPHA_RESPONSE & interferon alpha response & 9.17 & 2.23 & 4.9E-11 & 2.4E-09 \\
\hline HALLMARK_ANGIOGENESIS & angiogenesis & 8.38 & 1.32 & 4.5E-07 & 2.2E-05 \\
\hline HALLMARK_IL6_JAK_STAT3_SIGNALING & il6 jak stat3 signaling & 8.32 & 1.95 & $1.3 \mathrm{E}-09$ & $6.5 \mathrm{E}-08$ \\
\hline HALLMARK_INFLAMMATORY_RESPONSE & inflammatory response & 8.24 & 2.78 & $1.9 \mathrm{E}-08$ & 9.7E-07 \\
\hline HALLMARK_COMPLEMENT & complement & 7.67 & 2.54 & 7.7E-09 & 3.9E-07 \\
\hline HALLMARK_ESTROGEN_RESPONSE_LATE & estrogen response late & 7.49 & 2.46 & 7.7E-08 & $3.8 \mathrm{E}-06$ \\
\hline HALLMARK_TGF_BETA_SIGNALING & tgf beta signaling & 6.63 & 1.22 & 1.7E-07 & 8.7E-06 \\
\hline HALLMARK_APOPTOSIS & apoptosis & 6.17 & 1.82 & $5.8 \mathrm{E}-07$ & 2.9E-05 \\
\hline HALLMARK_ALLOGRAFT_REJECTION & allograft rejection & 5.71 & 1.80 & $5.6 \mathrm{E}-05$ & $2.8 \mathrm{E}-03$ \\
\hline HALLMARK_ESTROGEN_RESPONSE_EARLY & estrogen response early & 5.33 & 1.64 & $3.1 \mathrm{E}-04$ & $1.5 \mathrm{E}-02$ \\
\hline HALLMARK_CHOLESTEROL_HOMEŌ-̄TASIS & cholesterol homeostasis & 5.17 & 1.07 & $8.8 \mathrm{E}-05$ & $4.4 \mathrm{E}-03$ \\
\hline HALLMARK_COAAGULATION & coagulation & 5.17 & 1.38 & $1.8 \mathrm{E}-04$ & $9.1 E-03$ \\
\hline HALLMARK_P53_PATHWAY & p53 pathway & 5.02 & 1.52 & $9.5 \mathrm{E}-04$ & $4.8 \mathrm{E}-02$ \\
\hline HALLMARK_MYŌGENESIS & myogenesis & 4.78 & 1.44 & $2.3 \mathrm{E}-03$ & $1.2 \mathrm{E}-01$ \\
\hline HALLMARK_G2M_CHECKPOINT & g2m checkpoint & 4.63 & 1.38 & $3.3 \mathrm{E}-03$ & 1.7E-01 \\
\hline HALLMARK_APICAL_JUNCTION & apical junction & 4.16 & 1.21 & $1.4 \mathrm{E}-02$ & 7.1E-01 \\
\hline HALLMARK_E2F_TARGETS & e2f targets & 4.13 & 1.18 & $1.6 \mathrm{E}-02$ & $8.2 \mathrm{E}-01$ \\
\hline HALLMARK_MTORC1_SIGNALING & mtorc1 signaling & 3.95 & 1.13 & $2.4 \mathrm{E}-02$ & $1.0 \mathrm{E}+00$ \\
\hline HALLMARK_UV_RESPONSE_UP & uv response up & 3.90 & 1.03 & $1.3 \mathrm{E}-02$ & $6.5 \mathrm{E}-01$ \\
\hline HALLMARK_XEN̄OBIOTIC_MĒETABOLISM & xenobiotic metabolism & 3.81 & 1.06 & $3.7 \mathrm{E}-02$ & $1.0 \mathrm{E}+00$ \\
\hline HALLMARK_UV_RESPONSEE_DN & uv response dn & 3.77 & 0.96 & $1.7 \mathrm{E}-02$ & $8.3 \mathrm{E}-01$ \\
\hline HALLMARK_BILE_E_ACID_METABOLISM & bile acid metabolism & 2.68 & 0.55 & $1.3 \mathrm{E}-01$ & $1.0 \mathrm{E}+00$ \\
\hline HALLMARK_GLYC̄OLYSIS & glycolysis & 2.08 & 0.41 & $5.0 \mathrm{E}-01$ & $1.0 \mathrm{E}+00$ \\
\hline HALLMARK_FATTY_ACID_METABOLISM & fatty acid metabolism & 1.99 & 0.38 & 4.5E-01 & $1.0 \mathrm{E}+00$ \\
\hline HALLMARK_SPERMATOGENESIS & spermatogenesis & 1.95 & 0.36 & $4.2 \mathrm{E}-01$ & $1.0 \mathrm{E}+00$ \\
\hline HALLMARK_WNT_BETA_CATENIN_SIGNALING & wnt beta catenin signaling & 1.81 & 0.24 & $2.2 \mathrm{E}-01$ & $1.0 \mathrm{E}+00$ \\
\hline HALLMARK_ADIPŌGENESIS & adipogenesis & 1.76 & 0.29 & $6.4 \mathrm{E}-01$ & $1.0 \mathrm{E}+00$ \\
\hline HALLMARK_HEDGEHOG_SIGNALING & hedgehog signaling & 1.74 & 0.21 & $2.3 \mathrm{E}-01$ & $1.0 \mathrm{E}+00$ \\
\hline HALLMARK_ANDROGEN_RESPONSE & androgen response & 1.72 & 0.27 & 4.5E-01 & $1.0 \mathrm{E}+00$ \\
\hline HALLMARK_PEROXISOME & peroxisome & 1.70 & 0.28 & 4.5E-01 & $1.0 \mathrm{E}+00$ \\
\hline HALLMARK_NOTCH_SIGNALING & notch signaling & 1.59 & 0.18 & $2.8 \mathrm{E}-01$ & $1.0 \mathrm{E}+00$ \\
\hline HALLMARK_PANCREAS_BETA_CELLS & pancreas beta cells & 1.50 & 0.18 & $3.5 \mathrm{E}-01$ & $1.0 \mathrm{E}+00$ \\
\hline HALLMARK_KRAS_SIGNĀING_DN & kras signaling dn & 1.37 & 0.14 & $8.2 \mathrm{E}-01$ & $1.0 \mathrm{E}+00$ \\
\hline HALLMARK_MITOTIC_SPINDLE & mitotic spindle & 0.98 & -0.01 & $9.8 \mathrm{E}-01$ & $1.0 \mathrm{E}+00$ \\
\hline HALLMARK_UNFOLDED_PROTEIN_RESPONSE & unfolded protein response & 0.64 & -0.03 & $9.4 \mathrm{E}-01$ & $1.0 \mathrm{E}+00$ \\
\hline HALLMARK_MYC_TARGETS_V2 & myc targets $\mathrm{v} 2$ & 0.12 & -0.09 & 7.3E-01 & $1.0 \mathrm{E}+00$ \\
\hline HALLMARK_REACTIVE_OXIGEN_SPECIES_PATHWAY & reactive oxigen species pathway & 0.12 & -0.07 & $7.5 \mathrm{E}-01$ & $1.0 \mathrm{E}+00$ \\
\hline HALLMARK_PI3K_AKT_MTOR_SIGNALING & pi3k akt mtor signaling & 0.11 & -0.17 & $6.5 \mathrm{E}-01$ & $1.0 \mathrm{E}+00$ \\
\hline HALLMARK_APICAL_SŪRFACĒ & apical surface & 0.10 & -0.07 & 7.5E-01 & $1.0 \mathrm{E}+00$ \\
\hline HALLMARK_PROTEIN_SECRETION & protein secretion & -3.28 & -1.07 & $3.5 \mathrm{E}-04$ & $1.8 \mathrm{E}-02$ \\
\hline HALLMARK_HEME_METABOLISM & heme metabolism & -3.41 & -1.69 & $2.5 \mathrm{E}-04$ & $1.3 \mathrm{E}-02$ \\
\hline HALLMARK_DNA_REPAIR & dna repair & -3.77 & -1.51 & $0.0 \mathrm{E}+00$ & $0.0 \mathrm{E}+00$ \\
\hline HALLMARK_MYC_TARGETS_V1 & myc targets $\mathrm{v} 1$ & -6.49 & -2.86 & $0.0 \mathrm{E}+00$ & $0.0 \mathrm{E}+00$ \\
\hline HALLMARK_OXIDATIVE_PHOSPHORYLATION & oxidative phosphorylation & -12.79 & -5.25 & $0.0 \mathrm{E}+00$ & $0.0 \mathrm{E}+00$ \\
\hline
\end{tabular}

Figure 2-1. DLA identifies biological processes common to diseases that perturb the $L y n \times 1^{-\prime-}$ plasticity signature. To identify shared pathophysiology across the diverse list of diseases predicted to dysregulate the $L y n \times 1^{-/-}$plasticity signature, we applied DLA. Large regression coefficients indicate that the biological pathway may disrupt $L y n \times 1^{-/-}$plasticity. As with the juvenile plasticity signature, using a multiple test-corrected, empirical $p<5 \times 10^{-5}$, we found that every inflammation-related gene set in the hallmark library was strongly associated with diseases that dysregulate plasticity genes $(7$ of 7 inflammation gene sets at $p_{\text {corrected }}<5 \times 10^{-5}: \mathrm{OR}=63.0,95 \% \mathrm{Cl}=3.2-1229.8, p=7.6 \times 10^{-5}$ Fisher's exact test). A total of 20,000 permutations of the gene sets were used to estimate $p$ values and to normalize the regression coefficients to allow comparison between effect sizes for different biological pathways. Inflammation-related gene sets: TNF- $\alpha$ signaling via NF- $\kappa \mathrm{B}$, IFN- $\gamma$ response, inflammatory response, complement, IL-2-Stat5 signaling, IFN- $\alpha$ response, IL-6-Jak-Stat3 signaling.

opening of the critical period (Huang et al., 1999), is decreased after LPS administration (Fig. 4), which is consistent with the reported antagonistic relationship of peripheral LPS with BDNF (Guan and Fang, 2006; Schnydrig et al., 2007). Interestingly, we also found that the microglial activator Lcn2 (Jang et al., 2013) is a member of both the juvenile and $L y n \times 1^{-1-}$ plasticity signatures (Tables 2,4 ) and is dramatically increased after LPS in V1 during the critical period (Fig. 3). Activation may inhibit microglia from carrying out their "resting-state" role in mediating experience-dependent plasticity (Sipe et al., 2016), contributing to the dampening of plasticity by inflammation. Collectively, our work suggests a conflict between developmental cortical plasticity and immune-related molecular networks during inflammation, ultimately resulting in the suppression of plasticity during inflammation. Our study provides a novel subset of transcripts that can be used to guide future mechanistic studies into inflammationplasticity interactions. 


\section{a In silico identification of plasticity genes} regulated by lipopolysaccharide

(Molecular match rank $=14$ th, FDR $=7.9 \times 10^{-4}$ )

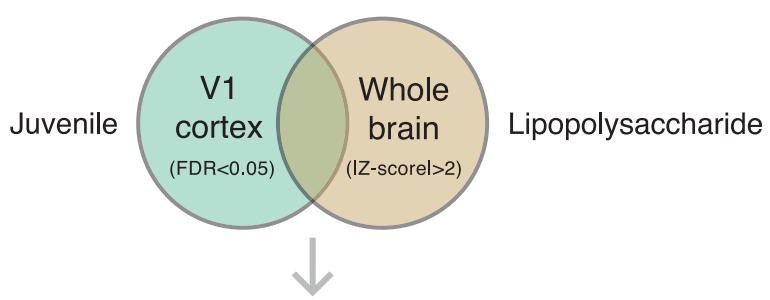

b Gene expression is anticorrelated (cor $=-0.77$ )

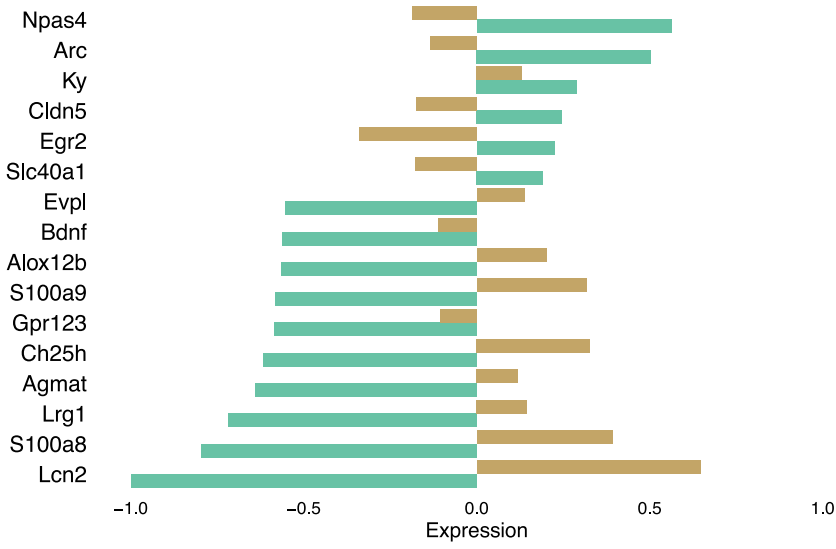

C Validated anticorrelated expression

\begin{tabular}{cc} 
& LPS Harvest V1C \\
& $\downarrow \downarrow$ \\
Birth & P26 \\
\hline
\end{tabular}

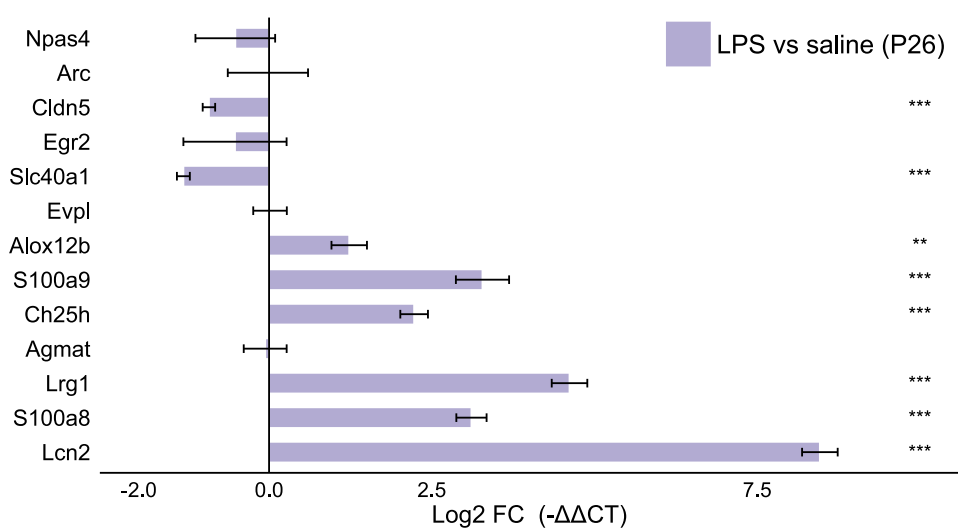

Figure 3. LPS reverses plasticity signature gene expression. a, LPS disease signature shares plasticity signature genes in silico (molecular match rank \#14, $p=7.9 \times 10^{-4}$; Table 3; disease signature is from GSE3253: adult mouse whole-brain homogenate harvested $4 \mathrm{~h}$ after peripheral LPS injected intraperitoneally; genes with absolute value of the standardized expression ( $z$-score) $\geq 2$ SDs from the mean were selected as the most differentially expressed by LPS). $\boldsymbol{b}$, The expression of the 16 genes shared between juvenile plasticity and the LPS disease signatures is anticorrelated (Spearman's $\rho=-0.77, p=7.4 \times 10^{-4}$; LPS disease signature gene expression values fell in the range $[-1,+1]$; for plotting purposes, the plasticity gene expression fold change was linear transformed to $[-1,+1])$. $c$, Of the 13 genes of the 16 predicted to be reversed by LPS, the majority (8 of $13 ; 61.5 \%)$ showed a complete reversal in their differential expression pattern in V1 after LPS administration ( $300 \mu \mathrm{g} / \mathrm{kg}$ LPS, intraperitoneally, at P26 during the peak of juvenile plasticity) relative to saline. LPS downregulated Cldn5 and S/c40a1 and upregulated Alox12b, S100a9a, Ch25h, Lrg1, S100a8, and Lcn2 ( $n=5$ mice per group). $* * * p<0.001, * * p>0.001$ and $\leq 0.01, * p>0.01$ and $\leq 0.05$ (two-sided $t$ tests of $\Delta$ CTs). Log2 fold change is $-\Delta \Delta$ CT. Error bars indicate the SEM. 


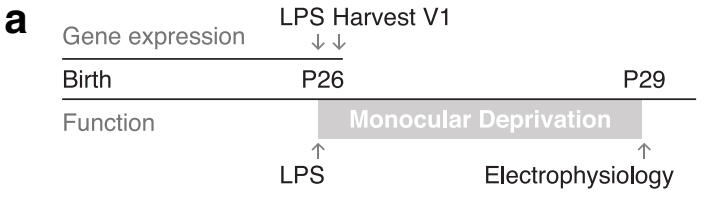

b

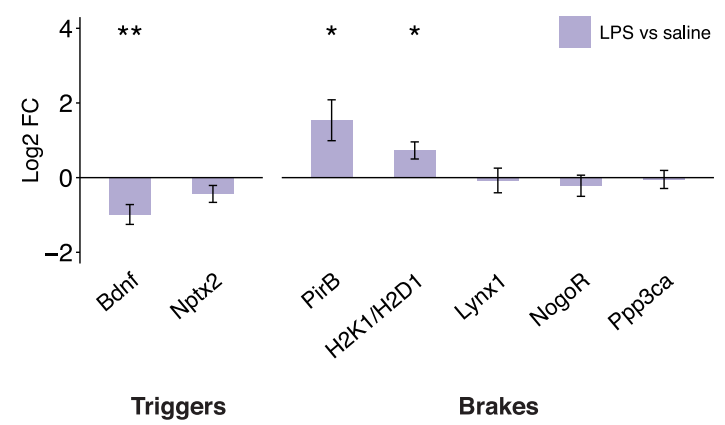

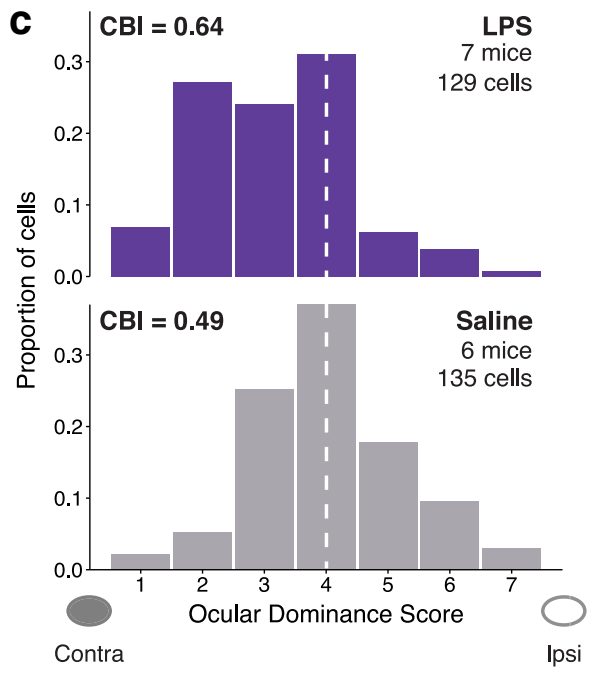

Figure 4. Inflammation induced by LPS suppresses experience-dependent plasticity in juvenile cortex. $\boldsymbol{a}$, Juvenile mice (P26) during the peak of ocular dominance plasticity were injected intraperitoneally with either LPS (300 $\mu \mathrm{g} / \mathrm{kg})$ or saline. $\boldsymbol{b}, \boldsymbol{c}$, Mice were either subjected to qPCR analysis of plasticity effectors from V1 $4 \mathrm{~h}$ after the injection (b) or underwent $3 \mathrm{~d}$ of MD followed by in vivo extracellular recordings to assess ocular dominance plasticity (c). $\boldsymbol{b}$, LPS increased known plasticity brakes PirB and H2K1/H2D1, and decreased the plasticity trigger BDNF. LPS had no effect on the plasticity effectors Nptx2, Lynx1, NogoR, or Ppp3ca. Log2 FC (fold change $)$ is $-\Delta \Delta$ CT ( $n=5$ mice per group). Error bar indicates the SEM. $* * * p<0.001, * * p>0.001$ and $\leq 0.01, * p>0.01$ and $\leq 0.05$ ( $t$ test of $\Delta$ CTs). $c$, Neurons from peripheral LPS-treated mice (purple histogram: $n=7$ mice, 129 cells) showed decreased cortical responsivity to light in the ipsilateral vs contralateral eye, as quantified by a reduced right shift in the ODS distribution after $3 \mathrm{~d}$ of MD compared with control saline-treated juvenile mice with MD (gray histogram: 6 mice, 135 cells; $\chi^{2}$ test of ODS distribution: $p=2.6 \times$ $10^{-6}$ ). Animal-level quantification of ocular dominance plasticity by CBI reflects the extent of the ocular dominance shift after $3 \mathrm{~d}$ of MD (right-side plot; low CBI indicates higher plasticity). CBI was strongly increased in the LPS-treated group (purple discs: CBI = 0.64 $\pm 0.02,7$ mice) compared with saline-treated group (gray discs: CBI $=0.49 \pm 0.04,6$ mice), indicating that proinflammatory LPS had suppressed developmental plasticity (LPS vs saline, $* * p=6 \times 10^{-3}$, one-sided $t$ test). qPCR data are reported as the mean \pm SEM. Horizontal bars for the CBI plot indicate the mean.

Our efforts to understand the molecular machinery involved in the suppression of developmental plasticity focused on immediate changes in gene expression in V1 via acute inflammation (qPCR $4 \mathrm{~h}$ after a single intraperitoneal injection of LPS). We expected this time point to be particularly sensitive to disruption because the earliest experience-dependent changes occur within hours to a day of MD at the level of firing rate of parvalbumin interneurons (Aton et al., 2013; Kuhlman et al., 2013; Reh and Hensch, 2014) and protease (Mataga et al., 2002) and microglia activity (Sipe et al., 2016) as triggers for subsequent global ocular dominance plasticity, which takes a few days to be detected by single-unit recordings (Gordon and Stryker, 1996). Importantly, such trigger events occur only during the juvenile critical period when our assay was performed, but not in the adult period (Kuhlman et al., 2013). Thus, we reasoned that the baseline cortical expression signature at this early time point would be critical to gate global ocular dominance plasticity. In addition, peak acute inflammatory response, as measured by an increase in IL-1 $\beta$ in brain after peripheral LPS injection, is between 1 and $4 \mathrm{~h}$ (Layé et al., 1994; Eklind et al., 2006; Richwine et al., 2009), a time course well suited to disrupt these earliest experience-dependent plasticity events. While we speculate that LPS disrupted these early trigger events unique to juvenile cortex, more work needs to be performed to understand the molecular events underlying the functional changes seen within hours of MD and to dissect the impact of inflammation on these events. In addition to the early phase of plasticity, inflammation may also impact plasticity mechanisms during the later phases of MD because TNF- $\alpha$ is essential to nondeprived eye potentiation via a homeostatic mechanism at 5-6 d of MD (Kaneko et al., 2008). Ultimately, further work is necessary to tease out the interaction between inflammatory and plasticity mechanisms that contribute to the suppression of functional plasticity across multiple days of experience deprivation. Performing such work comparing acute versus chronic inflammatory models would provide fascinating insights into neuroimmune biology and would help to inform the important clinical question of the potential impact of acute and chronic inflammation on the neurodevelopmental trajectory in children.

While our experimental efforts focused on the impact of acute inflammation on plasticity, our list of diseases predicted to impact plasticity include diseases that accompany chronic inflammation (Table 3). Efforts to study human disease and animal models shed light on how acute versus chronic inflammation may affect plasticity. For example, components of plasticity and inflammation are dysregulated in epilepsy (Vezzani and Granata, 2005). Acute inflammation from low to high doses (LPS) decreases the threshold for the induction of seizure (Sayyah et al., 2003), and a single early life inflammatory insult 
increases susceptibility to seizure even into adulthood (Galic et al., 2008). Chronic overexpression of inflammation-related genes in rodents causes an increased or decreased susceptibility to seizure, depending on gene dose (Vezzani and Granata, 2005), and seizure itself appears to chronically induce inflammatory markers (De Simoni et al., 2000). This evidence indicates a potential bidirectional effect of epilepsy and inflammation, wherein acute and chronic inflammation may have immediate and long-term effects on epilepsy-related plasticity mechanisms. In addition to epilepsy, cortical lesions and hypoxia-ischemia induce a robust inflammatory response that can endure chronically (Bona et al., 1999; Schroeter et al., 2002) and disrupt ocular dominance plasticity weeks after the injury (Failor et al., 2010; Greifzu et al., 2011). Interestingly, anti-inflammatory (ibuprofen) treatment rescues MD-induced sensory learning (increased visual acuity of the nondeprived eye) in adult (P70-P110) after cortical injury via photothrombosis in the nearby primary somatosensory; however, ibuprofen did not restore ocular dominance plasticity (Greifzu et al., 2011). It is possible that the anti-inflammatory regimen or mechanism of action used was not sufficient to eliminate the inflammation and rescue ocular dominance plasticity, or it may reflect distinct mechanisms of plasticity and their modulation by inflammation in the juvenile cortex versus the adult. While it has been proposed that causes of plasticity disruption may be cortical deafferentiation in the case of cortical lesions or disruption of inhibitory interneurons in the case of hypoxia-ischemia, it is possible that inflammation downstream of injury disrupts plasticity and should be investigated further. In sum, there is evidence that chronic and acute inflammation go hand in hand with disrupted plasticity across a variety of brain disorders, on different time scales, and as a function of different underlying mechanisms. Going forward, work is necessary to understand the contribution of diverse inflammatory mechanisms in the disruption of various types of plasticity across a wide variety of neurological and neurodevelopmental conditions.

Our finding that inflammation suppresses developmental cortical plasticity suggests a potential public health concern related to neurodevelopmental trajectory. During the height of the critical period for visual plasticity (peak is 0.5-2 years in humans; Morishita and Hensch, 2008), children $<5$ years of age have the highest incidence of contracting LPS-carrying Gram-negative foodborne pathogens relative to other childhood or adult periods (Centers for Disease Control and Prevention, 2013). Other infections that induce inflammation also show an increased incidence during the peak of developmental plasticity in humans; $>80 \%$ of children $<3$ years of age experience otitis media (ear infection; Marom et al., 2014) and children $<5$ years of age are hospitalized for influenza-related complications nearly an order of magnitude more often than children 5-17 years of age (incidence rate ratio $=8.1,95 \% \mathrm{Cl}=7.3-9.0$; data are from Dawood et al., 2010). Our work suggests that this increased incidence of infection during postnatal periods of developmental plasticity (relative to older ages) may be an unrecognized mechanism by which inflammation alters the neurodevelopmental trajectory. Most directly, the suppression of visual cortex plasticity could disrupt the development of binocular matching (Wang et al., 2010), a process central to the development of normal vision that specifically depends on heightened plasticity during the critical period for visual development. In addition, higher-order cognitive processes could be disrupted, due to the hierarchical dependency of various critical periods of plasticity (Takesian and Hensch, 2013). In addition, given that mechanisms of plasticity identified in the visual critical period have translated to other brain regions and functions (Levelt and Hübener, 2012; Nabel and Morishita, 2013; Werker and Hensch, 2015), it is likely that inflammation could disrupt plasticity in other systems.

Our work is a natural extension into the postnatal epoch of the growing body of research indicating deleterious brain and behavioral outcomes due to prenatal inflammatory exposure (Choi et al., 2016; Steullet et al., 2016; Weber-Stadlbauer et al., 2017) and suggests that inflammation may have a more extensive impact on postnatal neurodevelopment and brain function than previously realized. In fact, childhood infections and inflammation are associated with subsequent diagnoses of autism, depression, and schizophrenia as well as declines in cognitive capacity (Dalman et al., 2008; Atladóttir et al., 2010; Khandaker et al., 2014; Benros et al., 2015). The elevated incidence rate of infections during childhood neurodevelopment (relative to older ages) and the association of childhood infection with subsequent neurodevelopmental disorder may indicate a partial explanation for the observed onset of psychiatric disorders in childhood and adolescence (Lee et al., 2014). Our work showing that inflammation disrupts developmental cortical plasticity suggests an unrecognized risk factor for neuropsychiatric disorders and provides a starting point to investigate the underlying pathophysiology.

We show here that an integrative bioinformatics approach is well suited to interrogate the interactions between disease processes and disruptions in developmental plasticity. To extend this approach further, molecular matching could be expanded to the $>71,000$ experiments publically available (as of 4 August 2016, there were 71,885 Gene Expression Omnibus "Series"), and Disease Leverage Analysis could be expanded to the universe of biologically defined gene sets (as of 4 August 2016, MSigDb alone contained 13,311 sets), facilitating more comprehensive interrogation of the disease space and generation of more specific hypotheses about disease processes that disrupt plasticity. Moreover, this approach is not limited to interrogating neurodevelopment but can be extended to other neurological signatures beyond plasticity. We expect it will be useful for identifying connections between disease processes and other brain phenotypes that can be appropriately represented by a transcriptional signature. 
Table 2: Juvenile plasticity signature

\begin{tabular}{|c|c|c|c|c|c|c|c|c|}
\hline $\mathrm{RP}$ & FC & pfp & $p$ value & Probe_id & Symbol & mm_Entrez_ID & hs_Entrez_ID & Gene_name \\
\hline 2.8187 & 3.7313 & 0 & 0 & ILMN_2641456 & Pсp2 & 18545 & 126006 & Purkinje cell protein $2(\mathrm{~L} 7)$ \\
\hline 3.2916 & 3.422 & 0 & 0 & ILMN_2503052 & Tnnc1 & 21924 & 7134 & Troponin C, cardiac/slow skeletal \\
\hline 4.2819 & 3.1519 & 0 & 0 & ILMN_2794645 & Cyr61 & 16007 & 3491 & Cysteine-rich protein 61 \\
\hline 13.632 & 2.5389 & 0 & 0 & ILMN_1251414 & Npas4 & 225872 & 266743 & Neuronal PAS domain protein 4 \\
\hline 28.3181 & 2.375 & 0 & 0 & ILMN_2597827 & Arc & 11838 & 23237 & Activity-regulated cytoskeletal-associated protein \\
\hline 15.7472 & 2.3415 & 0 & 0 & ILMN_1230397 & A630064P09Rik & NA & NA & NA \\
\hline 15.7373 & 2.331 & 0 & 0 & ILMN_2622983 & Dusp1 & 19252 & 1843 & Dual-specificity phosphatase 1 \\
\hline 14.4292 & 2.3046 & 0 & 0 & ILMN_3160970 & Gpr17 & 574402 & 2840 & G-protein-coupled receptor 17 \\
\hline 16.9658 & 2.2123 & 0 & 0 & ILMN_1250438 & Marcksl1 & 17357 & 65108 & MARCKS-like 1 \\
\hline 21.67 & 2.1606 & 0 & 0 & ILMN_2710253 & Cyr61 & 16007 & 3491 & Cysteine-rich protein 61 \\
\hline 20.9478 & 2.1439 & 0 & 0 & ILMN_1217458 & 8430403J19Rik & NA & NA & NA \\
\hline 23.8738 & 2.111 & 0 & 0 & ILMN_1220034 & Junb & 16477 & 3726 & jun B proto-oncogene \\
\hline 27.1365 & 2.0864 & 0 & 0 & ILMN_2744890 & Gadd $45 \mathrm{~g}$ & 23882 & 10912 & Growth arrest and DNA-damage-inducible 45 gamma \\
\hline 25.9586 & 2.0549 & 0 & 0 & ILMN_1227299 & Mbp & 17196 & 4155 & Myelin basic protein \\
\hline 29.3188 & 2.0001 & 0 & 0 & ILMN_1239557 & Ugt8a & 22239 & 7368 & UDP galactosyltransferase $8 \mathrm{~A}$ \\
\hline 27.0514 & 1.9972 & 0 & 0 & ILMN_2619767 & Pdlim2 & 213019 & 64236 & PDZ and LIM domain 2 \\
\hline 32.1696 & 1.9948 & 0 & 0 & ILMN_2707616 & Col22a1 & 69700 & 169044 & Collagen, type XXII, alpha 1 \\
\hline 32.3997 & 1.9656 & 0 & 0 & ILMN_1221178 & Pdlim2 & 213019 & 64236 & PDZ and LIM domain 2 \\
\hline 38.5983 & 1.9267 & $5.00 \mathrm{E}-04$ & 0 & ILMN_2463181 & Tnc & 21923 & 3371 & Tenascin C \\
\hline 37.2206 & 1.9239 & $5.00 \mathrm{E}-04$ & 0 & ILMN_2810882 & Ppic & 19038 & 5480 & Peptidylprolyl isomerase C \\
\hline 41.0256 & 1.9217 & $5.00 \mathrm{E}-04$ & 0 & ILMN_2615034 & Mog & 17441 & 4340 & Myelin oligodendrocyte glycoprotein \\
\hline 37.2906 & 1.9117 & $5.00 \mathrm{E}-04$ & 0 & ILMN_2653205 & Gp1bb & 14724 & 2812 & Glycoprotein Ib, beta polypeptide \\
\hline 43.0584 & 1.9067 & $4.00 \mathrm{E}-04$ & 0 & ILMN_1212702 & Hba-a1 & NA & NA & NA \\
\hline 47.3908 & 1.8855 & $8.00 \mathrm{E}-04$ & 0 & ILMN_1240973 & Slc29a4 & 243328 & 222962 & Solute carrier family 29 (nucleoside transporters), member 4 \\
\hline 145.4493 & 1.8339 & 0.0108 & 0 & ILMN_1253365 & Lypd1 & 71111 & 2863 & G-protein-coupled receptor 39 \\
\hline 49.1546 & 1.832 & $8.00 \mathrm{E}-04$ & 0 & ILMN_2802263 & Cnp & 12799 & 1267 & 2',3'-cyclic nucleotide 3' phosphodiesterase \\
\hline 89.4321 & 1.8212 & 0.0037 & 0 & ILMN_2491182 & A130010C12Rik & NA & NA & NA \\
\hline 85.0435 & 1.8206 & 0.0024 & 0 & ILMN_2766894 & Enpp6 & 320981 & 133121 & Ectonucleotide pyrophosphatase/phosphodiesterase 6 \\
\hline 60.0087 & 1.7971 & 8.00E-04 & 0 & ILMN_1223244 & $\mathrm{Hbb}-\mathrm{b} 1$ & NA & NA & NA \\
\hline 71.2786 & 1.7908 & 0.0012 & 0 & ILMN_2906855 & Ky & 16716 & 339855 & Kyphoscoliosis peptidase \\
\hline 63.327 & 1.7828 & 7.00E-04 & 0 & ILMN_2880906 & Pdlim2 & 213019 & 64236 & PDZ and LIM domain 2 \\
\hline 79.6764 & 1.7799 & 0.0024 & 0 & ILMN_1256343 & $\mathrm{H} 19$ & 14955 & NA & $\mathrm{H} 19$, imprinted maternally expressed transcript \\
\hline 100.4221 & 1.7744 & 0.0048 & 0 & ILMN_1252953 & Cbln1 & 12404 & 869 & Cerebellin 1 precursor protein \\
\hline 62.1078 & 1.7686 & 7.00E-04 & 0 & ILMN_2617162 & Mlp & 17357 & 65108 & MARCKS-like 1 \\
\hline 83.6683 & 1.7607 & 0.0025 & 0 & ILMN_2955919 & Mcam & 84004 & 4162 & Melanoma cell adhesion molecule \\
\hline 70.6284 & 1.7566 & 0.001 & 0 & ILMN_1259536 & Mog & 17441 & 4340 & Myelin oligodendrocyte glycoprotein \\
\hline 68.3987 & 1.753 & 0.001 & 0 & ILMN_2754447 & Mkrn3 & 22652 & 7681 & Makorin, ring finger protein, 3 \\
\hline 68.3151 & 1.7464 & 0.001 & 0 & ILMN_2597606 & Gjc2 & 118454 & 57165 & Gap junction protein, gamma 2 \\
\hline 95.7042 & 1.7345 & 0.0044 & 0 & ILMN_2544056 & $\mathrm{Hbb}-\mathrm{b} 1$ & 100503605 & 3043 & Hemoglobin, beta adult s chain \\
\hline 76.7826 & 1.7239 & 0.0024 & 0 & ILMN_1242456 & Kank1 & 107351 & 23189 & $\mathrm{KN}$ motif and ankyrin repeat domains 1 \\
\hline 82.1412 & 1.7197 & 0.0026 & 0 & ILMN_1237021 & Mag & 17136 & 4099 & Myelin-associated glycoprotein \\
\hline 107.5658 & 1.7077 & 0.0049 & 0 & ILMN_2675874 & Alas2 & 11656 & 212 & Aminolevulinic acid synthase 2 , erythroid \\
\hline 105.2858 & 1.6961 & 0.0049 & 0 & ILMN_3161282 & Dpys|5 & 65254 & 56896 & Dihydropyrimidinase-like 5 \\
\hline 104.9667 & 1.6801 & 0.005 & 0 & ILMN_1216452 & Hbb-b1 & NA & NA & NA \\
\hline 101.7441 & 1.677 & 0.0048 & 0 & ILMN_2735184 & Col18a1 & 12822 & 80781 & Collagen, type XVIII, alpha 1 \\
\hline 165.7567 & 1.6719 & 0.0137 & $1.00 \mathrm{E}-04$ & ILMN_1241293 & Cldn5 & 12741 & 7122 & Claudin 5 \\
\hline 104.234 & 1.67 & 0.0051 & 0 & ILMN_2991389 & Ly6g6e & 70274 & NA & Lymphocyte antigen 6 complex, locus G6E \\
\hline 109.9056 & 1.6629 & 0.006 & 0 & ILMN_3105563 & Dmkn & 73712 & 93099 & Dermokine \\
\hline 100.5225 & 1.6611 & 0.0046 & 0 & ILMN_1259039 & Sox8 & NA & NA & NA \\
\hline 119.8152 & 1.6562 & 0.0082 & 0 & ILMN_1236718 & $\mathrm{Hbb}-\mathrm{b} 1$ & NA & NA & NA \\
\hline 107.4491 & 1.6543 & 0.005 & 0 & ILMN_1234698 & Tspan2 & 70747 & 10100 & Tetraspanin 2 \\
\hline 114.2191 & 1.651 & 0.0071 & 0 & ILMN_2457585 & Trp53inp2 & 68728 & 58476 & Transformation-related protein 53-inducible nuclear protein 2 \\
\hline 127.672 & 1.6497 & 0.0091 & 0 & ILMN_2977558 & Dapk2 & 13143 & 23604 & Death-associated protein kinase 2 \\
\hline 115.4908 & 1.6484 & 0.0078 & 0 & ILMN_2777359 & Serpinh1 & 12406 & 871 & Serine (or cysteine) peptidase inhibitor, clade $\mathrm{H}$, member 1 \\
\hline 133.2106 & 1.6468 & 0.009 & 0 & ILMN_2757125 & Prc1 & 233406 & 9055 & Protein regulator of cytokinesis 1 \\
\hline 168.1391 & 1.645 & 0.0138 & $1.00 \mathrm{E}-04$ & ILMN_2440194 & 5330423l11Rik & NA & NA & NA \\
\hline 133.3424 & 1.6326 & 0.0088 & 0 & ILMN_2903945 & Gadd45g & 23882 & 10912 & Growth arrest and DNA-damage-inducible 45 gamma \\
\hline 237.4537 & 1.6307 & 0.0286 & $2.00 \mathrm{E}-04$ & ILMN_3159435 & Mid1 & 17318 & NA & Midline 1 \\
\hline 121.1858 & 1.6264 & 0.0083 & 0 & ILMN_2598103 & Emp2 & 13731 & 2013 & Epithelial membrane protein 2 \\
\hline 129.3051 & 1.6258 & 0.0091 & 0 & ILMN_1215632 & Marcksl1 & 17357 & 65108 & MARCKS-like 1 \\
\hline 132.4496 & 1.6257 & 0.0091 & 0 & ILMN_3144289 & Traf3 & 22031 & 7187 & TNF receptor-associated factor 3 \\
\hline 139.3631 & 1.6219 & 0.0092 & 0 & ILMN_2675000 & 4930511J11Rik & 74720 & 283953 & Claudin 26 \\
\hline 125.9 & 1.6217 & 0.0091 & 0 & ILMN_2439638 & Traf3 & 22031 & 7187 & TNF receptor-associated factor 3 \\
\hline 264.9656 & 1.6146 & 0.0379 & 2.00E-04 & ILMN_2623983 & Egr2 & 13654 & 1959 & Early growth response 2 \\
\hline 167.9258 & 1.6117 & 0.0141 & 1.00E-04 & ILMN_2506428 & Ky & 16716 & 339855 & Kyphoscoliosis peptidase \\
\hline 149.169 & 1.6067 & 0.0109 & 0 & ILMN_2545963 & $\mathrm{Hbb}-\mathrm{b} 1$ & NA & NA & NA \\
\hline 147.5637 & 1.6053 & 0.0108 & 0 & ILMN_2769490 & 5430435G22Rik & 226421 & 338382 & RIKEN cDNA 5430435G22 gene \\
\hline 216.6505 & 1.6037 & 0.0234 & 1.00E-04 & ILMN_2443330 & Ttr & 22139 & 7276 & Transthyretin \\
\hline 147.9521 & 1.6023 & 0.0111 & 0 & ILMN_2467151 & Cyp11a1 & NA & NA & NA \\
\hline 177.2045 & 1.6005 & 0.0155 & 1.00E-04 & ILMN_1245549 & 6330404C01Rik & 80982 & 57214 & Cell migration inducing protein, hyaluronan binding \\
\hline 156.4386 & 1.5987 & 0.0116 & 0 & ILMN_1235571 & Cyr61 & 16007 & 3491 & Cysteine-rich protein 61 \\
\hline 151.0446 & 1.5966 & 0.0108 & 0 & ILMN_2784078 & Mmp15 & 17388 & 4324 & Matrix metallopeptidase 15 \\
\hline 128.5692 & 1.592 & 0.0091 & 0 & ILMN_1234099 & Fermt1 & 241639 & 55612 & Fermitin family homolog 1 (Drosophila) \\
\hline 153.0722 & 1.591 & 0.0109 & 0 & ILMN_2701891 & Marcksl1 & 17357 & 65108 & MARCKS-like 1 \\
\hline 169.069 & 1.5888 & 0.0138 & $1.00 \mathrm{E}-04$ & ILMN_1255462 & Hbb-b1 & NA & NA & NA \\
\hline 238.1918 & 1.5774 & 0.0283 & $2.00 \mathrm{E}-04$ & ILMN_2750515 & Fos & 14281 & 2353 & FBJ osteosarcoma oncogene \\
\hline 179.4286 & 1.5767 & 0.0157 & $1.00 \mathrm{E}-04$ & ILMN_1258028 & Gal3st1 & $\begin{array}{c}53897 \\
\text { (Continued) }\end{array}$ & 9514 & Galactose-3-O-sulfotransferase 1 \\
\hline
\end{tabular}


Table 2: Continued

\begin{tabular}{|c|c|c|c|c|c|c|c|c|}
\hline $\mathrm{RP}$ & $\mathrm{FC}$ & pfp & $p$ value & Probe_id & Symbol & mm_Entrez_ID & hs_Entrez_ID & Gene_name \\
\hline 168.0194 & 1.5754 & 0.0139 & $1.00 \mathrm{E}-04$ & ILMN_2621544 & 2700060E02Rik & 18074 & 22795 & Nidogen 2 \\
\hline 179.1935 & 1.5706 & 0.0159 & $1.00 \mathrm{E}-04$ & ILMN_2711163 & Ctsk & 13038 & 1513 & Cathepsin $\mathrm{K}$ \\
\hline 203.9522 & 1.5702 & 0.021 & $1.00 \mathrm{E}-04$ & ILMN_2965660 & Apcdd1 & 494504 & 147495 & Adenomatosis polyposis coli downregulated 1 \\
\hline 186.0794 & 1.5661 & 0.0162 & $1.00 \mathrm{E}-04$ & ILMN_2778722 & Ppapdc1a & 381925 & 196051 & Phosphatidic acid phosphatase type 2 domain containing $1 \mathrm{~A}$ \\
\hline 183.6942 & 1.5565 & 0.0158 & $1.00 \mathrm{E}-04$ & ILMN_1246139 & Cldn11 & 18417 & 5010 & Claudin 11 \\
\hline 183.6736 & 1.5551 & 0.0161 & $1.00 \mathrm{E}-04$ & ILMN_2838308 & Fmo1 & 14261 & 2326 & Flavin-containing monooxygenase 1 \\
\hline 209.5265 & 1.5551 & 0.0219 & $1.00 \mathrm{E}-04$ & ILMN_2769777 & Msc & 17681 & 9242 & Musculin \\
\hline 256.1212 & 1.5496 & 0.0346 & $2.00 \mathrm{E}-04$ & ILMN_2703138 & Tmem125 & 230678 & 128218 & Transmembrane protein 125 \\
\hline 204.0502 & 1.5465 & 0.0207 & 1.00E-04 & ILMN_2623184 & Nkiras2 & 71966 & 28511 & $\mathrm{NF}-\kappa \mathrm{B}$ inhibitor interacting Ras-like protein 2 \\
\hline 202.9992 & 1.5454 & 0.0207 & $1.00 \mathrm{E}-04$ & ILMN_2650447 & Col23a1 & 237759 & 91522 & Collagen, type XXIII, alpha 1 \\
\hline 215.8733 & 1.545 & 0.0231 & $1.00 \mathrm{E}-04$ & ILMN_1239117 & $\mathrm{Hbb}-\mathrm{b} 1$ & NA & NA & NA \\
\hline 221.9056 & 1.5432 & 0.0251 & $1.00 \mathrm{E}-04$ & ILMN_2638473 & 1190003M12Rik & 68888 & NA & Gastrokine 3 \\
\hline 202.5197 & 1.5425 & 0.0208 & $1.00 \mathrm{E}-04$ & ILMN_2753342 & Hapln1 & 12950 & 1404 & Hyaluronan and proteoglycan link protein 1 \\
\hline 210.5965 & 1.5409 & 0.022 & $1.00 \mathrm{E}-04$ & ILMN_2759371 & Fgfbp1 & 14181 & 9982 & Fibroblast growth factor binding protein 1 \\
\hline 235.9454 & 1.5331 & 0.0284 & 2.00E-04 & ILMN_3097381 & Mobp & 17433 & 4336 & Myelin-associated oligodendrocytic basic protein \\
\hline 217.9308 & 1.5305 & 0.0236 & 1.00E-04 & ILMN_2909782 & Rras2 & 66922 & 22800 & Related RAS viral (r-ras) oncogene homolog 2 \\
\hline 229.1399 & 1.5299 & 0.0263 & 1.00E-04 & ILMN_2472451 & Traf4 & 22032 & 9618 & TNF receptor-associated factor 4 \\
\hline 271.8732 & 1.5286 & 0.0398 & 2.00E-04 & ILMN_3162060 & EG574403 & 574403 & 100131897 & Family with sequence similarity 196, member B \\
\hline 233.6047 & 1.5221 & 0.0277 & 2.00E-04 & ILMN_2747923 & Slc40a1 & 53945 & 30061 & Solute carrier family 40 (iron-regulated transporter), member 1 \\
\hline 227.3295 & 1.5175 & 0.0263 & 1.00E-04 & ILMN_2517041 & Uhrf1 & 18140 & 29128 & Ubiquitin-like, containing PHD and RING finger domains, 1 \\
\hline 280.3468 & 1.5086 & 0.0429 & $3.00 \mathrm{E}-04$ & ILMN_1241168 & Dok4 & 114255 & 55715 & Docking protein 4 \\
\hline 254.0057 & 1.5079 & 0.0341 & 2.00E-04 & ILMN_2625854 & 2310016C16Rik & 69590 & 493869 & Glutathione peroxidase 8 (putative) \\
\hline 256.2349 & 1.5077 & 0.0342 & 2.00E-04 & ILMN_1229726 & Fibcd1 & 98970 & 84929 & Fibrinogen $\mathrm{C}$ domain containing 1 \\
\hline 304.0763 & 1.5074 & 0.0497 & 3.00E-04 & ILMN_2522884 & 9930105H17Rik & NA & NA & NA \\
\hline 270.2753 & 1.5045 & 0.0393 & 2.00E-04 & ILMN_2815506 & Gamt & 14431 & 2593 & Guanidinoacetate methyltransferase \\
\hline 262.3132 & 1.5016 & 0.0369 & $2.00 \mathrm{E}-04$ & ILMN_2778111 & Etv4 & 18612 & 2118 & ets variant 4 \\
\hline 288.425 & 1.4979 & 0.0449 & $3.00 E-04$ & ILMN_2604224 & Sema5a & 20356 & 9037 & $\begin{array}{l}\text { Sema domain, seven thrombospondin repeats (type } 1 \text { and type 1-like), } \\
\text { transmembrane domain (TM) and short cytoplasmic } \\
\text { domain, (semaphorin) } 5 \mathrm{~A}\end{array}$ \\
\hline 268.7263 & 1.4966 & 0.039 & 2.00E-04 & ILMN_2688236 & Atp2a3 & 53313 & 489 & ATPase, $\mathrm{Ca}++$ transporting, ubiquitous \\
\hline 284.2455 & 1.4958 & 0.044 & 3.00E-04 & ILMN_1236788 & Igfbp2 & 16008 & 3485 & Insulin-like growth factor-binding protein 2 \\
\hline 287.3425 & 1.492 & 0.0451 & 3.00E-04 & ILMN_2737479 & Slc12a9 & 83704 & 56996 & Solute carrier family 12 (potassium/chloride transporters), member 9 \\
\hline 274.5651 & 1.4905 & 0.041 & 3.00E-04 & ILMN_1257097 & Cnp & 12799 & 1267 & 2',3'-cyclic nucleotide 3' phosphodiesterase \\
\hline 288.7593 & 1.4897 & 0.0446 & 3.00E-04 & ILMN_1219025 & 9030409G11Rik & 71529 & 23254 & Kazrin, periplakin interacting protein \\
\hline 297.6994 & 1.4891 & 0.0481 & 3.00E-04 & ILMN_1251524 & Them4 & 75778 & 117145 & Thioesterase superfamily member 4 \\
\hline 303.8564 & 1.4877 & 0.0501 & 3.00E-04 & ILMN_1226329 & Cd93 & 17064 & 22918 & CD93 antigen \\
\hline 305.5889 & 1.4821 & 0.0492 & 3.00E-04 & ILMN_3126277 & Palmd & 114301 & 54873 & Palmdelphin \\
\hline 299.226 & 1.4801 & 0.0486 & 3.00E-04 & ILMN_2655204 & Apc & 11789 & 324 & Adenomatosis polyposis coli \\
\hline 303.6034 & 1.4788 & 0.0505 & 3.00E-04 & ILMN_2726030 & AB023957 & NA & NA & NA \\
\hline 304.1851 & 1.476 & 0.0493 & 3.00E-04 & ILMN_2772155 & LOC100045780 & 11492 & 8728 & A disintegrin and metallopeptidase domain 19 (meltrin beta) \\
\hline 326.2746 & -1.5473 & 0.0492 & 4.00E-04 & ILMN_2939681 & Lyzs & 17110 & 4069 & Lysozyme 1 \\
\hline 324.3234 & -1.5513 & 0.0485 & 4.00E-04 & ILMN_2718266 & Fkbp5 & 14229 & 2289 & FK506 binding protein 5 \\
\hline 300.7726 & -1.5755 & 0.0398 & 3.00E-04 & ILMN_2775885 & Calm2 & 12314 & NA & Calmodulin 2 \\
\hline 278.2959 & -1.5868 & 0.0343 & $2.00 \mathrm{E}-04$ & ILMN_1224363 & Slc12a5 & 57138 & 57468 & Solute carrier family 12 , member 5 \\
\hline 281.5906 & -1.6113 & 0.0347 & 3.00E-04 & ILMN_1251998 & Gm765 & 330390 & NA & Predicted gene 765 \\
\hline 226.9486 & -1.6145 & 0.0249 & $1.00 \mathrm{E}-04$ & ILMN_2488510 & Ppm1k & 243382 & 152926 & Protein phosphatase $1 \mathrm{~K}$ (PP2C domain containing) \\
\hline 308.258 & -1.6168 & 0.0431 & $3.00 \mathrm{E}-04$ & ILMN_1248368 & Mat2a & 232087 & 4144 & Methionine adenosyltransferase II, alpha \\
\hline 275.8602 & -1.6184 & 0.0343 & 2.00E-04 & ILMN_2669088 & 4930461P20Rik & 78244 & 134218 & DNAJ (Hsp40) homolog, subfamily C, member 21 \\
\hline 253.8942 & -1.62 & 0.0298 & $2.00 \mathrm{E}-04$ & ILMN_2435835 & Evpl & 14027 & 2125 & Envoplakin \\
\hline 197.6328 & -1.6297 & 0.0211 & $1.00 \mathrm{E}-04$ & ILMN_2602387 & $\mathrm{Nr} 1 \mathrm{~d} 2$ & 353187 & 9975 & Nuclear receptor subfamily 1 , group D, member 2 \\
\hline 311.5841 & -1.6329 & 0.0428 & 3.00E-04 & ILMN_2734000 & Elavl4 & 15572 & 1996 & ELAV (embryonic lethal, abnormal vision, Drosophila)-like 4 (Hu antigen D) \\
\hline 311.1495 & -1.6404 & 0.043 & 3.00E-04 & ILMN_2859032 & Gfod1 & 328232 & 54438 & Glucose-fructose oxidoreductase domain containing 1 \\
\hline 253.0893 & -1.6455 & 0.0299 & 2.00E-04 & ILMN_2445958 & Tssc8 & 63830 & NA & KCNQ1 overlapping transcript 1 \\
\hline 258.1943 & -1.6504 & 0.0299 & 2.00E-04 & ILMN_2419660 & mtDNA_ND4L & NA & NA & NA \\
\hline 215.9199 & -1.6523 & 0.0237 & $1.00 \mathrm{E}-04$ & ILMN_1221817 & $\mathrm{Cd} 74$ & 16149 & 972 & CD74 antigen (invariant polypeptide of MHC, class II antigen-associated) \\
\hline 308.2304 & -1.6595 & 0.0434 & 3.00E-04 & ILMN_2545149 & Nos1ap & 70729 & NA & Nitric oxide synthase 1 (neuronal) adaptor protein \\
\hline 256.5251 & -1.6631 & 0.0294 & $2.00 \mathrm{E}-04$ & ILMN_1219573 & C130072A16Rik & 105727 & 81539 & Solute carrier family 38, member 1 \\
\hline 292.3656 & -1.6664 & 0.0367 & 3.00E-04 & ILMN_2475376 & BC044804 & NA & NA & NA \\
\hline 229.2861 & -1.6683 & 0.0251 & $1.00 \mathrm{E}-04$ & ILMN_1253544 & 2900060B14Rik & 68204 & NA & RIKEN cDNA 2900060 B14 gene \\
\hline 318.4001 & -1.6694 & 0.0454 & 4.00E-04 & ILMN_1246494 & LOC381445 & 26422 & 26960 & Neurobeachin \\
\hline 282.6027 & -1.6717 & 0.0345 & 3.00E-04 & ILMN_2666980 & BDNF & 12064 & 627 & BDNF \\
\hline 219.961 & -1.6722 & 0.0236 & $1.00 \mathrm{E}-04$ & ILMN_1231445 & Inmt & 21743 & 11185 & Indolethylamine N-methyltransferase \\
\hline 240.372 & -1.6762 & 0.0269 & 2.00E-04 & ILMN_1240202 & Fnip1 & 216742 & 96459 & Folliculin-interacting protein 1 \\
\hline 269.2034 & -1.6764 & 0.033 & 2.00E-04 & ILMN_2987863 & Per2 & 18627 & 8864 & Period circadian clock 2 \\
\hline 201.3209 & -1.677 & 0.0212 & $1.00 \mathrm{E}-04$ & ILMN_3157692 & Ankrd35 & 213121 & 148741 & Ankyrin repeat domain 35 \\
\hline 310.3109 & -1.679 & 0.0432 & 3.00E-04 & ILMN_1218471 & 3-Sep & 24050 & 55964 & Septin 3 \\
\hline 229.1441 & -1.6798 & 0.0254 & $1.00 \mathrm{E}-04$ & ILMN_1229216 & Zbtb16 & 235320 & 7704 & Zinc finger and BTB domain containing 16 \\
\hline 264.7303 & -1.6841 & 0.0316 & $2.00 \mathrm{E}-04$ & ILMN_1253985 & A330021D07Rik & NA & NA & NA \\
\hline 171.7223 & -1.6861 & 0.0163 & $1.00 \mathrm{E}-04$ & ILMN_1235966 & Alox12b & 11686 & 242 & Arachidonate 12-lipoxygenase, 12R type \\
\hline 253.9144 & -1.6861 & 0.0295 & 2.00E-04 & ILMN_1245687 & Ash1I & 192195 & 55870 & ash1 (absent, small, or homeotic)-like (Drosophila) \\
\hline 294.7856 & -1.6875 & 0.0375 & $3.00 \mathrm{E}-04$ & ILMN_2674890 & Tbl1x & 21372 & 6907 & Transducin (beta)-like $1 \mathrm{X}$-linked \\
\hline 267.8862 & -1.6889 & 0.0328 & $2.00 \mathrm{E}-04$ & ILMN_2828916 & Frmd6 & 319710 & 122786 & FERM domain containing 6 \\
\hline 254.4102 & -1.6932 & 0.0293 & 2.00E-04 & ILMN_1228077 & 6330437B22Rik & 78283 & 256714 & MAP7 domain containing 2 \\
\hline 282.4957 & -1.6935 & 0.0347 & $3.00 \mathrm{E}-04$ & ILMN_2589525 & Cpeb3 & 208922 & 22849 & Cytoplasmic polyadenylation element binding protein 3 \\
\hline 277.0563 & -1.6955 & 0.0345 & 2.00E-04 & ILMN_2466121 & Twistnb & 28071 & 221830 & TWIST neighbor \\
\hline 250.5161 & -1.6978 & 0.029 & $2.00 \mathrm{E}-04$ & ILMN_2514631 & scl0002315.1_12 & 217869 & 1983 & Eukaryotic translation initiation factor 5 \\
\hline 186.3783 & -1.7007 & 0.0195 & $1.00 \mathrm{E}-04$ & ILMN_2493030 & 2310043N10Rik & 66961 & NA & Nuclear paraspeckle assembly transcript 1 (non-protein coding) \\
\hline 263.9285 & -1.7033 & 0.0315 & $2.00 \mathrm{E}-04$ & ILMN_2677270 & Peg3 & 18616 & 5178 & Paternally expressed 3 \\
\hline
\end{tabular}


Table 2: Continued

\begin{tabular}{|c|c|c|c|c|c|c|c|c|}
\hline $\mathrm{RP}$ & $\mathrm{FC}$ & pfp & $p$ value & Probe_id & Symbol & mm_Entrez_ID & hs_Entrez_ID & Gene_name \\
\hline 239.6678 & -1.7039 & 0.0271 & 2.00E-04 & ILMN_1214405 & Cnksr2 & 245684 & 22866 & Connector enhancer of kinase suppressor of Ras 2 \\
\hline 253.7716 & -1.7042 & 0.03 & $2.00 \mathrm{E}-04$ & ILMN_2763404 & Nrxn3 & 18191 & NA & Neurexin III \\
\hline 182.2435 & -1.7079 & 0.0186 & $1.00 \mathrm{E}-04$ & ILMN_1246861 & Ctss & 13040 & 1520 & Cathepsin S \\
\hline 278.7674 & -1.7082 & 0.0341 & $2.00 \mathrm{E}-04$ & ILMN_1239608 & Arid4a & 238247 & 5926 & AT-rich interactive domain 4A (RBP1-like) \\
\hline 242.1379 & -1.7088 & 0.0269 & $2.00 \mathrm{E}-04$ & ILMN_2745614 & Fam134b & 66270 & 54463 & Family with sequence similarity 134 , member $B$ \\
\hline 273.3035 & -1.7094 & 0.0336 & $2.00 \mathrm{E}-04$ & ILMN_2762701 & Scn1a & 20265 & 6323 & Sodium channel, voltage-gated, type I, alpha \\
\hline 235.4555 & -1.7097 & 0.0263 & $2.00 \mathrm{E}-04$ & ILMN_1243910 & Zfp292 & 30046 & 23036 & Zinc finger protein 292 \\
\hline 182.6041 & -1.71 & 0.0184 & $1.00 \mathrm{E}-04$ & ILMN_2690603 & Spp1 & 20750 & 6696 & Secreted phosphoprotein 1 \\
\hline 262.6651 & -1.7167 & 0.0313 & $2.00 \mathrm{E}-04$ & ILMN_2733314 & Rgs7bp & 52882 & 401190 & Regulator of G-protein signaling 7 binding protein \\
\hline 218.5161 & -1.7173 & 0.0237 & $1.00 \mathrm{E}-04$ & ILMN_2593368 & Mat2a & 232087 & 4144 & Methionine adenosyltransferase II, alpha \\
\hline 248.3251 & -1.7218 & 0.0284 & $2.00 \mathrm{E}-04$ & ILMN_2525034 & Cc1 & 12421 & 9821 & RB1-inducible coiled-coil 1 \\
\hline 244.6249 & -1.7232 & 0.0273 & 2.00E-04 & ILMN_2713008 & C030011014Rik & 215708 & 374986 & Family with sequence similarity 73 , member $A$ \\
\hline 244.4499 & -1.7244 & 0.0276 & $2.00 \mathrm{E}-04$ & ILMN_1228020 & 1500010G04Rik & NA & NA & NA \\
\hline 214.8649 & -1.7247 & 0.0242 & $1.00 \mathrm{E}-04$ & ILMN_2664706 & Chic1 & 12212 & 53344 & Cysteine-rich hydrophobic domain 1 \\
\hline 224.3588 & -1.7256 & 0.0252 & $1.00 \mathrm{E}-04$ & ILMN_1251488 & A430041B07Rik & 328108 & 23116 & Family with sequence similarity 179 , member $B$ \\
\hline 167.7266 & -1.7283 & 0.0158 & $1.00 \mathrm{E}-04$ & ILMN_2651054 & LOC100047173 & 269589 & 84958 & Synaptotagmin-like 1 \\
\hline 233.1724 & -1.7313 & 0.0262 & $2.00 \mathrm{E}-04$ & ILMN_2713004 & C030011014Rik & 215708 & 374986 & Family with sequence similarity 73 , member $A$ \\
\hline 224.4289 & -1.7346 & 0.0249 & $1.00 \mathrm{E}-04$ & ILMN_1233554 & Pbrm1 & 66923 & 55193 & Polybromo 1 \\
\hline 215.0498 & -1.7355 & 0.0239 & $1.00 \mathrm{E}-04$ & ILMN_2669461 & $\mathrm{Bbx}$ & 70508 & 56987 & Bobby sox homolog (Drosophila) \\
\hline 220.6021 & -1.7382 & 0.0238 & $1.00 \mathrm{E}-04$ & ILMN_1218712 & Jph4 & NA & NA & NA \\
\hline 229.662 & -1.7394 & 0.0248 & $1.00 \mathrm{E}-04$ & ILMN_1231596 & Mtap7 & NA & NA & NA \\
\hline 217.0292 & -1.7397 & 0.0237 & 1.00E-04 & ILMN_2492395 & 2900064A13Rik & NA & NA & NA \\
\hline 194.6882 & -1.7416 & 0.0213 & $1.00 \mathrm{E}-04$ & ILMN_1218051 & lqgap2 & 544963 & 10788 & IQ motif containing GTPase activating protein 2 \\
\hline 224.9623 & -1.7422 & 0.0249 & $1.00 \mathrm{E}-04$ & ILMN_1220626 & 2010007K12Rik & NA & NA & NA \\
\hline 193.5535 & -1.7437 & 0.0213 & $1.00 \mathrm{E}-04$ & ILMN_2689307 & Spnb2 & 20742 & 6711 & Spectrin $\beta$, non-erythrocytic 1 \\
\hline 211.5491 & -1.7446 & 0.0235 & $1.00 \mathrm{E}-04$ & ILMN_2594593 & Mpp5 & 56217 & 64398 & Membrane protein, palmitoylated 5 (MAGUK p55 subfamily member 5) \\
\hline 196.6783 & -1.7461 & 0.0214 & $1.00 \mathrm{E}-04$ & ILMN_2541675 & LOC382128 & 319675 & 85459 & RIKEN cDNA 5830418K08 gene \\
\hline 225.9716 & -1.7473 & 0.0251 & $1.00 \mathrm{E}-04$ & ILMN_1230605 & Gm336 & 212285 & 116984 & ArfGAP with RhoGAP domain, ankyrin repeat and PH domain 2 \\
\hline 172.8921 & -1.7587 & 0.0162 & 1.00E-04 & ILMN_2803674 & S100a9 & 20202 & 6280 & S100 calcium binding protein A9 (calgranulin B) \\
\hline 192.6629 & -1.759 & 0.0213 & $1.00 \mathrm{E}-04$ & ILMN_3072536 & Eif5 & 217869 & 1983 & Eukaryotic translation initiation factor 5 \\
\hline 138.7531 & -1.7606 & 0.0112 & 0 & ILMN_1255416 & Ly6a & 110454 & NA & Lymphocyte antigen 6 complex, locus A \\
\hline 206.7346 & -1.7624 & 0.0217 & $1.00 \mathrm{E}-04$ & ILMN_2596077 & 2810474O19Rik & 67246 & 55196 & RIKEN cDNA 2810474019 gene \\
\hline 190.8274 & -1.7627 & 0.0211 & $1.00 \mathrm{E}-04$ & ILMN_1237335 & A730028C12Rik & NA & NA & NA \\
\hline 197.1239 & -1.7662 & 0.0214 & $1.00 \mathrm{E}-04$ & ILMN_2593230 & Mllt4 & 17356 & 4301 & $\begin{array}{l}\text { Myeloid/lymphoid or mixed-lineage leukemia (trithorax } \\
\text { homolog, Drosophila); translocated to, } 4\end{array}$ \\
\hline 200.8213 & -1.769 & 0.0212 & $1.00 \mathrm{E}-04$ & ILMN_2595282 & 2600005C20Rik & 72462 & 23076 & Ribosomal RNA processing 1 homolog B (S. cerevisiae) \\
\hline 200.7106 & -1.7702 & 0.0215 & $1.00 \mathrm{E}-04$ & ILMN_2481389 & Zfp326 & 54367 & 284695 & Zinc finger protein 326 \\
\hline 164.0235 & -1.774 & 0.0155 & $1.00 \mathrm{E}-04$ & ILMN_1220828 & 2900075B16Rik & 78506 & 286097 & Mitochondrial calcium uptake family, member 3 \\
\hline 155.2155 & -1.7756 & 0.0142 & 0 & ILMN_2571934 & D030034I04Rik & 105727 & 81539 & Solute carrier family 38, member 1 \\
\hline 176.004 & -1.7781 & 0.0166 & $1.00 \mathrm{E}-04$ & ILMN_1229727 & Gpr123 & 52389 & 84435 & G-protein-coupled receptor 123 \\
\hline 175.0744 & -1.7835 & 0.0164 & $1.00 \mathrm{E}-04$ & ILMN_1237059 & Kcna1 & 16485 & 3736 & Potassium voltage-gated channel, shaker-related subfamily, member 1 \\
\hline 152.5807 & -1.7867 & 0.014 & 0 & ILMN_2512204 & mt-Nd4l & NA & NA & NA \\
\hline 191.3641 & -1.7915 & 0.021 & $1.00 \mathrm{E}-04$ & ILMN_1236941 & Csnk2a1-rs3 & 12995 & 1457 & Casein kinase 2 , alpha 1 polypeptide \\
\hline 117.9399 & -1.796 & 0.0095 & 0 & ILMN_2629112 & Asah3l & 230379 & 340485 & Alkaline ceramidase 2 \\
\hline 154.7781 & -1.7976 & 0.0144 & 0 & ILMN_2423249 & 2010321I05Rik & 233833 & 27327 & Trinucleotide repeat containing $6 a$ \\
\hline 169.376 & -1.7979 & 0.0157 & $1.00 \mathrm{E}-04$ & ILMN_1260446 & Ttc3 & 22129 & 7267 & Tetratricopeptide repeat domain 3 \\
\hline 159.9385 & -1.8005 & 0.0148 & 0 & ILMN_3151492 & Ankrd12 & 106585 & 23253 & ankyrin repeat domain 12 \\
\hline 159.7083 & -1.8008 & 0.0149 & 0 & ILMN_2747381 & Ddx24 & 27225 & 57062 & DEAD (Asp-Glu-Ala-Asp) box polypeptide 24 \\
\hline 117.7708 & -1.806 & 0.0094 & 0 & ILMN_2746797 & Hsf4 & 26386 & 3299 & Heat shock transcription factor 4 \\
\hline 154.9416 & -1.8113 & 0.0141 & 0 & ILMN_1227149 & Meg3 & 17263 & NA & Maternally expressed 3 \\
\hline 154.4618 & -1.8188 & 0.0141 & 0 & ILMN_2544603 & 2610015J01Rik & 67039 & NA & RNA binding motif protein 25 \\
\hline 149.6626 & -1.8218 & 0.0137 & 0 & ILMN_1234357 & A230057E24Rik & NA & NA & NA \\
\hline 160.7228 & -1.8235 & 0.0145 & 0 & ILMN_2737867 & Mtap1b & 17755 & 4131 & Microtubule-associated protein 1B \\
\hline 146.4398 & -1.8285 & 0.0132 & 0 & ILMN_2657911 & Cnot4 & 53621 & 4850 & CCR4-NOT transcription complex, subunit 4 \\
\hline 137.4716 & -1.8312 & 0.0115 & 0 & ILMN_2654932 & Pdap1 & 231887 & 11333 & PDGFA-associated protein 1 \\
\hline 149.0718 & -1.8342 & 0.0133 & 0 & ILMN_2542231 & LOC382157 & 228005 & 9360 & Peptidyl-prolyl isomerase G (cyclophilin G) \\
\hline 136.8161 & -1.8372 & 0.0118 & 0 & ILMN_1256701 & 2900016B01Rik & 74901 & 9920 & Kelch repeat and BTB (POZ) domain containing 11 \\
\hline 140.2596 & -1.8406 & 0.0112 & 0 & ILMN_1217776 & MII5 & 69188 & 55904 & Lysine $(\mathrm{K})$-specific methyltransferase $2 \mathrm{E}$ \\
\hline 123.3913 & -1.8632 & 0.0097 & 0 & ILMN_2466797 & scl0001284.1_18 & NA & NA & NA \\
\hline 120.66 & -1.8657 & 0.0092 & 0 & ILMN_2495555 & Mapk8ip2 & NA & NA & NA \\
\hline 110.3349 & -1.8716 & 0.008 & 0 & ILMN_2720479 & Lpgat1 & 226856 & 9926 & Lysophosphatidylglycerol acyltransferase 1 \\
\hline 107.1799 & -1.8815 & 0.0084 & 0 & ILMN_3031781 & Arid5b & 71371 & 84159 & AT-rich interactive domain 5B (MRF1-like) \\
\hline 108.2637 & -1.8822 & 0.0082 & 0 & ILMN_2968123 & Slc7a14 & 241919 & 57709 & $\begin{array}{l}\text { Solute carrier family } 7 \text { (cationic amino acid transporter, } \\
\text { y+ system), member } 14\end{array}$ \\
\hline 102.8964 & -1.8896 & 0.0082 & 0 & ILMN_2524100 & Zswim6 & 67263 & 57688 & Zinc finger SWIM-type containing 6 \\
\hline 106.148 & -1.8943 & 0.008 & 0 & ILMN_1243996 & Ash1l & 192195 & 55870 & ash1 (absent, small, or homeotic)-like (Drosophila) \\
\hline 108.9677 & -1.8986 & 0.0082 & 0 & ILMN_1226085 & Syt1 & NA & NA & NA \\
\hline 99.6837 & -1.8993 & 0.0081 & 0 & ILMN_2844963 & Nos1ap & 70729 & NA & Nitric oxide synthase 1 (neuronal) adaptor protein \\
\hline 80.4955 & -1.9004 & 0.0043 & 0 & ILMN_3107059 & Espn & 56226 & 83715 & Espin \\
\hline 150.8775 & -1.9026 & 0.0136 & 0 & ILMN_1245389 & LOC236604 & 236604 & NA & Phosphatidylserine decarboxylase, pseudogene 1 \\
\hline 99.2247 & -1.9029 & 0.0085 & 0 & ILMN_2715848 & Slitrk4 & 245446 & 139065 & SLIT and NTRK-like family, member 4 \\
\hline 104.8752 & -1.9033 & 0.0083 & 0 & ILMN_2771709 & Ppargc1b & 170826 & 133522 & Peroxisome proliferative-activated receptor, $\gamma$, coactivator $1 \beta$ \\
\hline 93.2724 & -1.922 & 0.0076 & 0 & ILMN_3028837 & Pcdh9 & 211712 & 5101 & Protocadherin 9 \\
\hline 70.0507 & -1.9234 & 0.0043 & 0 & ILMN_2752883 & Hsp90aa1 & 15519 & 3320 & Heat shock protein 90, alpha (cytosolic), class A member 1 \\
\hline 68.4948 & -1.9249 & 0.0045 & 0 & ILMN_2702303 & Ch25h & 12642 & 9023 & Cholesterol 25-hydroxylase \\
\hline 78.6377 & -1.9335 & 0.0045 & 0 & ILMN_3144164 & Irs2 & 384783 & 8660 & Insulin receptor substrate 2 \\
\hline 83.4984 & -1.9539 & 0.005 & 0 & ILMN_1255854 & Mtap9 & 213582 & 79884 & Microtubule-associated protein 9 \\
\hline 62.4352 & -1.9916 & 0.0039 & 0 & ILMN_2639442 & Rock2 & 19878 & 9475 & Rho-associated coiled-coil containing protein kinase 2 \\
\hline
\end{tabular}


Table 2: Continued

\begin{tabular}{|c|c|c|c|c|c|c|c|c|}
\hline $\mathrm{RP}$ & FC & pfp & $p$ value & Probe_id & Symbol & mm_Entrez_ID & hs_Entrez_ID & Gene_name \\
\hline 65.2953 & -2.006 & 0.0047 & 0 & ILMN_2703913 & Mtf2 & 17765 & 22823 & Metal response element binding transcription factor 2 \\
\hline 57.2834 & -2.0145 & 0.0018 & 0 & ILMN_1236844 & A830094I09Rik & NA & NA & NA \\
\hline 55.3183 & -2.0239 & 0.0021 & 0 & ILMN_1236820 & 9430047F21Rik & NA & NA & NA \\
\hline 55.866 & -2.0392 & 0.0019 & 0 & ILMN_2432200 & Epb4.1 & NA & NA & NA \\
\hline 49.8425 & -2.0396 & 0.0023 & 0 & ILMN_2642426 & Agmat & 75986 & 79814 & agmatine ureohydrolase (agmatinase) \\
\hline 45.5522 & -2.0743 & 0.0017 & 0 & ILMN_1237548 & 5830407P18Rik & NA & NA & NA \\
\hline 44.5367 & -2.0756 & 0.0018 & 0 & ILMN_1259747 & $\| 33$ & 77125 & 90865 & Interleukin-33 \\
\hline 40.11 & -2.0942 & 0.001 & 0 & ILMN_3124885 & Pdpk1 & 18607 & 5170 & 3-Phosphoinositide dependent protein kinase 1 \\
\hline 35.7678 & -2.1106 & 0 & 0 & ILMN_2601176 & Meg3 & 17263 & NA & Maternally expressed 3 \\
\hline 38.3554 & -2.1249 & 0.0011 & 0 & ILMN_1225423 & Mslnl & 328783 & NA & Mesothelin-like \\
\hline 55.718 & -2.1295 & 0.002 & 0 & ILMN_2668333 & $\operatorname{Prg} 4$ & 96875 & NA & $\begin{array}{l}\text { Proteoglycan } 4 \text { (megakaryocyte stimulating factor, } \\
\text { articular superficial zone protein) }\end{array}$ \\
\hline 27.1219 & -2.1716 & 0 & 0 & ILMN_1216085 & B230387C07Rik & 106585 & 23253 & Ankyrin repeat domain 12 \\
\hline 25.1926 & -2.2119 & 0 & 0 & ILMN_1238436 & Cplx2 & 12890 & 10814 & Complexin 2 \\
\hline 107.5742 & -2.2202 & 0.0081 & 0 & ILMN_2965669 & XIr4a & NA & NA & NA \\
\hline 28.7047 & -2.2624 & 0 & 0 & ILMN_2661820 & Agxt2l1 & 71760 & 64850 & Ethanolamine phosphate phospholyase \\
\hline 23.2317 & -2.4004 & 0 & 0 & ILMN_2652500 & Lrg1 & 76905 & 116844 & Leucine-rich alpha-2-glycoprotein 1 \\
\hline 11.5889 & -2.5107 & 0 & 0 & ILMN_1229990 & Agxt2l1 & 71760 & 64850 & Ethanolamine phosphate phospholyase \\
\hline 14.3442 & -2.7824 & 0 & 0 & ILMN_2710905 & $\mathrm{S} 100 \mathrm{a} 8$ & 20201 & 6279 & S100 calcium binding protein $\mathrm{A} 8$ (calgranulin $\mathrm{A}$ ) \\
\hline 3.6486 & -3.7411 & 0 & 0 & ILMN_2712075 & Lcn2 & 16819 & 3934 & Lipocalin 2 \\
\hline
\end{tabular}

V1 transcriptomes were profiled with microarray from juvenile mice with naturally elevated experience-dependent plasticity to generate the juvenile plasticity differential expression signature. Using RankProd differential expression (DE) analysis, V1 of juvenile male mice C57BL/6 at P29 was compared to adult C57BL/6 mice ( $>$ P60; $n=3$ each group) to identify 248 DE probes, which mapped to 193 unique mouse Entrez IDs. For downstream analysis, mouse Entrez IDs were mapped to human orthologs using the Mouse Genome Informatics homology reference to yield a 176 gene juvenile plasticity signature. FC, fold change. RP, rank product. pfp, percent false positive (i.e. false discovery rate).

Table 3: Molecular matching among 436 disease signatures and the juvenile plasticity signature indicates diverse diseases may disrupt plasticity

\begin{tabular}{|c|c|c|c|c|c|c|c|}
\hline Rank & $\begin{array}{l}\text { Normalized } \\
\text { molecular } \\
\text { match score }\end{array}$ & Emp_pval & FDR & Source_dat & Species & Disease & Tissue \\
\hline 1 & 9.64 & $4.53 \mathrm{E}-08$ & $1.22 \mathrm{E}-05$ & GSE7958 & Mus musculus & Huntington's disease & CNS, brain, striatum (MMHCC) \\
\hline 2 & 8.35 & 7.74E-08 & $1.22 \mathrm{E}-05$ & GSE1623 & Mus musculus & Type 1 diabetes mellitus & Pancreas \\
\hline 3 & 8.32 & $8.58 \mathrm{E}-07$ & 3.40E-05 & GSE9857 & Mus musculus & Huntington's disease & CNS, brain, striatum (MMHCC) \\
\hline 4 & 7.96 & $1.38 \mathrm{E}-07$ & $1.22 \mathrm{E}-05$ & GSE4648 & Mus musculus & Acute myocardial infarction & Myocardial tissue \\
\hline 5 & 7.59 & $1.40 \mathrm{E}-07$ & $1.22 \mathrm{E}-05$ & GSE4290 & Homo sapiens & Glioblastoma & CNS, brain (MMHCC) \\
\hline 6 & 7.52 & 3.36E-07 & 2.44E-05 & GSE1481 & Homo sapiens & Anterior horn cell disease & CNS, spinal cord (MMHCC) \\
\hline 7 & 6.81 & $9.04 \mathrm{E}-08$ & $1.22 \mathrm{E}-05$ & GSE2240 & Homo sapiens & Atrial fibrillation & Myocardial tissue \\
\hline 8 & 6.73 & 1.47E-06 & 4.94E-05 & GSE5500 & Mus musculus & Cardiac hypertrophy & Myocardial tissue \\
\hline 9 & 6.47 & 8.10E-07 & $3.40 \mathrm{E}-05$ & GSE5389 & Homo sapiens & Bipolar disorder & frontal cortex \\
\hline 10 & 6.33 & 8.15E-07 & $3.40 \mathrm{E}-05$ & GSE5078 & Mus musculus & Senescence & Hippocampus \\
\hline 11 & 6.25 & $1.75 \mathrm{E}-06$ & $5.46 \mathrm{E}-05$ & GSE4764 & Mus musculus & Yersinia enterocolitica food poisoning & Peyer's patch \\
\hline 12 & 5.75 & $7.82 \mathrm{E}-07$ & 3.40E-05 & GSE4290 & Homo sapiens & Astrocytoma & CNS, brain (MMHCC) \\
\hline 13 & 5.7 & 1.73E-05 & 3.59E-04 & GSE1621 & Mus musculus & Cardiac hypertrophy & Myocardial tissue \\
\hline 14 & 5.67 & $6.55 \mathrm{E}-05$ & $7.88 \mathrm{E}-04$ & GSE3253 & Mus musculus & Bacterial infection & CNS, brain (MMHCC) \\
\hline 15 & 5.61 & 1.16E-06 & $4.22 \mathrm{E}-05$ & GSE10599 & Mus musculus & Spinal muscular atrophy & Kidney \\
\hline 16 & 5.55 & $2.49 \mathrm{E}-06$ & $7.25 \mathrm{E}-05$ & GSE3744 & Homo sapiens & Breast cancer & Mammary gland tissue \\
\hline 17 & 5.43 & $1.32 \mathrm{E}-05$ & 3.04E-04 & GSE6731 & Homo sapiens & Crohn's disease & Intestine, large intestine, colon (MMHCC) \\
\hline 18 & 5.38 & $2.24 \mathrm{E}-05$ & 4.24E-04 & GSE6731 & Homo sapiens & Ulcerative colitis & Intestine, large intestine, colon (MMHCC) \\
\hline 19 & 5.35 & $1.29 \mathrm{E}-05$ & 3.04E-04 & GSE11343 & Mus musculus & Diabetic neuropathy & Sciatic nerve \\
\hline 20 & 5.35 & 7.33E-07 & 3.40E-05 & GSE4316 & Homo sapiens & Primary open angle glaucoma & Trabecular meshwork \\
\hline 21 & 5.28 & 2.67E-05 & 4.65E-04 & GSE5406 & Homo sapiens & Cardiomyopathy & Myocardial tissue \\
\hline 22 & 5.02 & 3.36E-05 & $5.29 \mathrm{E}-04$ & GSE464 & Rattus norvegicus & Spinal cord injury & CNS, spinal cord (MMHCC) \\
\hline 23 & 4.98 & 1.87E-05 & 3.71E-04 & EXPE-MEXP-567 & Homo sapiens & Glioblastoma & Brain \\
\hline 24 & 4.94 & 1.17E-04 & $1.13 \mathrm{E}-03$ & GSE1025 & Mus musculus & DMD & Muscle, striated (skeletal) (MMHCC) \\
\hline 25 & 4.9 & $5.26 \mathrm{E}-05$ & $6.95 \mathrm{E}-04$ & GSE1843 & Rattus norvegicus & Hepatic cirrhosis & Hepatic tissue \\
\hline 26 & 4.86 & $1.54 \mathrm{E}-05$ & 3.37E-04 & GSE1572 & Homo sapiens & Senescence & frontal cortex \\
\hline 27 & 4.81 & $6.87 \mathrm{E}-05$ & $7.88 \mathrm{E}-04$ & GSE1472 & Mus musculus & DMD & Muscle, striated (skeletal) (MMHCC) \\
\hline 28 & 4.81 & 9.47E-06 & 2.43E-04 & GSE2510 & Homo sapiens & Obesity & Adipocyte \\
\hline 29 & 4.8 & $3.91 \mathrm{E}-05$ & $5.49 \mathrm{E}-04$ & GSE3383 & Mus musculus & Cardiac hypertrophy & Myocardial tissue \\
\hline 30 & 4.78 & $1.06 \mathrm{E}-04$ & $1.05 \mathrm{E}-03$ & GSE1629 & Homo sapiens & Dental cavity, complex & Dental pulp \\
\hline 31 & 4.72 & $6.79 \mathrm{E}-05$ & 7.88E-04 & GSE2629 & Mus musculus & Muscular dystrophy & Muscle, striated (skeletal) (MMHCC) \\
\hline 32 & 4.67 & $3.90 \mathrm{E}-05$ & $5.49 \mathrm{E}-04$ & GSE4290 & Homo sapiens & Oligodendroglioma & CNS, brain (MMHCC) \\
\hline 33 & 4.63 & $1.71 \mathrm{E}-04$ & 1.49E-03 & GSE10760 & Homo sapiens & Muscular dystrophy & Musculus vastus lateralis \\
\hline 34 & 4.62 & 9.53E-05 & $1.01 E-03$ & GSE1988 & Mus musculus & Cardiac failure & Myocardial tissue \\
\hline 35 & 4.61 & 4.84E-05 & $6.59 \mathrm{E}-04$ & GSE3467 & Homo sapiens & Papillary carcinoma of the thyroid & Thyroid gland (MMHCC) \\
\hline 36 & 4.57 & 3.84E-05 & $5.49 \mathrm{E}-04$ & GSE3621 & Mus musculus & Huntington's disease & Brain \\
\hline 37 & 4.56 & 3.35E-05 & $5.29 \mathrm{E}-04$ & GSE4107 & Homo sapiens & Cancer of colon & Intestine, large intestine, colon (MMHCC) \\
\hline 38 & 4.54 & $1.20 \mathrm{E}-04$ & $1.14 \mathrm{E}-03$ & GSE842 & Mus musculus & MS & CNS, spinal cord (MMHCC) \\
\hline 39 & 4.53 & $8.18 \mathrm{E}-05$ & $9.14 \mathrm{E}-04$ & GSE14905 & Homo sapiens & Psoriasis vulgaris & Skin tissue \\
\hline 40 & 4.51 & $3.40 \mathrm{E}-05$ & 5.29E-04 & GSE7305 & Homo sapiens & Endometriosis & Endometrium \\
\hline 41 & 4.48 & 8.91E-06 & 2.43E-04 & GSE16524 & Homo sapiens & Setleis syndrome & Skin fibroblast \\
\hline 42 & 4.46 & $6.85 \mathrm{E}-05$ & $7.88 \mathrm{E}-04$ & GSE4183 & Homo sapiens & Carcinoma in situ of large intestine & Colon \\
\hline 43 & 4.43 & 2.37E-05 & 4.30E-04 & GSE12654 & $\begin{array}{l}\text { Homo sapiens } \\
\text { (Continued) }\end{array}$ & Schizophrenia & Cerebral cortex \\
\hline
\end{tabular}


Table 3: Continued

\begin{tabular}{|c|c|c|c|c|c|c|c|}
\hline Rank & $\begin{array}{l}\text { Normalized } \\
\text { molecular } \\
\text { match score }\end{array}$ & Emp_pval & FDR & Source_dat & Species & Disease & Tissue \\
\hline 44 & 4.3 & $1.62 \mathrm{E}-04$ & 1.44E-03 & GSE2866 & Mus musculus & $\gamma$-Hydroxybutyric acidemia & CNS, brain, cerebellum (MMHCC) \\
\hline 45 & 4.22 & $9.23 \mathrm{E}-05$ & 1.01E-03 & GSE1859 & Mus musculus & FDIU & Hepatic tissue \\
\hline 46 & 4.19 & 5.52E-05 & 7.08E-04 & GSE4587 & Homo sapiens & Malignant melanoma & Epidermis \\
\hline 47 & 4.16 & $2.13 \mathrm{E}-04$ & $1.82 \mathrm{E}-03$ & GSE63 & Mus musculus & Cerebral infarction & CNS, brain (MMHCC) \\
\hline 48 & 4.16 & $2.26 \mathrm{E}-04$ & 1.83E-03 & GSE6614 & Mus musculus & Generalized seizures & Brain \\
\hline 49 & 4.08 & $1.58 \mathrm{E}-04$ & 1.44E-03 & GSE6280 & Homo sapiens & Chronic kidney disease & Kidney \\
\hline 50 & 4.01 & 3.19E-04 & 2.44E-03 & GSE5390 & Homo sapiens & Down's syndrome & Brain \\
\hline 51 & 4.01 & $2.66 \mathrm{E}-04$ & 2.11E-03 & GSE2052 & Homo sapiens & Idiopathic fibrosing alveolitis & Lung tissue \\
\hline 52 & 4 & 2.23E-04 & 1.83E-03 & GSE1873 & Mus musculus & Obstructive sleep apnea & Hepatic tissue \\
\hline 53 & 3.97 & 4.39E-04 & 3.07E-03 & GSE4183 & Homo sapiens & IBD & Colon \\
\hline 54 & 3.96 & $1.01 \mathrm{E}-04$ & $1.02 \mathrm{E}-03$ & GSE3075 & Mus musculus & Spinal muscular atrophy, infantile & CNS, spinal cord (MMHCC) \\
\hline 55 & 3.94 & 1.42E-04 & $1.32 \mathrm{E}-03$ & GSE3167 & Homo sapiens & Urothelial carcinoma in situ & Urothelium \\
\hline 56 & 3.93 & $2.20 \mathrm{E}-04$ & 1.83E-03 & GSE8514 & Homo sapiens & Adenoma & Adrenal gland \\
\hline 57 & 3.93 & 4.01E-04 & $2.92 \mathrm{E}-03$ & GSE6764 & Homo sapiens & Carcinoma, hepatocellular & Liver \\
\hline 58 & 3.92 & 4.89E-04 & $3.18 \mathrm{E}-03$ & GSE3585 & Homo sapiens & Cardiomyopathy, dilated & Myocardial tissue \\
\hline 59 & 3.89 & 3.39E-04 & $2.55 \mathrm{E}-03$ & GSE1420 & Homo sapiens & Barrett esophagus & Esophageal tissue \\
\hline 60 & 3.88 & 9.89E-05 & $1.02 \mathrm{E}-03$ & GSE1420 & Homo sapiens & Adenocarcinoma of esophagus & Esophageal tissue \\
\hline 61 & 3.87 & 4.40E-04 & 3.07E-03 & GSE781 & Homo sapiens & Clear cell carcinoma of kidney & Renal tissue \\
\hline 62 & 3.87 & 5.95E-04 & 3.51E-03 & GSE2528 & Mus musculus & Breast cancer & Mammary gland \\
\hline 63 & 3.84 & 9.37E-04 & $4.92 \mathrm{E}-03$ & GSE1026 & Mus musculus & DMD & Muscle, striated (skeletal), diaphragm (MMHCC) \\
\hline 64 & 3.79 & 5.25E-04 & 3.35E-03 & GSE3678 & Homo sapiens & Papillary carcinoma of the thyroid & Thyroid gland (MMHCC) \\
\hline 65 & 3.74 & 4.88E-04 & $3.18 \mathrm{E}-03$ & GSE4619 & Homo sapiens & MDS & Bone marrow stem cell \\
\hline 66 & 3.73 & 5.92E-04 & $3.51 \mathrm{E}-03$ & GSE3112 & Homo sapiens & Polymyositis & Muscle tissue \\
\hline 67 & 3.72 & 3.51E-04 & $2.59 \mathrm{E}-03$ & GSE3189 & Homo sapiens & Multiple benign melanocytic nevi & Epidermis \\
\hline 68 & 3.68 & $5.76 \mathrm{E}-04$ & 3.49E-03 & GSE769 & Mus musculus & Cystic fibrosis & Pancreas \\
\hline 69 & 3.66 & $5.76 \mathrm{E}-04$ & $3.49 \mathrm{E}-03$ & GSE10432 & Homo sapiens & Acne & Sebocyte \\
\hline 70 & 3.65 & 1.30E-03 & $6.16 \mathrm{E}-03$ & GSE3252 & Mus musculus & Muscular dystrophy & Muscle, striated (skeletal), diaphragm (MMHCC) \\
\hline 71 & 3.62 & 4.81E-04 & $3.18 \mathrm{E}-03$ & GSE12649 & Homo sapiens & Schizophrenia & Cerebral cortex \\
\hline 72 & 3.6 & $7.41 \mathrm{E}-04$ & 4.17E-03 & GSE2501 & Mus musculus & Thymic carcinoma & Thymus \\
\hline 73 & 3.59 & $1.20 \mathrm{E}-03$ & $5.87 \mathrm{E}-03$ & GSE3268 & Homo sapiens & Squamous cell carcinoma of lung & Lung tissue \\
\hline 74 & 3.58 & $7.82 \mathrm{E}-04$ & 4.32E-03 & GSE857 & Mus musculus & Huntington's disease & CNS, brain (MMHCC) \\
\hline 75 & 3.58 & 2.96E-04 & $2.30 \mathrm{E}-03$ & GSE1009 & Homo sapiens & Diabetic nephropathy & Renal tissue \\
\hline 76 & 3.57 & $1.20 \mathrm{E}-03$ & 5.87E-03 & GSE977 & Mus musculus & Alexander disease & CNS, brain, olfactory bulb (MMHCC) \\
\hline 77 & 3.55 & 5.37E-04 & 3.35E-03 & GSE2826 & Mus musculus & Bruton's agammaglobulinemia & B-cell lymphocyte \\
\hline 78 & 3.54 & 7.46E-04 & 4.17E-03 & GSE2640 & Mus musculus & Pulmonary fibrosis & Lung tissue \\
\hline 79 & 3.53 & 5.37E-04 & $3.35 \mathrm{E}-03$ & GSE2514 & Homo sapiens & Adenocarcinoma of lung & Lung tissue \\
\hline 80 & 3.53 & $8.90 \mathrm{E}-04$ & 4.73E-03 & GSE1551 & Homo sapiens & Dermatomyositis & Muscle, striated (skeletal) (MMHCC) \\
\hline 81 & 3.52 & 4.50E-04 & 3.07E-03 & GSE2507 & Mus musculus & Muscular dystrophy & Muscle, striated (skeletal) (MMHCC) \\
\hline 82 & 3.5 & 7.15E-04 & 4.10E-03 & GSE3189 & Homo sapiens & Malignant melanoma & Epidermis \\
\hline 83 & 3.5 & 1.10E-03 & $5.58 \mathrm{E}-03$ & GSE4764 & Mus musculus & Y. enterocolitica food poisoning & Lymph node \\
\hline 84 & 3.45 & $8.68 \mathrm{E}-04$ & 4.67E-03 & EXPE-MEXP-567 & Homo sapiens & Glioblastoma & Brain \\
\hline 85 & 3.43 & 4.44E-04 & 3.07E-03 & GSE3408 & Homo sapiens & Atypical mycobacterial infection & macrophage \\
\hline 86 & 3.43 & 1.10E-03 & $5.58 \mathrm{E}-03$ & GSE6428 & Rattus norvegicus & Type 2 diabetes mellitus & $\begin{array}{l}\text { Endocrine pancreas, islet cell of Langerhans, } \\
\beta \text {-cell (MMHCC) }\end{array}$ \\
\hline 87 & 3.42 & 8.45E-04 & 4.61E-03 & GSE10575 & Homo sapiens & Arthropathy & Chondrocyte \\
\hline 88 & 3.4 & $6.73 \mathrm{E}-04$ & 3.91E-03 & GSE9375 & Mus musculus & Huntington's disease & CNS, brain, striatum (MMHCC) \\
\hline 89 & 3.39 & 2.10E-03 & $9.16 \mathrm{E}-03$ & GSE4390 & Mus musculus & ALS & CNS, spinal cord (MMHCC) \\
\hline 90 & 3.38 & $1.21 \mathrm{E}-03$ & $5.87 \mathrm{E}-03$ & GSE3644 & Mus musculus & Acute pancreatitis & Pancreas \\
\hline 91 & 3.38 & $1.30 \mathrm{E}-03$ & $6.16 \mathrm{E}-03$ & GSE3112 & Homo sapiens & Inclusion body myositides & Muscle tissue \\
\hline 92 & 3.33 & $1.10 \mathrm{E}-03$ & $5.58 \mathrm{E}-03$ & GSE466 & Mus musculus & DMD & Muscle, striated (skeletal) (MMHCC) \\
\hline 93 & 3.29 & $1.40 \mathrm{E}-03$ & $6.36 \mathrm{E}-03$ & GSE2144 & Homo sapiens & GERD & Esophageal tissue \\
\hline 94 & 3.27 & $1.40 \mathrm{E}-03$ & $6.36 \mathrm{E}-03$ & EXPE-MEXP-1296 & Mus musculus & Cancer of prostate & Prostate \\
\hline 95 & 3.24 & $1.70 \mathrm{E}-03$ & 7.64E-03 & GSE2724 & Homo sapiens & Uterine leiomyoma & Uterus \\
\hline 96 & 3.21 & 3.30E-03 & 1.30E-02 & GSE2825 & Rattus norvegicus & Idiosyncratic drug effect & Hepatic tissue \\
\hline 97 & 3.19 & 2.60E-03 & $1.08 \mathrm{E}-02$ & GSE1007 & Homo sapiens & DMD & Muscle, striated (skeletal) (MMHCC) \\
\hline 98 & 3.19 & $1.20 \mathrm{E}-03$ & $5.87 \mathrm{E}-03$ & GSE1781 & Rattus norvegicus & Sepsis & Hepatic tissue \\
\hline 99 & 3.18 & $2.40 \mathrm{E}-03$ & $1.03 \mathrm{E}-02$ & GSE2899 & Mus musculus & Type 2 diabetes mellitus & Adipose tissue \\
\hline 100 & 3.18 & 1.90E-03 & 8.37E-03 & GSE2557 & Mus musculus & $\begin{array}{l}\text { Kidney disorder associated with } \\
\text { type } 2 \text { diabetes mellitus }\end{array}$ & Mesangial cell \\
\hline 101 & 3.18 & $1.40 \mathrm{E}-03$ & $6.36 \mathrm{E}-03$ & GSE3524 & Homo sapiens & Squamous cell carcinoma of mouth & Oropharynx epithelium \\
\hline 102 & 3.17 & $1.40 \mathrm{E}-03$ & $6.36 \mathrm{E}-03$ & GSE13355 & Homo sapiens & Psoriasis vulgaris & Skin tissue \\
\hline 103 & 3.15 & 2.20E-03 & $9.50 \mathrm{E}-03$ & GSE2866 & Mus musculus & $\gamma$-Hydroxybutyric acidemia & Cerebral cortex \\
\hline 104 & 3.12 & $2.60 \mathrm{E}-03$ & 1.08E-02 & GSE4911 & Mus musculus & Cleidocranial dysostosis & Humerus \\
\hline 105 & 3.12 & $1.90 \mathrm{E}-03$ & 8.37E-03 & GSE24807 & Homo sapiens & NASH & Liver \\
\hline 106 & 3.12 & $3.20 \mathrm{E}-03$ & $1.28 \mathrm{E}-02$ & GSE10631 & Homo sapiens & LGLL & Peripheral blood mononuclear cell \\
\hline 107 & 3.11 & 2.70E-03 & $1.11 \mathrm{E}-02$ & GSE2052 & Homo sapiens & Scleroderma & Lung tissue \\
\hline 108 & 3.07 & $2.90 \mathrm{E}-03$ & 1.17E-02 & GSE4692 & Mus musculus & Obesity & Adipose tissue \\
\hline 109 & 3.05 & $2.50 \mathrm{E}-03$ & 1.06E-02 & GSE4824 & Homo sapiens & Non-small cell lung cancer & Bronchial epithelium \\
\hline 110 & 3.03 & $3.80 \mathrm{E}-03$ & 1.47E-02 & GSE1145 & Homo sapiens & Ischemic cardiomyopathy & Myocardial tissue \\
\hline 111 & 3.01 & 4.90E-03 & 1.77E-02 & GSE6678 & Mus musculus & Infantile neuronal ceroid lipofuscinosis & Brain \\
\hline 112 & 3 & $3.30 \mathrm{E}-03$ & 1.30E-02 & GSE3064 & Homo sapiens & Dystonia & Brain \\
\hline 113 & 2.99 & 4.70E-03 & $1.72 \mathrm{E}-02$ & GSE2527 & Mus musculus & Thrombocytopenia & Megakaryocyte \\
\hline 114 & 2.99 & 4.30E-03 & $1.62 \mathrm{E}-02$ & GSE2433 & Mus musculus & Leukemia, acute megakaryocytic & Megakaryocyte \\
\hline 115 & 2.93 & 4.60E-03 & 1.71E-02 & GSE1776 & Mus musculus & Nutritional deficiency, NEC & Skeletal myocyte \\
\hline 116 & 2.93 & 3.90E-03 & 1.49E-02 & GSE4587 & Homo sapiens & In situ melanoma of skin & Epidermis \\
\hline 117 & 2.92 & 5.30E-03 & $1.88 \mathrm{E}-02$ & GSE9579 & Homo sapiens & Appendicitis & Appendix \\
\hline 118 & 2.91 & $5.80 \mathrm{E}-03$ & 2.01E-02 & GSE2411 & Mus musculus & Ventilator-associated lung injury & Lung tissue \\
\hline \multicolumn{8}{|c|}{ (Continued) } \\
\hline
\end{tabular}


Table 3: Continued

\begin{tabular}{|c|c|c|c|c|c|c|c|}
\hline Rank & $\begin{array}{l}\text { Normalized } \\
\text { molecular } \\
\text { match score }\end{array}$ & Emp_pval & FDR & Source_dat & Species & Disease & Tissue \\
\hline 119 & 2.9 & $2.80 \mathrm{E}-03$ & 1.14E-02 & GSE1037 & Homo sapiens & Small cell carcinoma of lung & Lung tissue \\
\hline 120 & 2.86 & $5.20 \mathrm{E}-03$ & 1.86E-02 & GSE2401 & Rattus norvegicus & Hypotensive episode & Renal tissue \\
\hline 121 & 2.85 & 4.70E-03 & $1.72 \mathrm{E}-02$ & GSE765 & Mus musculus & Cystic fibrosis & Intestinal epithelium \\
\hline 122 & 2.83 & $3.60 \mathrm{E}-03$ & $1.40 \mathrm{E}-02$ & EXPE-MEXP-882 & Homo sapiens & Invasive ductal breast cancer & Mammary epithelium \\
\hline 123 & 2.83 & $6.70 \mathrm{E}-03$ & $2.28 \mathrm{E}-02$ & GSE1869 & Homo sapiens & Ischemic cardiomyopathy & Myocardial tissue \\
\hline 124 & 2.82 & $5.60 \mathrm{E}-03$ & 1.95E-02 & GSE4183 & Homo sapiens & Adenoma & Colon \\
\hline 125 & 2.82 & $5.40 \mathrm{E}-03$ & $1.90 \mathrm{E}-02$ & GSE1004 & Homo sapiens & DMD & Muscle, striated (skeletal) (MMHCC) \\
\hline 126 & 2.81 & 4.30E-03 & $1.62 \mathrm{E}-02$ & GSE9944 & Homo sapiens & Glaucoma & Astrocyte \\
\hline 127 & 2.79 & $6.20 \mathrm{E}-03$ & 2.13E-02 & EXPE-TABM-176 & Homo sapiens & $\begin{array}{l}\text { Irritable bowel syndrome variant } \\
\text { of childhood with diarrhea }\end{array}$ & Sigmoid colon \\
\hline 128 & 2.72 & $8.40 \mathrm{E}-03$ & $2.75 \mathrm{E}-02$ & GSE2779 & Homo sapiens & MDS & Bone marrow stem cell \\
\hline 129 & 2.72 & $7.20 \mathrm{E}-03$ & 2.43E-02 & GSE1947 & Mus musculus & Peripheral motor neuropathy & Sciatic nerve \\
\hline 130 & 2.71 & $8.40 \mathrm{E}-03$ & $2.75 \mathrm{E}-02$ & GSE593 & Homo sapiens & Uterine leiomyoma & Uterus, myometrium (MMHCC) \\
\hline 131 & 2.71 & $7.50 \mathrm{E}-03$ & $2.52 \mathrm{E}-02$ & GSE2712 & Homo sapiens & Clear cell sarcoma of kidney & Renal tissue \\
\hline 132 & 2.69 & 8.50E-03 & $2.75 \mathrm{E}-02$ & GSE1459 & Mus musculus & Bacterial Infection & Macrophage \\
\hline 133 & 2.67 & 8.50E-03 & $2.75 \mathrm{E}-02$ & GSE1811 & Mus musculus & Occupational lung disease & Lung Tissue \\
\hline 134 & 2.67 & 8.90E-03 & $2.85 \mathrm{E}-02$ & GSE2508 & Homo sapiens & Obesity & Adipocyte \\
\hline 135 & 2.66 & 8.10E-03 & 2.70E-02 & GSE1462 & Homo sapiens & $\begin{array}{l}\text { MELAS (mitochondrial myopathy, } \\
\text { encephalopathy, lactic acidosis } \\
\text { and stroke-like episodes) }\end{array}$ & Muscle, striated (skeletal) (MMHCC) \\
\hline 136 & 2.65 & $9.00 \mathrm{E}-03$ & $2.86 \mathrm{E}-02$ & GSE4130 & Rattus norvegicus & Dehydration & CNS, brain, hypothalamus (MMHCC) \\
\hline 137 & 2.61 & $9.10 \mathrm{E}-03$ & $2.88 \mathrm{E}-02$ & GSE1378 & Homo sapiens & Breast cancer & Mammary gland tissue \\
\hline 138 & 2.6 & 1.14E-02 & $3.45 \mathrm{E}-02$ & GSE1375 & Mus musculus & Alzheimer's disease & Cerebral cortex \\
\hline 139 & 2.59 & $9.80 \mathrm{E}-03$ & 3.03E-02 & GSE2719 & Homo sapiens & Gastrointestinal stromal tumor & Connective tissue \\
\hline 140 & 2.59 & $9.60 \mathrm{E}-03$ & $3.01 \mathrm{E}-02$ & GSE7036 & Homo sapiens & Bipolar disorder & Lymphocyte \\
\hline 141 & 2.57 & $1.00 \mathrm{E}-02$ & 3.07E-02 & GSE1724 & Homo sapiens & Scleroderma & Fibroblast \\
\hline 142 & 2.56 & $9.70 \mathrm{E}-03$ & $3.02 \mathrm{E}-02$ & GSE3790 & Homo sapiens & Huntington's disease & Caudate nucleus \\
\hline 143 & 2.55 & $1.25 \mathrm{E}-02$ & 3.68E-02 & GSE6764 & Homo sapiens & Hepatic cirrhosis & Liver \\
\hline 144 & 2.54 & $1.24 \mathrm{E}-02$ & $3.68 \mathrm{E}-02$ & GSE2457 & Rattus norvegicus & $\begin{array}{l}\text { Erectile dysfunction associated with } \\
\text { type } 2 \text { diabetes mellitus }\end{array}$ & Penis, NOS \\
\hline 145 & 2.54 & $1.47 \mathrm{E}-02$ & 4.14E-02 & GSE2457 & Rattus norvegicus & Erectile dysfunction & Penis erectile tissue \\
\hline 146 & 2.54 & 1.05E-02 & 3.20E-02 & GSE3110 & Rattus norvegicus & Dehydration & Hypothalamus \\
\hline 147 & 2.53 & $1.22 \mathrm{E}-02$ & 3.64E-02 & GSE2712 & Homo sapiens & Nephroblastoma & Renal tissue \\
\hline 148 & 2.51 & $1.42 \mathrm{E}-02$ & 4.05E-02 & GSE7999 & Rattus norvegicus & Tachycardia & Myocardial tissue \\
\hline 149 & 2.51 & 1.29E-02 & 3.77E-02 & GSE609 & Homo sapiens & SCID & Thymic lymphocyte \\
\hline 150 & 2.49 & 1.19E-02 & $3.58 \mathrm{E}-02$ & GSE1869 & Homo sapiens & Cardiomyopathy & Myocardial tissue \\
\hline 151 & 2.49 & 1.36E-02 & 3.93E-02 & GSE7621 & Homo sapiens & Parkinson's disease & Substantia nigra \\
\hline 152 & 2.48 & 1.35E-02 & $3.92 \mathrm{E}-02$ & GSE10971 & Homo sapiens & Serous carcinoma & Fallopian tube \\
\hline 153 & 2.48 & $1.40 \mathrm{E}-02$ & 4.02E-02 & GSE3418 & Mus musculus & Lung transplant rejection & Trachea \\
\hline 154 & 2.47 & $1.45 \mathrm{E}-02$ & 4.11E-02 & EXPE-MEXP-476 & Homo sapiens & Cancer of prostate & Endothelial cell \\
\hline 155 & 2.47 & $1.54 \mathrm{E}-02$ & $4.28 \mathrm{E}-02$ & GSE3184 & Mus musculus & Asthma, allergic & Lung tissue \\
\hline 156 & 2.46 & 1.49E-02 & 4.16E-02 & GSE4616 & Mus musculus & Type 1 diabetes mellitus & Myocardial tissue \\
\hline 157 & 2.41 & $1.68 \mathrm{E}-02$ & 4.64E-02 & GSE4612 & Mus musculus & Carcinoma, hepatocellular & Hepatic tissue \\
\hline 158 & 2.4 & 1.77E-02 & $4.85 \mathrm{E}-02$ & GSE2725 & Homo sapiens & Uterine leiomyoma & Uterus \\
\hline 159 & 2.39 & $1.81 \mathrm{E}-02$ & 4.90E-02 & GSE3365 & Homo sapiens & Ulcerative colitis & Peripheral blood mononuclear cell \\
\hline 160 & 2.37 & $1.80 \mathrm{E}-02$ & 4.90E-02 & GSE1813 & Rattus norvegicus & Obesity & Adipose tissue \\
\hline 161 & 2.36 & 1.87E-02 & 5.03E-02 & GSE4060 & Homo sapiens & Cushing syndrome & Adrenal gland \\
\hline 162 & 2.35 & 2.07E-02 & 5.50E-02 & GSE1145 & Homo sapiens & Primary cardiomyopathy & Myocardial tissue \\
\hline 163 & 2.31 & $1.88 \mathrm{E}-02$ & $5.03 \mathrm{E}-02$ & GSE6461 & Mus musculus & Synovial sarcoma & Synovial membrane \\
\hline 164 & 2.3 & $2.15 \mathrm{E}-02$ & $5.68 \mathrm{E}-02$ & GSE1037 & Homo sapiens & Non-small cell lung cancer & Lung tissue \\
\hline 165 & 2.27 & 2.29E-02 & $6.01 \mathrm{E}-02$ & GSE10921 & Homo sapiens & Idiopathic fibrosing alveolitis & Fibroblast \\
\hline 166 & 2.26 & $2.41 \mathrm{E}-02$ & $6.28 \mathrm{E}-02$ & GSE3248 & Mus musculus & Huntington's disease & CNS, brain, cerebellum (MMHCC) \\
\hline 167 & 2.25 & 2.42E-02 & $6.28 \mathrm{E}-02$ & GSE4788 & Mus musculus & Parkinson's disease & Substantia nigra \\
\hline 168 & 2.24 & $2.52 \mathrm{E}-02$ & $6.46 \mathrm{E}-02$ & GSE4710 & Mus musculus & Heart injury & Myocardial tissue \\
\hline 169 & 2.21 & $2.52 \mathrm{E}-02$ & $6.46 \mathrm{E}-02$ & GSE6364 & Homo sapiens & Endometriosis & Endometrium \\
\hline 170 & 2.2 & $2.68 \mathrm{E}-02$ & $6.83 \mathrm{E}-02$ & GSE1462 & Homo sapiens & CPEO (chronic progressive external ophthalmoplegia) & Muscle, striated (skeletal) (MMHCC) \\
\hline 171 & 2.19 & 3.00E-02 & 7.56E-02 & GSE1724 & Homo sapiens & Idiopathic fibrosing alveolitis & Fibroblast \\
\hline 172 & 2.18 & 2.87E-02 & $7.28 \mathrm{E}-02$ & GSE6955 & Homo sapiens & Rett syndrome & frontal cortex \\
\hline 173 & 2.13 & $3.24 \mathrm{E}-02$ & 8.12E-02 & GSE1017 & Homo sapiens & Myopathy NOS & Skeletal muscle \\
\hline 174 & 2.13 & $3.39 \mathrm{E}-02$ & 8.45E-02 & GSE2429 & Homo sapiens & Breast cancer & Mammary gland tissue \\
\hline 175 & 2.12 & 3.57E-02 & 8.79E-02 & GSE6764 & Homo sapiens & Hepatocellular dysplasia & Liver \\
\hline 176 & 2.11 & $3.64 \mathrm{E}-02$ & 8.92E-02 & GSE4516 & Rattus norvegicus & Smoke inhalation & Lung tissue \\
\hline 177 & 2.1 & $3.41 E-02$ & 8.45E-02 & GSE567 & Homo sapiens & Essential thrombocythemia & Megakaryocyte \\
\hline 178 & 2.09 & 3.92E-02 & $9.39 \mathrm{E}-02$ & EXPE-TABM-176 & Homo sapiens & $\begin{array}{l}\text { Irritable bowel syndrome variant of } \\
\text { childhood with constipation }\end{array}$ & Sigmoid colon \\
\hline 179 & 2.08 & 3.69E-02 & 8.99E-02 & GSE4130 & Rattus norvegicus & Dehydration & Pituitary gland \\
\hline 180 & 2.07 & $3.72 \mathrm{E}-02$ & 9.01E-02 & GSE9006 & Homo sapiens & Type 2 diabetes mellitus & Peripheral blood mononuclear cell \\
\hline 181 & 2.06 & 4.00E-02 & $9.40 \mathrm{E}-02$ & GSE2899 & Mus musculus & Type 2 diabetes mellitus & Soleus muscle \\
\hline 182 & 2.06 & 4.01E-02 & $9.40 \mathrm{E}-02$ & GSE3125 & Rattus norvegicus & Dehydration & Hypothalamus \\
\hline 183 & 2.06 & 3.99E-02 & $9.40 \mathrm{E}-02$ & GSE3407 & Homo sapiens & Cockayne syndrome & Fibroblast \\
\hline 184 & 2.06 & $3.79 \mathrm{E}-02$ & $9.13 \mathrm{E}-02$ & GSE2866 & Mus musculus & $\gamma$-Hydroxybutyric acidemia & Hippocampus \\
\hline 185 & 2.05 & 4.07E-02 & $9.49 \mathrm{E}-02$ & GSE2077 & Homo sapiens & Protozoan Infection & Intestinal epithelium \\
\hline 186 & 2.05 & 4.14E-02 & $9.60 \mathrm{E}-02$ & GSE9006 & Homo sapiens & Type 1 diabetes mellitus & Peripheral blood mononuclear cell \\
\hline 187 & 2.03 & 4.01E-02 & $9.40 \mathrm{E}-02$ & GSE10123 & Homo sapiens & Premature aging & Skin fibroblast \\
\hline 188 & 2.01 & 4.45E-02 & $1.01 \mathrm{E}-01$ & GSE3365 & Homo sapiens & Crohn's disease & Peripheral blood mononuclear cell \\
\hline 189 & 2.01 & 4.33E-02 & $9.99 \mathrm{E}-02$ & GSE1297 & Homo sapiens & Alzheimer's disease & Hippocampus \\
\hline 190 & 2 & 4.40E-02 & $1.01 \mathrm{E}-01$ & GSE2254 & Mus musculus & Type 1 diabetes mellitus & pancreatic islet \\
\hline 191 & 2 & 4.57E-02 & 1.03E-01 & GSE3489 & Homo sapiens & HIV encephalitis & frontal cortex \\
\hline \multicolumn{8}{|c|}{$\begin{array}{l}\text { HIV encephalitis } \\
\text { inued) }\end{array}$} \\
\hline
\end{tabular}


Table 3: Continued

\begin{tabular}{|c|c|c|c|c|c|c|c|}
\hline Rank & $\begin{array}{l}\text { Normalized } \\
\text { molecular } \\
\text { match score }\end{array}$ & Emp_pval & FDR & Source_dat & Species & Disease & Tissue \\
\hline 192 & 2 & 4.44E-02 & $1.01 \mathrm{E}-01$ & GSE3203 & Mus musculus & Influenza & B-cell lymphocyte \\
\hline 193 & 1.99 & 4.67E-02 & 1.05E-01 & GSE2559 & Homo sapiens & Pulmonary hypertension, primary & Pulmonary artery \\
\hline 194 & 1.98 & 4.76E-02 & $1.06 \mathrm{E}-01$ & GSE3807 & Homo sapiens & Aplastic anemia & Bone marrow \\
\hline 195 & 1.98 & 4.85E-02 & $1.07 \mathrm{E}-01$ & GSE4105 & Rattus norvegicus & Myocardial infarction & Myocardial tissue \\
\hline 196 & 1.96 & 4.72E-02 & $1.06 \mathrm{E}-01$ & GSE4479 & Mus musculus & Sepsis & Splenocyte \\
\hline 197 & 1.95 & 5.26E-02 & 1.15E-01 & GSE3676 & Mus musculus & Infertility due to azoospermia & Testicular tissue \\
\hline 198 & 1.94 & $5.21 \mathrm{E}-02$ & 1.15E-01 & GSE10064 & Homo sapiens & MS & B-cell lymphocyte \\
\hline 199 & 1.93 & $5.48 \mathrm{E}-02$ & 1.17E-01 & GSE5090 & Homo sapiens & Polycystic ovary syndrome & Adipose tissue \\
\hline 200 & 1.93 & $5.43 \mathrm{E}-02$ & 1.17E-01 & GSE11 & Mus musculus & Type 1 diabetes mellitus & Thymic epithelial cell \\
\hline 201 & 1.92 & $5.28 \mathrm{E}-02$ & $1.15 \mathrm{E}-01$ & GSE582 & Mus musculus & Transplanted heart complication & Myocardial tissue \\
\hline 202 & 1.92 & $5.44 \mathrm{E}-02$ & 1.17E-01 & GSE10586 & Homo sapiens & Type 1 diabetes mellitus & T lymphocyte \\
\hline 203 & 1.92 & 5.77E-02 & $1.21 \mathrm{E}-01$ & GSE2049 & Homo sapiens & AML & Haematopoietic stem cell \\
\hline 204 & 1.91 & $5.56 \mathrm{E}-02$ & $1.18 \mathrm{E}-01$ & GSE11208 & Homo sapiens & Nicotine addiction & Ganglioneuroblastoma \\
\hline 205 & 1.91 & $5.61 \mathrm{E}-02$ & 1.18E-01 & GSE5538 & Mus musculus & Hepatic lipidosis & Hepatic Tissue \\
\hline 206 & 1.9 & 5.37E-02 & 1.16E-01 & EXPE-MEXP-692 & Homo sapiens & Barrett esophagus & Esophagus \\
\hline 207 & 1.9 & $5.60 \mathrm{E}-02$ & $1.18 \mathrm{E}-01$ & GSE1659 & Mus musculus & Type 1 diabetes mellitus & Muscle, striated (skeletal) (MMHCC) \\
\hline 208 & 1.89 & $6.00 \mathrm{E}-02$ & $1.25 \mathrm{E}-01$ & GSE4170 & Homo sapiens & $\mathrm{CML}$ & Haematopoietic stem cell \\
\hline 209 & 1.88 & 6.33E-02 & $1.31 \mathrm{E}-01$ & EXPE-MEXP-692 & Homo sapiens & Adenocarcinoma of esophagus & Esophagus \\
\hline 210 & 1.86 & $6.21 \mathrm{E}-02$ & 1.29E-01 & GSE422 & Mus musculus & Carcinoma in situ of small intestine & Intestinal epithelium \\
\hline 211 & 1.82 & $6.93 \mathrm{E}-02$ & $1.41 \mathrm{E}-01$ & GSE1822 & Homo sapiens & Ewing's sarcoma & Renal tissue \\
\hline 212 & 1.81 & $6.69 \mathrm{E}-02$ & 1.37E-01 & GSE755 & Homo sapiens & Osteolysis & $\begin{array}{l}\text { Leukocyte, lymphocyte, B lymphocyte, } \\
\text { plasma cell (MMHCC) }\end{array}$ \\
\hline 213 & 1.81 & $6.60 \mathrm{E}-02$ & $1.36 \mathrm{E}-01$ & GSE3004 & Homo sapiens & Asthma, allergic & Bronchial epithelium \\
\hline 214 & 1.78 & 7.26E-02 & 1.47E-01 & GSE4060 & Homo sapiens & ACTH-dependent Cushing syndrome & Adrenal gland \\
\hline 215 & 1.76 & 7.71E-02 & 1.54E-01 & GSE4120 & Mus musculus & Arrhythmogenic right ventricular cardiomyopathy & Myocardial tissue \\
\hline 216 & 1.76 & 8.01E-02 & 1.59E-01 & GSE3790 & Homo sapiens & Huntington's disease & frontal cortex \\
\hline 217 & 1.76 & 7.70E-02 & $1.54 \mathrm{E}-01$ & GSE9800 & Homo sapiens & Cardiomyopathy, dilated & Myocardial tissue \\
\hline 218 & 1.71 & 8.68E-02 & $1.70 \mathrm{E}-01$ & GSE3915 & Mus musculus & Cancer of the intestine & Small bowel \\
\hline 219 & 1.69 & $9.30 \mathrm{E}-02$ & 1.80E-01 & GSE5581 & Mus musculus & Retinoschisis & Retina \\
\hline 220 & 1.68 & 8.96E-02 & 1.75E-01 & GSE868 & Mus musculus & Familial hypophosphatemic rickets & Renal tissue \\
\hline 221 & 1.68 & 8.99E-02 & $1.75 \mathrm{E}-01$ & EXPE-TABM-176 & Homo sapiens & IBS & Sigmoid colon \\
\hline 222 & 1.66 & $9.61 \mathrm{E}-02$ & $1.85 \mathrm{E}-01$ & GSE6965 & Homo sapiens & Infection by Aspergillus fumigatus & Dendritic cell \\
\hline 223 & 1.66 & $9.71 \mathrm{E}-02$ & $1.87 \mathrm{E}-01$ & GSE6012 & Homo sapiens & Eczema & Integument \\
\hline 224 & 1.65 & $9.80 \mathrm{E}-02$ & 1.87E-01 & GSE3554 & Mus musculus & Glaucoma & Retina \\
\hline 225 & 1.65 & $1.00 \mathrm{E}-01$ & $1.90 \mathrm{E}-01$ & GSE2223 & Homo sapiens & Glioblastoma & CNS, brain (MMHCC) \\
\hline 226 & 1.63 & $9.98 \mathrm{E}-02$ & $1.90 \mathrm{E}-01$ & EXPE-TABM-26 & Homo sapiens & Cancer of prostate & Prostate \\
\hline 227 & 1.62 & 1.03E-01 & $1.94 \mathrm{E}-01$ & GSE4172 & Homo sapiens & Viral cardiomyopathy & Myocardial tissue \\
\hline 228 & 1.6 & $1.08 \mathrm{E}-01$ & 2.01E-01 & GSE2191 & Homo sapiens & AML & Mononuclear leukocyte \\
\hline 229 & 1.6 & $1.08 \mathrm{E}-01$ & $2.01 \mathrm{E}-01$ & GSE2155 & Homo sapiens & Breast cancer & Epithelial cell \\
\hline 230 & 1.56 & $1.18 \mathrm{E}-01$ & 2.16E-01 & GSE1299 & Homo sapiens & Breast cancer & Mammary epithelium \\
\hline 231 & 1.55 & 1.15E-01 & 2.13E-01 & GSE3320 & Homo sapiens & COPD & Bronchial epithelium \\
\hline 232 & 1.55 & 1.19E-01 & 2.17E-01 & GSE5774 & Homo sapiens & Nonspecific interstitial pneumonia & Lung tissue \\
\hline 233 & 1.55 & $1.18 \mathrm{E}-01$ & 2.16E-01 & GSE6710 & Homo sapiens & Psoriasis vulgaris & Skin tissue \\
\hline 234 & 1.53 & $1.29 \mathrm{E}-01$ & $2.31 E-01$ & GSE4250 & Homo sapiens & Hereditary gingival fibromatosis & Gingiva \\
\hline 235 & 1.53 & $1.24 \mathrm{E}-01$ & 2.25E-01 & GSE5364 & Homo sapiens & Cancer of thyroid & Thyroid \\
\hline 236 & 1.53 & $1.18 \mathrm{E}-01$ & 2.16E-01 & GSE3583 & Mus musculus & Huntington's disease & CNS, brain, striatum (MMHCC) \\
\hline 237 & 1.52 & 1.30E-01 & $2.32 \mathrm{E}-01$ & GSE12654 & Homo sapiens & Bipolar disorder & Cerebral cortex \\
\hline 238 & 1.52 & 1.29E-01 & 2.31E-01 & GSE973 & Homo sapiens & Funisitis & Umbilical blood \\
\hline 239 & 1.51 & $1.32 \mathrm{E}-01$ & $2.34 \mathrm{E}-01$ & GSE12649 & Homo sapiens & Bipolar disorder & Cerebral cortex \\
\hline 240 & 1.5 & 1.33E-01 & $2.35 \mathrm{E}-01$ & GSE925 & Rattus norvegicus & Cardiac hypertrophy & Cardiomyocyte \\
\hline 241 & 1.48 & $1.38 \mathrm{E}-01$ & $2.42 \mathrm{E}-01$ & GSE3544 & Mus musculus & MODY & Pancreatic islet \\
\hline 242 & 1.47 & $1.42 \mathrm{E}-01$ & 2.46E-01 & GSE420 & Homo sapiens & Atherosclerosis & Aorta smooth muscle tissue \\
\hline 243 & 1.47 & 1.37E-01 & $2.42 \mathrm{E}-01$ & GSE422 & Mus musculus & Adenoma of small intestine & Intestinal epithelium \\
\hline 244 & 1.46 & $1.41 \mathrm{E}-01$ & $2.46 \mathrm{E}-01$ & EXPE-TABM-36 & Homo sapiens & Hepatocellular adenoma & Hepatocyte \\
\hline 245 & 1.45 & $1.38 \mathrm{E}-01$ & $2.42 E-01$ & GSE4302 & Homo sapiens & Asthma & Epithelial cell \\
\hline 246 & 1.45 & 1.44E-01 & $2.50 \mathrm{E}-01$ & GSE5370 & Homo sapiens & Dermatomyositis & Muscle, striated (skeletal) (MMHCC) \\
\hline 247 & 1.42 & $1.53 \mathrm{E}-01$ & $2.61 E-01$ & GSE2172 & Mus musculus & Colitis & Intestine, large intestine, colon (MMHCC) \\
\hline 248 & 1.41 & 1.55E-01 & 2.63E-01 & GSE11750 & Homo sapiens & Senescence & Muscle, striated (skeletal) (MMHCC) \\
\hline 249 & 1.41 & $1.56 \mathrm{E}-01$ & 2.63E-01 & GSE3 & Homo sapiens & Chromophobe cell carcinoma of kidney & Renal cell \\
\hline 250 & 1.41 & $1.52 \mathrm{E}-01$ & $2.61 \mathrm{E}-01$ & GSE2705 & Homo sapiens & Primary open angle glaucoma & Optic disk \\
\hline 251 & 1.37 & $1.68 \mathrm{E}-01$ & $2.80 \mathrm{E}-01$ & GSE3860 & Homo sapiens & Progeria & Fibroblast \\
\hline 252 & 1.37 & $1.73 \mathrm{E}-01$ & $2.86 \mathrm{E}-01$ & GSE674 & Homo sapiens & Senescence & Muscle, striated (skeletal) (MMHCC) \\
\hline 253 & 1.36 & $1.72 \mathrm{E}-01$ & 2.84E-01 & GSE2549 & Homo sapiens & Malignant mesothelioma of pleura & Pleura \\
\hline 254 & 1.36 & $1.71 \mathrm{E}-01$ & $2.84 \mathrm{E}-01$ & GSE1466 & Homo sapiens & Lymphoblastic leukemia & T lymphocyte \\
\hline 255 & 1.33 & $1.82 \mathrm{E}-01$ & 2.97E-01 & GSE1611 & Mus musculus & Down syndrome & CNS, brain, cerebellum (MMHCC) \\
\hline 256 & 1.33 & 1.79E-01 & 2.93E-01 & GSE997 & Homo sapiens & Essential thrombocythemia & Megakaryocyte \\
\hline 257 & 1.32 & $1.91 \mathrm{E}-01$ & 3.09E-01 & GSE6798 & Homo sapiens & Polycystic ovary syndrome & Skeletal muscle \\
\hline 258 & 1.32 & $1.83 \mathrm{E}-01$ & $2.98 \mathrm{E}-01$ & GSE3790 & Homo sapiens & Huntington's disease & CNS, brain, cerebellum (MMHCC) \\
\hline 259 & 1.31 & $1.87 \mathrm{E}-01$ & 3.03E-01 & GSE2503 & Homo sapiens & Actinic keratosis & Skin tissue \\
\hline 260 & 1.29 & $1.94 \mathrm{E}-01$ & $3.12 \mathrm{E}-01$ & GSE1010 & Homo sapiens & Familial combined hyperlipidemia & Lymphoblast \\
\hline 261 & 1.27 & $2.00 \mathrm{E}-01$ & 3.17E-01 & GSE1028 & Homo sapiens & Scott syndrome & B-cell lymphocyte \\
\hline 262 & 1.27 & $1.98 \mathrm{E}-01$ & 3.16E-01 & GSE5388 & Homo sapiens & Bipolar disorder & Frontal cortex \\
\hline 263 & 1.27 & 2.00E-01 & 3.17E-01 & GSE2067 & Homo sapiens & Hepatitis C infection & Hepatocyte \\
\hline 264 & 1.26 & 2.04E-01 & $3.22 \mathrm{E}-01$ & GSE3280 & Homo sapiens & Acute monocytic leukemia & Blood monocyte \\
\hline 265 & 1.26 & 2.07E-01 & 3.24E-01 & GSE642 & Mus musculus & Type 2 diabetes mellitus & Renal tissue \\
\hline 266 & 1.26 & 2.07E-01 & $3.24 \mathrm{E}-01$ & GSE5281 & Homo sapiens & Alzheimer's disease & Superior frontal gyrus \\
\hline \multicolumn{8}{|c|}{ (Continued) } \\
\hline
\end{tabular}


Table 3: Continued

\begin{tabular}{|c|c|c|c|c|c|c|c|}
\hline Rank & $\begin{array}{l}\text { Normalized } \\
\text { molecular } \\
\text { match score }\end{array}$ & Emp_pval & FDR & Source_dat & Species & Disease & Tissue \\
\hline 267 & 1.21 & $2.28 \mathrm{E}-01$ & 3.54E-01 & GSE11348 & Homo sapiens & Rhinovirus infection & Nose \\
\hline 268 & 1.2 & 2.34E-01 & 3.61E-01 & GSE7486 & Homo sapiens & Epilepsy & Lymphoblast \\
\hline 269 & 1.16 & 2.46E-01 & 3.74E-01 & GSE3384 & Mus musculus & Nemaline myopathy & Tibialis Muscle \\
\hline 270 & 1.16 & $2.45 \mathrm{E}-01$ & 3.73E-01 & GSE473 & Homo sapiens & Asthma & CD4-positive lymphocyte \\
\hline 271 & 1.16 & 2.45E-01 & 3.73E-01 & GSE474 & Homo sapiens & Obesity & Muscle, striated (skeletal) (MMHCC) \\
\hline 272 & 1.14 & $2.50 \mathrm{E}-01$ & $3.78 \mathrm{E}-01$ & EXPE-MEXP-669 & NULL & Neuroblastoma & Adrenal cortex \\
\hline 273 & 1.12 & $2.62 \mathrm{E}-01$ & 3.95E-01 & GSE3889 & Mus musculus & Hypercholesterolemia & Hepatic tissue \\
\hline 274 & 1.11 & 2.66E-01 & 3.97E-01 & GSE2175 & Homo sapiens & Adenoma of pituitary gland & Pituitary gland \\
\hline 275 & 1.1 & 2.71E-01 & 4.03E-01 & GSE3925 & Mus musculus & Hyperreactive airway disease & Lung tissue \\
\hline 276 & 1.09 & 2.79E-01 & 4.13E-01 & GSE10162 & Mus musculus & Nephrolithiasis & Kidney \\
\hline 277 & 1.09 & $2.62 \mathrm{E}-01$ & 3.95E-01 & GSE2470 & Rattus norvegicus & Type 2 diabetes mellitus & Pancreas \\
\hline 278 & 1.08 & 2.77E-01 & 4.10E-01 & GSE362 & Homo sapiens & Senescence & Muscle, striated (skeletal) (MMHCC) \\
\hline 279 & 1.06 & 2.87E-01 & 4.23E-01 & GSE2973 & Mus musculus & Infection by $Y$. enterocolitica & Macrophage \\
\hline 280 & 1.04 & $2.98 \mathrm{E}-01$ & 4.35E-01 & GSE4785 & Homo sapiens & Simian acquired immune deficiency syndrome & T lymphocyte \\
\hline 281 & 1.04 & 2.97E-01 & 4.35E-01 & GSE923 & Homo sapiens & Pseudomonas infection & Lung tissue \\
\hline 282 & 1.02 & 3.07E-01 & 4.46E-01 & GSE12654 & Homo sapiens & Depression & Cerebral cortex \\
\hline 283 & 1.01 & $3.08 \mathrm{E}-01$ & 4.47E-01 & GSE2053 & Homo sapiens & RA & Synovial membrane \\
\hline 284 & 1.01 & $3.14 \mathrm{E}-01$ & 4.54E-01 & GSE1037 & Homo sapiens & Adenocarcinoma of lung & Lung tissue \\
\hline 285 & 1 & 3.18E-01 & 4.58E-01 & GSE4333 & Mus musculus & Lymphatic edema & Skin tissue \\
\hline 286 & 0.99 & $3.22 \mathrm{E}-01$ & 4.62E-01 & GSE10964 & Mus musculus & COPD & Lung \\
\hline 287 & 0.99 & $3.28 \mathrm{E}-01$ & 4.69E-01 & GSE2657 & Homo sapiens & Sarcoidosis & T lymphocyte \\
\hline 288 & 0.96 & $3.41 \mathrm{E}-01$ & 4.81E-01 & GSE1767 & Homo sapiens & Huntington's disease & Blood \\
\hline 289 & 0.96 & 3.35E-01 & 4.77E-01 & GSE7753 & Homo sapiens & JRA & Peripheral blood mononuclear cell \\
\hline 290 & 0.95 & $3.40 \mathrm{E}-01$ & 4.81E-01 & GSE4125 & Homo sapiens & Adenocarcinoma of kidney & Kidney \\
\hline 291 & 0.94 & $3.46 \mathrm{E}-01$ & 4.87E-01 & GSE8762 & Homo sapiens & Huntington's disease & Lymphocyte \\
\hline 292 & 0.93 & $3.48 \mathrm{E}-01$ & 4.88E-01 & GSE5788 & Homo sapiens & Leukemia, chronic T cell & T lymphocyte \\
\hline 293 & 0.92 & $3.56 \mathrm{E}-01$ & 4.98E-01 & GSE483 & Mus musculus & Asthma, allergic & Lung tissue \\
\hline 294 & 0.91 & $3.58 \mathrm{E}-01$ & 4.99E-01 & GSE2566 & Rattus norvegicus & Neurogenic muscular atrophy & Muscle, striated (skeletal) (MMHCC) \\
\hline 295 & 0.91 & 3.60E-01 & 4.99E-01 & GSE2600 & Homo sapiens & Anaplasmosis & Leukemic cell \\
\hline 296 & 0.91 & $3.68 \mathrm{E}-01$ & 5.06E-01 & GSE2127 & Mus musculus & Carcinoma, hepatocellular & Hepatic tissue \\
\hline 297 & 0.91 & 3.59E-01 & 4.99E-01 & GSE2052 & Homo sapiens & MCTD & Lung tissue \\
\hline 298 & 0.84 & 3.85E-01 & $5.26 \mathrm{E}-01$ & GSE2276 & Mus musculus & Asthma, allergic & Lung tissue \\
\hline 299 & 0.84 & 4.07E-01 & $5.52 \mathrm{E}-01$ & GSE4707 & Homo sapiens & Preeclampsia & Placenta \\
\hline 300 & 0.81 & 4.22E-01 & $5.68 \mathrm{E}-01$ & GSE3871 & Homo sapiens & Androgen insensitivity syndrome & Fibroblast \\
\hline 301 & 0.81 & 4.17E-01 & 5.63E-01 & GSE1606 & Mus musculus & Turner syndrome & CNS, brain (MMHCC) \\
\hline 302 & 0.8 & 4.27E-01 & 5.70E-01 & GSE1674 & Mus musculus & Hypertension & Adrenal gland \\
\hline 303 & 0.8 & 4.28E-01 & 5.70E-01 & GSE3195 & Mus musculus & Hypoxia & Fibroblast \\
\hline 304 & 0.79 & 4.28E-01 & 5.70E-01 & GSE475 & Homo sapiens & COPD & Muscle, striated (skeletal), diaphragm (MMHCC) \\
\hline 305 & 0.79 & 4.34E-01 & $5.75 \mathrm{E}-01$ & GSE1872 & Rattus norvegicus & Breast cancer & Mammary gland tissue \\
\hline 306 & 0.79 & 4.29E-01 & 5.70E-01 & GSE3868 & Homo sapiens & Cancer of prostate & Prostate \\
\hline 307 & 0.76 & 4.46E-01 & 5.87E-01 & EXPE-MEXP-669 & NULL & Neuroblastoma & Adrenal cortex \\
\hline 308 & 0.76 & 4.43E-01 & $5.85 \mathrm{E}-01$ & GSE5109 & Homo sapiens & Obesity & Muscle, striated (skeletal) (MMHCC) \\
\hline 309 & 0.73 & 4.64E-01 & 6.07E-01 & GSE1413 & Mus musculus & Cancer of prostate & Prostate \\
\hline 310 & 0.72 & 4.76E-01 & $6.18 \mathrm{E}-01$ & GSE5281 & Homo sapiens & Alzheimer's Disease & Middle temporal gyrus \\
\hline 311 & 0.72 & 4.71E-01 & $6.15 \mathrm{E}-01$ & GSE3384 & Mus musculus & Nemaline myopathy & Extensor digitorum longus muscle \\
\hline 312 & 0.69 & 4.89E-01 & $6.32 \mathrm{E}-01$ & GSE2223 & Homo sapiens & Astrocytoma & CNS, brain (MMHCC) \\
\hline 313 & 0.68 & 4.97E-01 & $6.42 \mathrm{E}-01$ & EXPE-MEXP-476 & Homo sapiens & Cancer of prostate & Endothelial cell \\
\hline 314 & 0.68 & 4.99E-01 & $6.42 \mathrm{E}-01$ & EXPE-MEXP-476 & Homo sapiens & Cancer of prostate & Endothelial cell \\
\hline 315 & 0.66 & $5.10 \mathrm{E}-01$ & $6.54 \mathrm{E}-01$ & GSE9877 & Homo sapiens & Sickle cell anemia & Endothelial cell \\
\hline 316 & 0.65 & $5.18 \mathrm{E}-01$ & $6.62 \mathrm{E}-01$ & GSE3026 & Homo sapiens & Bacterial infection & Peripheral blood mononuclear cell \\
\hline 317 & 0.63 & 5.30E-01 & 6.76E-01 & GSE128 & Mus musculus & Retinitis pigmentosa & Retina \\
\hline 318 & 0.61 & 5.34E-01 & $6.77 \mathrm{E}-01$ & GSE1379 & Homo sapiens & Breast cancer & Mammary gland tissue \\
\hline 319 & 0.58 & 5.63E-01 & $7.02 \mathrm{E}-01$ & GSE867 & Mus musculus & Hepatitis, autoimmune & Hepatic tissue \\
\hline 320 & 0.58 & $5.63 E-01$ & 7.02E-01 & GSE465 & Homo sapiens & DMD & Muscle, striated (skeletal) (MMHCC) \\
\hline 321 & 0.58 & $5.61 \mathrm{E}-01$ & 7.02E-01 & GSE1871 & Mus musculus & Acute lung injury & Lung tissue \\
\hline 322 & 0.57 & $5.65 \mathrm{E}-01$ & 7.02E-01 & GSE5900 & Homo sapiens & MGUS & Bone marrow \\
\hline 323 & 0.57 & 5.70E-01 & 7.02E-01 & GSE2223 & Homo sapiens & Oligodendroglioma & CNS, brain (MMHCC) \\
\hline 324 & 0.57 & $5.65 \mathrm{E}-01$ & 7.02E-01 & GSE1055 & Rattus norvegicus & Cardiac hypertrophy & Cardiomyocyte \\
\hline 325 & 0.57 & $5.70 \mathrm{E}-01$ & 7.02E-01 & GSE4748 & Homo sapiens & Bacterial infection & Dendritic cell \\
\hline 326 & 0.57 & 5.73E-01 & 7.03E-01 & GSE3384 & Mus musculus & Nemaline myopathy & Muscle, striated (skeletal), diaphragm (MMHCC) \\
\hline 327 & 0.57 & $5.70 \mathrm{E}-01$ & 7.02E-01 & GSE2236 & Mus musculus & Congestive heart disease & Myocardial tissue \\
\hline 328 & 0.56 & 5.74E-01 & 7.03E-01 & GSE1008 & Mus musculus & DMD & Extraocular muscle \\
\hline 329 & 0.53 & $5.90 \mathrm{E}-01$ & 7.15E-01 & GSE1472 & Mus musculus & DMD & Extraocular muscle \\
\hline 330 & 0.53 & $6.02 \mathrm{E}-01$ & $7.20 \mathrm{E}-01$ & GSE85 & Mus musculus & APECED & Thymic epithelial cell \\
\hline 331 & 0.53 & $5.92 \mathrm{E}-01$ & 7.15E-01 & GSE1849 & Homo sapiens & Sickle cell anemia & Pulmonary artery \\
\hline 332 & 0.52 & $5.99 E-01$ & 7.19E-01 & GSE3311 & Rattus norvegicus & Alcohol poisoning & Pancreas \\
\hline 333 & 0.51 & $6.03 E-01$ & 7.21E-01 & GSE2503 & Homo sapiens & Squamous cell carcinoma & Skin tissue \\
\hline 334 & 0.5 & $6.17 \mathrm{E}-01$ & 7.35E-01 & GSE2899 & Mus musculus & Type 2 diabetes mellitus & Hepatic tissue \\
\hline 335 & 0.48 & $6.26 \mathrm{E}-01$ & 7.42E-01 & GSE1739 & Homo sapiens & SARS & Peripheral blood mononuclear cell \\
\hline 336 & 0.46 & $6.46 \mathrm{E}-01$ & 7.57E-01 & GSE5900 & Homo sapiens & Smoldering multiple myeloma & Bone marrow \\
\hline 337 & 0.45 & $6.64 \mathrm{E}-01$ & 7.74E-01 & GSE4678 & Mus musculus & Ventricular hypertrophy & Myocardial tissue \\
\hline 338 & 0.43 & 6.63E-01 & 7.74E-01 & GSE4128 & Mus musculus & Adenovirus infection & Hepatic tissue \\
\hline 339 & 0.42 & $6.79 \mathrm{E}-01$ & 7.81E-01 & GSE11889 & Homo sapiens & $\mathrm{CML}$ & Hematopoietic stem cell \\
\hline 340 & 0.42 & $6.72 \mathrm{E}-01$ & 7.79E-01 & GSE2779 & Homo sapiens & Vitamin B 12 deficiency & Bone marrow stem cell \\
\hline 341 & 0.4 & $6.89 \mathrm{E}-01$ & 7.90E-01 & GSE3 & Homo sapiens & Clear cell carcinoma of kidney & Renal cell \\
\hline 342 & 0.38 & 7.02E-01 & 7.97E-01 & GSE9692 & Homo sapiens & Septic shock & Whole blood \\
\hline 343 & 0.38 & 7.10E-01 & 8.01E-01 & GSE6740 & Homo sapiens & $\begin{array}{l}\text { HIV } \\
\text { ontinued) }\end{array}$ & T lymphocyte \\
\hline
\end{tabular}


Table 3: Continued

\begin{tabular}{|c|c|c|c|c|c|c|c|}
\hline Rank & $\begin{array}{l}\text { Normalized } \\
\text { molecular } \\
\text { match score }\end{array}$ & Emp_pval & FDR & Source_dat & Species & Disease & Tissue \\
\hline 344 & 0.36 & 7.13E-01 & 8.03E-01 & GSE121 & Homo sapiens & Type 2 diabetes mellitus & Muscle tissue \\
\hline 345 & 0.36 & $7.25 \mathrm{E}-01$ & 8.14E-01 & GSE1402 & Homo sapiens & Spondyloarthropathy & Peripheral blood mononuclear cell \\
\hline 346 & 0.34 & 7.34E-01 & 8.20E-01 & GSE2271 & Mus musculus & Hypoxia & Heart \\
\hline 347 & 0.34 & 7.40E-01 & $8.21 \mathrm{E}-01$ & GSE2466 & Homo sapiens & Lymphocytic leukemia, chronic, B Cell & PBL \\
\hline 348 & 0.34 & 7.37E-01 & 8.21E-01 & GSE1751 & Homo sapiens & Huntington's disease & Blood \\
\hline 349 & 0.28 & 7.76E-01 & $8.48 \mathrm{E}-01$ & GSE10211 & Mus musculus & Sendai virus infection & Tracheal epithelium \\
\hline 350 & 0.27 & 7.86E-01 & 8.57E-01 & GSE2379 & Homo sapiens & Hypopharyngeal cancer & Pharynx \\
\hline 351 & 0.25 & 8.01E-01 & 8.70E-01 & GSE2884 & Rattus norvegicus & Neurological pain disorder & Dorsal root ganglia \\
\hline 352 & 0.24 & 8.02E-01 & 8.70E-01 & GSE1560 & Mus musculus & Atherosclerosis & Aorta smooth muscle tissue \\
\hline 353 & 0.19 & 8.51E-01 & $9.11 \mathrm{E}-01$ & GSE18803 & Rattus norvegicus & Neurological pain disorder & CNS, spinal cord (MMHCC) \\
\hline 354 & 0.17 & 8.63E-01 & $9.18 \mathrm{E}-01$ & GSE1124 & Homo sapiens & Malaria & Blood \\
\hline 355 & 0.17 & 8.69E-01 & 9.19E-01 & EXPE-MEXP-1050 & Homo sapiens & IUGR & Decidua basalis \\
\hline 356 & 0.15 & 8.82E-01 & $9.28 \mathrm{E}-01$ & GSE4697 & Mus musculus & Obesity & Adipose tissue \\
\hline 357 & 0.12 & $9.02 \mathrm{E}-01$ & $9.43 \mathrm{E}-01$ & GSE3249 & Mus musculus & Leber congenital amaurosis & Retina \\
\hline 358 & 0.12 & $9.02 \mathrm{E}-01$ & 9.43E-01 & GSE1852 & Mus musculus & Marfan's syndrome & Myocardial tissue \\
\hline 359 & 0.08 & $9.34 \mathrm{E}-01$ & $9.66 \mathrm{E}-01$ & GSE7654 & Rattus norvegicus & Hepatitis & Liver \\
\hline 360 & 0.08 & 9.35E-01 & $9.66 \mathrm{E}-01$ & GSE2504 & Homo sapiens & HIV & T lymphocyte \\
\hline 361 & 0.08 & $9.39 \mathrm{E}-01$ & $9.66 \mathrm{E}-01$ & GSE1710 & Homo sapiens & Ulcerative colitis & Sigmoid colon \\
\hline 362 & 0.08 & $9.40 \mathrm{E}-01$ & $9.66 \mathrm{E}-01$ & GSE3167 & Homo sapiens & Urothelial carcinoma & Urothelium \\
\hline 363 & 0.07 & $9.45 \mathrm{E}-01$ & $9.66 \mathrm{E}-01$ & GSE5281 & Homo sapiens & Alzheimer's disease & Entorhinal cortex \\
\hline 364 & 0.07 & $9.46 \mathrm{E}-01$ & 9.66E-01 & GSE3586 & Homo sapiens & Cardiomyopathy, dilated & Myocardial tissue \\
\hline 365 & 0.04 & $9.70 \mathrm{E}-01$ & $9.88 \mathrm{E}-01$ & GSE10758 & Homo sapiens & Down syndrome & Fetus \\
\hline 366 & 0.02 & $9.82 \mathrm{E}-01$ & $9.89 \mathrm{E}-01$ & GSE15966 & Homo sapiens & Gastrointestinal stromal tumor & Gastric tissue \\
\hline 367 & 0.01 & $9.94 \mathrm{E}-01$ & 9.96E-01 & GSE11969 & Homo sapiens & Small cell carcinoma of lung & Lung tissue \\
\hline 368 & 0 & $9.98 \mathrm{E}-01$ & $9.98 \mathrm{E}-01$ & GSE4482 & Homo sapiens & Cancer of cervix & Cervix \\
\hline 369 & -0.01 & 9.93E-01 & 9.96E-01 & GSE11393 & Homo sapiens & Familial combined hyperlipidemia & Blood monocyte \\
\hline 370 & -0.02 & $9.81 \mathrm{E}-01$ & $9.89 \mathrm{E}-01$ & GSE10474 & Homo sapiens & Acute lung injury & Whole blood \\
\hline 371 & -0.02 & $9.81 \mathrm{E}-01$ & $9.89 \mathrm{E}-01$ & GSE574 & Homo sapiens & Purpura, idiopathic thrombocytopenic & T lymphocyte \\
\hline 372 & -0.02 & $9.80 \mathrm{E}-01$ & $9.89 \mathrm{E}-01$ & GSE3827 & Homo sapiens & $\mathrm{CBCL}$ & Skin tissue \\
\hline 373 & -0.03 & $9.76 \mathrm{E}-01$ & 9.89E-01 & GSE8835 & Homo sapiens & $\begin{array}{l}\text { B-cell chronic lymphocytic leukemia/small } \\
\text { lymphocytic lymphoma }\end{array}$ & Peripheral blood mononuclear cell \\
\hline 374 & -0.07 & $9.42 \mathrm{E}-01$ & $9.66 \mathrm{E}-01$ & GSE2779 & Homo sapiens & Folic acid deficiency & Bone marrow stem cell \\
\hline 375 & -0.1 & $9.19 \mathrm{E}-01$ & $9.54 \mathrm{E}-01$ & GSE860 & Homo sapiens & PTSD & Peripheral blood mononuclear cell \\
\hline 376 & -0.11 & $9.18 \mathrm{E}-01$ & $9.54 \mathrm{E}-01$ & GSE2935 & Mus musculus & Sendai virus infection & Macrophage \\
\hline 377 & -0.11 & $9.15 \mathrm{E}-01$ & $9.54 \mathrm{E}-01$ & GSE4483 & Homo sapiens & Hypoxia & Astrocyte \\
\hline 378 & -0.14 & 8.89E-01 & $9.34 \mathrm{E}-01$ & GSE1650 & Homo sapiens & COPD & Lung tissue \\
\hline 379 & -0.16 & 8.74E-01 & 9.23E-01 & EXPE-MEXP-1278 & Rattus norvegicus & Arteriotomy & Carotid artery \\
\hline 380 & -0.17 & $8.68 \mathrm{E}-01$ & $9.19 \mathrm{E}-01$ & GSE1541 & Homo sapiens & Lung injury & Lung tissue \\
\hline 381 & -0.18 & $8.52 \mathrm{E}-01$ & $9.11 \mathrm{E}-01$ & GSE2899 & Mus musculus & Type 2 diabetes mellitus & pancreatic islet \\
\hline 382 & -0.19 & 8.55E-01 & $9.12 \mathrm{E}-01$ & GSE935 & Homo sapiens & Granulomatous disease, chronic & Blood neutrophil \\
\hline 383 & -0.19 & $8.42 \mathrm{E}-01$ & 9.06E-01 & GSE2171 & Homo sapiens & HIV infection & Peripheral blood mononuclear cell \\
\hline 384 & -0.2 & $8.46 \mathrm{E}-01$ & $9.08 \mathrm{E}-01$ & GSE4036 & Homo sapiens & Schizophrenia & CNS, brain, cerebellum (MMHCC) \\
\hline 385 & -0.22 & 8.27E-01 & 8.93E-01 & GSE14245 & Homo sapiens & Malignant tumor of pancreas & Saliva \\
\hline 386 & -0.24 & 8.06E-01 & $8.72 \mathrm{E}-01$ & GSE2459 & Mus musculus & Hypertrophy, left ventricular & Myocardial tissue \\
\hline 387 & -0.29 & 7.69E-01 & 8.44E-01 & GSE1818 & Homo sapiens & Cancer of the testis & Testis \\
\hline 388 & -0.29 & 7.71E-01 & 8.44E-01 & GSE10789 & Homo sapiens & Leukemia, adult T cell & Blood monocyte \\
\hline 389 & -0.3 & 7.66E-01 & 8.43E-01 & GSE2368 & Mus musculus & Ventilator-associated lung injury & Lung tissue \\
\hline 390 & -0.32 & 7.59E-01 & 8.38E-01 & GSE11 & Mus musculus & Type 1 diabetes mellitus & Splenic tissue \\
\hline 391 & -0.32 & 7.44E-01 & 8.24E-01 & GSE2507 & Mus musculus & Muscular dystrophy & Myocardial tissue \\
\hline 392 & -0.34 & 7.39E-01 & $8.21 \mathrm{E}-01$ & GSE11969 & Homo sapiens & Adenocarcinoma of lung & Lung tissue \\
\hline 393 & -0.34 & 7.29E-01 & 8.17E-01 & GSE3 & Homo sapiens & Chromophil carcinoma of kidney & Renal cell \\
\hline 394 & -0.37 & 7.05E-01 & 7.99E-01 & GSE1710 & Homo sapiens & Crohn's disease & Sigmoid colon \\
\hline 395 & -0.38 & 6.97E-01 & 7.93E-01 & GSE1987 & Homo sapiens & Squamous cell carcinoma & Lung tissue \\
\hline 396 & -0.4 & $6.96 \mathrm{E}-01$ & 7.93E-01 & GSE1719 & Homo sapiens & Macular degeneration & Fibroblast \\
\hline 397 & -0.4 & $6.91 \mathrm{E}-01$ & 7.90E-01 & GSE2737 & Homo sapiens & Psoriasis vulgaris & Epidermis \\
\hline 398 & -0.41 & $6.78 \mathrm{E}-01$ & 7.81E-01 & GSE2729 & Homo sapiens & Rotavirus infection of children & Peripheral blood mononuclear cell \\
\hline 399 & -0.41 & $6.78 \mathrm{E}-01$ & $7.81 \mathrm{E}-01$ & GSE14577 & Homo sapiens & CFS & Peripheral blood mononuclear cell \\
\hline 400 & -0.43 & $6.66 \mathrm{E}-01$ & 7.74E-01 & GSE363 & Mus musculus & Atherosclerosis & Hepatic tissue \\
\hline 401 & -0.46 & $6.46 \mathrm{E}-01$ & 7.57E-01 & GSE1987 & Homo sapiens & Adenocarcinoma of lung & Lung tissue \\
\hline 402 & -0.47 & $6.42 \mathrm{E}-01$ & 7.57E-01 & GSE1786 & Homo sapiens & Senescence & Muscle, striated (skeletal) (MMHCC) \\
\hline 403 & -0.47 & 6.33E-01 & 7.48E-01 & GSE2018 & Homo sapiens & Lung transplant rejection & Lung tissue \\
\hline 404 & -0.49 & $6.26 \mathrm{E}-01$ & 7.42E-01 & GSE5113 & Mus musculus & Intestinal flagellate infection & Small intestinal lamina propria \\
\hline 405 & -0.52 & 5.99E-01 & 7.19E-01 & GSE4646 & Homo sapiens & Meningococcal infection & Umbilical vein \\
\hline 406 & -0.54 & $5.89 \mathrm{E}-01$ & 7.15E-01 & GSE3934 & Homo sapiens & Meningococcal infection & Blood \\
\hline 407 & -0.54 & $5.86 \mathrm{E}-01$ & 7.13E-01 & GSE11969 & Homo sapiens & Squamous cell carcinoma of lung & Lung tissue \\
\hline 408 & -0.55 & $5.80 \mathrm{E}-01$ & 7.08E-01 & GSE3606 & Homo sapiens & Overexertion & Leukocyte \\
\hline 409 & -0.59 & $5.55 \mathrm{E}-01$ & $6.99 \mathrm{E}-01$ & GSE2378 & Homo sapiens & Glaucoma & Astrocyte \\
\hline 410 & -0.61 & $5.43 \mathrm{E}-01$ & $6.86 \mathrm{E}-01$ & GSE11969 & Homo sapiens & Large cell carcinoma of lung & Lung tissue \\
\hline 411 & -0.63 & 5.34E-01 & 6.77E-01 & GSE1907 & Homo sapiens & Sarcoidosis & Blood corpuscle \\
\hline 412 & -0.7 & 4.74E-01 & 6.17E-01 & GSE3100 & Mus musculus & Cystic fibrosis & Lung \\
\hline 413 & -0.74 & 4.62E-01 & $6.07 \mathrm{E}-01$ & GSE7277 & Mus musculus & Arthritis & frontal cortex \\
\hline 414 & -0.85 & 3.97E-01 & 5.39E-01 & GSE3384 & Mus musculus & Nemaline myopathy & Gastrocnemius muscle \\
\hline 415 & -0.85 & 3.95E-01 & 5.38E-01 & GSE1363 & Mus musculus & Primary pulmonary hypoplasia & Lung tissue \\
\hline 416 & -0.86 & $3.85 \mathrm{E}-01$ & $5.26 \mathrm{E}-01$ & GSE11886 & Homo sapiens & Ankylosing spondylitis & macrophage \\
\hline 417 & -0.9 & 3.66E-01 & 5.05E-01 & GSE1542 & Homo sapiens & Duct cell carcinoma & Pancreas \\
\hline 418 & -0.94 & 3.40E-01 & 4.81E-01 & GSE3414 & Mus musculus & SCID & Lung tissue \\
\hline 419 & -1.04 & $2.98 \mathrm{E}-01$ & 4.35E-01 & GSE2223 & Homo sapiens & Anaplastic oligoastrocytoma & CNS, brain (MMHCC) \\
\hline 420 & -1.11 & 2.66E-01 & 3.97E-01 & GSE1615 & $\begin{array}{l}\text { Homo sapiens } \\
\text { (Continued) }\end{array}$ & Polycystic ovary syndrome & Theca cells \\
\hline
\end{tabular}


Table 3: Continued

\begin{tabular}{|c|c|c|c|c|c|c|c|}
\hline Rank & $\begin{array}{l}\text { Normalized } \\
\text { molecular } \\
\text { match score }\end{array}$ & Emp_pval & FDR & Source_dat & Species & Disease & Tissue \\
\hline 421 & -1.17 & $2.41 \mathrm{E}-01$ & 3.70E-01 & GSE1402 & Homo sapiens & Chronic polyarticular juvenile rheumatoid arthritis & Peripheral blood mononuclear cell \\
\hline 422 & -1.18 & 2.37E-01 & 3.65E-01 & GSE5786 & Mus musculus & Huntington's disease & CNS, brain, striatum (MMHCC) \\
\hline 423 & -1.23 & 2.19E-01 & $3.42 \mathrm{E}-01$ & GSE3284 & Homo sapiens & Bacterial infection & Leukocyte \\
\hline 424 & -1.28 & $2.01 \mathrm{E}-01$ & $3.18 \mathrm{E}-01$ & GSE3512 & Rattus norvegicus & Hyperlipidemia & Hepatic tissue \\
\hline 425 & -1.29 & $1.97 \mathrm{E}-01$ & $3.16 \mathrm{E}-01$ & EXPE-MEXP-357 & Rattus norvegicus & Hypertension & Left ventricle \\
\hline 426 & -1.36 & 1.75E-01 & $2.88 \mathrm{E}-01$ & GSE4630 & Homo sapiens & Hypoxia & macrophage \\
\hline 427 & -1.38 & $1.68 \mathrm{E}-01$ & $2.80 \mathrm{E}-01$ & GSE1294 & Mus musculus & Down's syndrome & CNS, brain (MMHCC) \\
\hline 428 & -1.39 & $1.61 \mathrm{E}-01$ & $2.70 \mathrm{E}-01$ & GSE5112 & Mus musculus & Intestinal flagellate infection & Intestinal epithelium \\
\hline 429 & -1.42 & $1.53 \mathrm{E}-01$ & 2.61E-01 & GSE2006 & Homo sapiens & Essential thrombocythemia & Thrombocyte \\
\hline 430 & -1.44 & $1.46 \mathrm{E}-01$ & $2.52 \mathrm{E}-01$ & GSE1402 & Homo sapiens & Pauciarticular juvenile arthritis & Peripheral blood mononuclear cell \\
\hline 431 & -1.54 & $1.24 \mathrm{E}-01$ & 2.25E-01 & EXPE-MEXP-1283 & Homo sapiens & Hodgkin's lymphoma & Peripheral blood mononuclear cell \\
\hline 432 & -1.63 & $1.03 \mathrm{E}-01$ & $1.94 \mathrm{E}-01$ & GSE1919 & Homo sapiens & RA & Synovial membrane \\
\hline 433 & -1.73 & $8.56 \mathrm{E}-02$ & $1.69 \mathrm{E}-01$ & GSE2395 & Homo sapiens & Cystic fibrosis & Bronchial epithelium \\
\hline 434 & -1.74 & 8.09E-02 & $1.60 \mathrm{E}-01$ & GSE6435 & Mus musculus & Bacterial infection & Leukocyte, monocyte, macrophage (MMHCC) \\
\hline 435 & -1.76 & 7.44E-02 & $1.50 \mathrm{E}-01$ & GSE1919 & Homo sapiens & Osteoarthritis & Synovial membrane \\
\hline 436 & -2.77 & $4.80 \mathrm{E}-03$ & $1.74 \mathrm{E}-02$ & GSE10121 & Homo sapiens & Squamous cell carcinoma of buccal mucosa & Buccal mucosa \\
\hline
\end{tabular}

We computationally matched the juvenile plasticity signature to 436 disease signatures derived from public microarray data. This systematic method applies a rank-based molecular matching algorithm to determine the molecular concordance between the plasticity signature and a given disease signature, where high scores indicate that plasticity genes are significantly dysregulated by the disease and low scores indicate that the disease has no impact on plasticity genes. Highly ranked diseases included not only brain disorders known to disrupt plasticity such as Huntington's disease, but also non-neurologic disorders (e.g., bacterial infections, inflammatory bowel disease, metabolic diseases), suggesting that a broad range of disease states may impact molecular pathways involved in plasticity. ALS, Amyotrophic lateral sclerosis; AML, acute myeloid leukemia; APECED, autoimmune polyendocrinopathy-candidiasis-ectodermal dystrophy; CBCL, cutaneous B-cell lymphoma; CFS, chronic fatigue syndrome; CML, chronic myeloid leukemia; COPD, chronic obstructive pulmonary disease; DMD, Duchenne muscular dystrophy; FDIU, fetal death in utero; FDR, false discovery rate; GERD, gastroesophageal reflux disease; HIV, human immunodeficiency virus; IBD, inflammatory bowel disease; IBS, irritable bowel syndrome; IUGR, intrauterine growth retardation; JRA, juvenile rheumatoid arthritis; LGLL, large granular lymphocytic leukemia; MCTD, mixed connective tissue disease; MDS, myelodysplastic syndrome; MGUS, Monoclonal gammopathy of undetermined significance; MMHCC, Mouse Models of Human Cancers Consortium; MODY, maturity onset diabetes in youth type 1; MS, multiple sclerosis; PBL, peripheral blood lymphocyte; PTSD, post-traumatic stress disorder; RA, rheumatoid arthritis; SARS, severe acute respiratory syndrome; SCID, severe combined immunodeficiency.

Table 4: Lynx1-1- plasticity signature

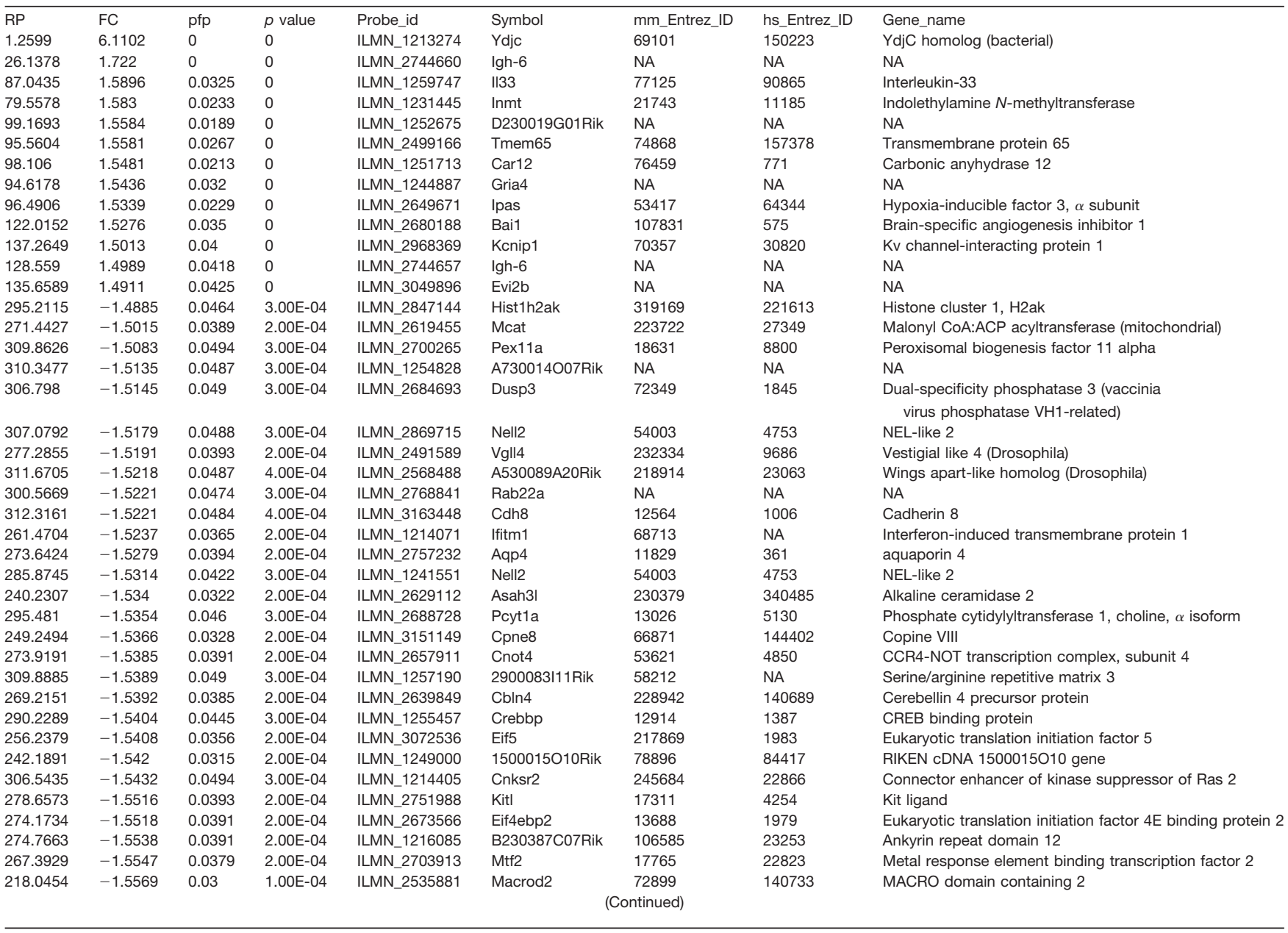


Table 4: Continued

\begin{tabular}{|c|c|c|c|c|c|c|c|c|}
\hline $\mathrm{RP}$ & FC & pfp & $p$ value & Probe_id & Symbol & mm_Entrez_ID & hs_Entrez_ID & Gene_name \\
\hline 298.574 & -1.5571 & 0.0468 & 3.00E-04 & ILMN_1246494 & LOC381445 & 26422 & 26960 & Neurobeachin \\
\hline 240.5714 & -1.5576 & 0.0318 & $2.00 \mathrm{E}-04$ & ILMN_1225224 & Ttc14 & 67120 & 151613 & Tetratricopeptide repeat domain 14 \\
\hline 257.4399 & -1.5601 & 0.0364 & $2.00 \mathrm{E}-04$ & ILMN_1259724 & Man1b & 17156 & 10905 & Mannosidase, $\alpha$, class $1 \mathrm{~A}$, member 2 \\
\hline 225.5851 & -1.5603 & 0.0305 & $1.00 \mathrm{E}-04$ & ILMN_1227376 & BC042720 & 329178 & 285175 & unc-80 homolog (Caenorhabditis elegans) \\
\hline 233.0899 & -1.5645 & 0.0306 & $1.00 \mathrm{E}-04$ & ILMN_2741677 & Bach1 & 12013 & 571 & BTB and CNC homology 1 \\
\hline 241.988 & -1.5645 & 0.0319 & $2.00 \mathrm{E}-04$ & ILMN_1230312 & A830054O04Rik & NA & NA & NA \\
\hline 309.3927 & -1.5684 & 0.0497 & 3.00E-04 & ILMN_2793638 & H2-Tw3 & NA & NA & NA \\
\hline 275.3065 & -1.5696 & 0.0391 & $2.00 \mathrm{E}-04$ & ILMN_2757889 & Zfp91-cntf & NA & NA & NA \\
\hline 225.8264 & -1.5706 & 0.0301 & $1.00 \mathrm{E}-04$ & ILMN_2654822 & Chd4 & 107932 & 1108 & Chromodomain helicase DNA binding protein 4 \\
\hline 247.466 & -1.5728 & 0.0324 & 2.00E-04 & ILMN_2731854 & Creg2 & 263764 & 200407 & Cellular repressor of E1A-stimulated genes 2 \\
\hline 218.4269 & -1.5755 & 0.0297 & $1.00 \mathrm{E}-04$ & ILMN_1221598 & 9330133014Rik & NA & NA & NA \\
\hline 259.2859 & -1.578 & 0.0363 & 2.00E-04 & ILMN_1227149 & Meg3 & 17263 & NA & Maternally expressed 3 \\
\hline 245.0182 & -1.579 & 0.032 & $2.00 \mathrm{E}-04$ & ILMN_2601176 & Meg3 & 17263 & NA & Maternally expressed 3 \\
\hline 246.2646 & -1.5793 & 0.0323 & $2.00 \mathrm{E}-04$ & ILMN_1230605 & Gm336 & 212285 & 116984 & ArfGAP with RhoGAP domain, ankyrin repeat and PH domain 2 \\
\hline 225.2295 & -1.5805 & 0.0309 & $1.00 \mathrm{E}-04$ & ILMN_2638066 & Gria3 & 53623 & 2892 & Glutamate receptor, ionotropic, AMPA3 (alpha 3) \\
\hline 224.7568 & -1.5808 & 0.0311 & $1.00 \mathrm{E}-04$ & ILMN_1253224 & Dhcr24 & 74754 & 1718 & 24-Dehydrocholesterol reductase \\
\hline 204.3878 & -1.5825 & 0.0256 & 1.00E-04 & ILMN_2544603 & 2610015J01Rik & 67039 & NA & RNA binding motif protein 25 \\
\hline 190.3687 & -1.5853 & 0.0233 & 1.00E-04 & ILMN_2593230 & Mllt4 & 17356 & 4301 & $\begin{array}{l}\text { Myeloid/lymphoid or mixed-lineage leukemia (trithorax } \\
\text { homolog, Drosophila); translocated to, } 4\end{array}$ \\
\hline 190.5304 & -1.5853 & 0.0225 & $1.00 \mathrm{E}-04$ & ILMN_2519673 & Vwf & 22371 & 7450 & Von Willebrand factor homolog \\
\hline 194.1056 & -1.5868 & 0.0229 & $1.00 \mathrm{E}-04$ & ILMN_1215713 & Egr4 & 13656 & 1961 & Early growth response 4 \\
\hline 220.9951 & -1.5896 & 0.0293 & 1.00E-04 & ILMN_1239599 & Bat2d & 226562 & 23215 & Proline-rich coiled-coil $2 \mathrm{C}$ \\
\hline 218.0063 & -1.5911 & 0.0304 & $1.00 \mathrm{E}-04$ & ILMN_2637413 & Dbpht2 & 386753 & NA & DNA binding protein with his-thr domain \\
\hline 185.7923 & -1.5957 & 0.023 & 1.00E-04 & ILMN_1247295 & Hook1 & 77963 & 51361 & Hook homolog 1 (Drosophila) \\
\hline 225.437 & -1.5957 & 0.0309 & $1.00 \mathrm{E}-04$ & ILMN_2520582 & Plxna4 & 243743 & 91584 & Plexin A4 \\
\hline 204.4627 & -1.6008 & 0.0249 & $1.00 \mathrm{E}-04$ & ILMN_2674890 & Tbl1x & 21372 & 6907 & Transducin $(\beta)$-like 1 X-linked \\
\hline 198.2794 & -1.6018 & 0.0238 & $1.00 \mathrm{E}-04$ & ILMN_2541675 & LOC382128 & 319675 & 85459 & RIKEN cDNA 5830418K08 gene \\
\hline 202.278 & -1.6049 & 0.0251 & $1.00 \mathrm{E}-04$ & ILMN_2690603 & Spp1 & 20750 & 6696 & Secreted phosphoprotein 1 \\
\hline 204.4135 & -1.6064 & 0.0252 & 1.00E-04 & ILMN_1224992 & Gcap14 & 72972 & 54462 & Coiled-coil serine rich 2 \\
\hline 236.1982 & -1.609 & 0.0309 & $2.00 \mathrm{E}-04$ & ILMN_1235124 & Thsd4 & 207596 & 79875 & Thrombospondin, type I, domain containing 4 \\
\hline 193.5829 & -1.616 & 0.0231 & $1.00 \mathrm{E}-04$ & ILMN_2737867 & Mtap1b & 17755 & 4131 & Microtubule-associated protein 1B \\
\hline 219.8212 & -1.616 & 0.0296 & $1.00 \mathrm{E}-04$ & ILMN_1254547 & $\mathrm{Nr} 4 \mathrm{a} 2$ & 18227 & 4929 & Nuclear receptor subfamily 4 , group A, member 2 \\
\hline 174.6364 & -1.6168 & 0.0212 & 1.00E-04 & ILMN_1235652 & Usp37 & 319651 & 57695 & Ubiquitin-specific peptidase 37 \\
\hline 190.4584 & -1.6202 & 0.0229 & 1.00E-04 & ILMN_1255854 & Mtap9 & 213582 & 79884 & Microtubule-associated protein 9 \\
\hline 183.2527 & -1.6215 & 0.0226 & 1.00E-04 & ILMN_3114632 & Ddx6 & 13209 & 1656 & DEAD (Asp-Glu-Ala-Asp) box polypeptide 6 \\
\hline 168.6428 & -1.6221 & 0.0204 & 1.00E-04 & ILMN_2561533 & Vps13a & 271564 & 23230 & Vacuolar protein sorting $13 \mathrm{~A}$ (yeast) \\
\hline 169.7224 & -1.6236 & 0.0204 & 1.00E-04 & ILMN_1241229 & Bat2d & 226562 & 23215 & Proline-rich coiled-coil $2 \mathrm{C}$ \\
\hline 161.0071 & -1.6316 & 0.0176 & 0 & ILMN_1231734 & Nsd1 & 18193 & 64324 & Nuclear receptor-binding SET-domain protein 1 \\
\hline 228.5556 & -1.6327 & 0.0303 & $1.00 \mathrm{E}-04$ & ILMN_1259781 & A430041B07Rik & 328108 & 23116 & Family with sequence similarity 179 , member B \\
\hline 164.2141 & -1.6332 & 0.0193 & $1.00 \mathrm{E}-04$ & ILMN_1250030 & Cdc42ep1 & 104445 & 11135 & CDC42 effector protein (Rho GTPase binding) 1 \\
\hline 186.6603 & -1.6332 & 0.0229 & $1.00 \mathrm{E}-04$ & ILMN_2795040 & Hist1h2ad & NA & NA & NA \\
\hline 189.467 & -1.6364 & 0.0239 & 1.00E-04 & ILMN_1216322 & Hmgcs2 & 15360 & 3158 & 3-Hydroxy-3-methylglutaryl-coenzyme A synthase 2 \\
\hline 189.7896 & -1.6367 & 0.0235 & 1.00E-04 & ILMN_2646070 & Mtap1a & 17754 & 4130 & Microtubule-associated protein $1 \mathrm{~A}$ \\
\hline 173.3318 & -1.6391 & 0.0212 & $1.00 \mathrm{E}-04$ & ILMN_1229727 & Gpr123 & 52389 & 84435 & G-protein-coupled receptor 123 \\
\hline 182.5954 & -1.642 & 0.0227 & $1.00 \mathrm{E}-04$ & ILMN_2715848 & Slitrk4 & 245446 & 139065 & SLIT and NTRK-like family, member 4 \\
\hline 154.7165 & -1.6445 & 0.0157 & 0 & ILMN_2481391 & Zfp326 & 54367 & 284695 & Zinc finger protein 326 \\
\hline 144.623 & -1.6461 & 0.0132 & 0 & ILMN_1224129 & Dennd3 & 105841 & 22898 & DENN/MADD domain containing 3 \\
\hline 175.2067 & -1.6461 & 0.0208 & $1.00 \mathrm{E}-04$ & ILMN_2445958 & Tssc8 & 63830 & NA & KCNQ1 overlapping transcript 1 \\
\hline 201.9407 & -1.6496 & 0.0253 & $1.00 \mathrm{E}-04$ & ILMN_3059326 & Sparc & 20692 & 6678 & Secreted acidic cysteine-rich glycoprotein \\
\hline 153.5956 & -1.6636 & 0.0154 & 0 & ILMN_3031781 & Arid5b & 71371 & 84159 & AT-rich interactive domain 5B (MRF1-like) \\
\hline 140.1691 & -1.6694 & 0.0126 & 0 & ILMN_2481389 & Zfp326 & 54367 & 284695 & Zinc finger protein 326 \\
\hline 134.6324 & -1.67 & 0.0109 & 0 & ILMN_1257525 & Cpeb3 & 208922 & 22849 & Cytoplasmic polyadenylation element binding protein 3 \\
\hline 135.784 & -1.6706 & 0.0108 & 0 & ILMN_1237548 & 5830407P18Rik & NA & NA & NA \\
\hline 158.0665 & -1.6714 & 0.0161 & 0 & ILMN_1220048 & A330086021Rik & 434089 & NA & Predicted gene 10010 \\
\hline 131.7096 & -1.672 & 0.0116 & 0 & ILMN_1254296 & Chd1 & 12648 & 1105 & Chromodomain helicase DNA binding protein 1 \\
\hline 134.8336 & -1.6821 & 0.0106 & 0 & ILMN_2654932 & Pdap1 & 231887 & 11333 & PDGFA-associated protein 1 \\
\hline 156.3313 & -1.6827 & 0.016 & 0 & ILMN_2457731 & A930010C08Rik & NA & NA & NA \\
\hline 124.0646 & -1.6846 & 0.0117 & 0 & ILMN_2747381 & $\operatorname{Ddx} 24$ & 27225 & 57062 & DEAD (Asp-Glu-Ala-Asp) box polypeptide 24 \\
\hline 138.2192 & -1.6875 & 0.0114 & 0 & ILMN_1248181 & Zbtb7a & 16969 & 51341 & Zinc finger and BTB domain containing $7 a$ \\
\hline 109.4147 & -1.7232 & 0.0089 & 0 & ILMN_2492395 & 2900064A13Rik & NA & NA & NA \\
\hline 127.2584 & -1.7307 & 0.0116 & 0 & ILMN_1251488 & A430041B07Rik & 328108 & 23116 & Family with sequence similarity 179 , member $B$ \\
\hline 93.3629 & -1.7373 & 0.0064 & 0 & ILMN_1218471 & 3-Sep & 24050 & 55964 & Septin 3 \\
\hline 93.4053 & -1.747 & 0.0062 & 0 & ILMN_2675914 & R3hdm1 & 226412 & 23518 & $\mathrm{R} 3 \mathrm{H}$ domain containing 1 \\
\hline 124.2134 & -1.7587 & 0.0113 & 0 & ILMN_2680128 & Zc3h13 & 67302 & NA & Zinc finger $\mathrm{CCCH}$ type containing 13 \\
\hline 80.5466 & -1.7652 & 0.0055 & 0 & ILMN_1239042 & Ankhd1 & 108857 & 54882 & Ankyrin repeat and $\mathrm{KH}$ domain containing 1 \\
\hline 86.1003 & -1.7765 & 0.0054 & 0 & ILMN_3162820 & Odz4 & 23966 & 26011 & Teneurin transmembrane protein 4 \\
\hline 82.5619 & -1.7931 & 0.0057 & 0 & ILMN_1236820 & 9430047F21Rik & NA & NA & NA \\
\hline 134.4843 & -1.794 & 0.0112 & 0 & ILMN_2750515 & Fos & 14281 & 2353 & FBJ osteosarcoma oncogene \\
\hline 71.9896 & -1.8054 & 0.0055 & 0 & ILMN_1258834 & Chd1 & 12648 & 1105 & Chromodomain helicase DNA binding protein 1 \\
\hline 141.8688 & -1.8109 & 0.0128 & 0 & ILMN_3035795 & Mllt3 & 70122 & 4300 & $\begin{array}{l}\text { Myeloid/lymphoid or mixed-lineage leukemia (trithorax } \\
\text { homolog, Drosophila); translocated to, } 3\end{array}$ \\
\hline 271.3241 & -1.8126 & 0.0392 & 2.00E-04 & ILMN_2965669 & $\mathrm{XIr} 4 \mathrm{a}$ & NA & NA & NA \\
\hline 58.7952 & -1.8477 & 0.0031 & 0 & ILMN_2589525 & Cpeb3 & 208922 & 22849 & Cytoplasmic polyadenylation element binding protein 3 \\
\hline 108.4816 & -1.8546 & 0.0093 & 0 & ILMN_2803674 & S100a9 & 20202 & 6280 & S100 calcium-binding protein A9 (calgranulin B) \\
\hline 73.6082 & -1.8653 & 0.0057 & 0 & ILMN_2639442 & Rock2 & 19878 & 9475 & Rho-associated coiled-coil containing protein kinase 2 \\
\hline 65.4886 & -1.8737 & 0.0032 & 0 & ILMN_2617920 & 1110017D15Rik & 73721 & 84688 & RIKEN cDNA 1110017D15 gene \\
\hline 48.1193 & -1.9436 & 0.0021 & 0 & ILMN_1217776 & MII5 & $\begin{array}{l}69188 \\
\text { (Continued) }\end{array}$ & 55904 & Lysine $(\mathrm{K})$-specific methyltransferase $2 \mathrm{E}$ \\
\hline
\end{tabular}


Table 4: Continued

\begin{tabular}{lllllllll}
\hline RP & FC & pfp & $p$ value & Probe_id & Symbol & mm_Entrez_ID & hs_Entrez_ID & Gene_name \\
53.5131 & -1.9814 & 0.0027 & 0 & ILMN_2702303 & Ch25h & 12642 & 9023 & Cholesterol 25-hydroxylase \\
43.2714 & -2.0064 & 0.0015 & 0 & ILMN_2649773 & Slc38a5 & 209837 & 92745 & Solute carrier family 38, member 5 \\
37.5276 & -2.0092 & $9.00 E-04$ & 0 & ILMN_1244343 & B230369L08Rik & 223697 & 25777 & Sad1 and UNC84 domain containing 2 \\
41.0522 & -2.0325 & 0.0017 & 0 & ILMN_1226085 & Syt1 & NA & NA & NA \\
30.3722 & -2.0661 & 0.0011 & 0 & ILMN_1256701 & $2900016 B 01$ Rik & 74901 & 9920 & Kelch repeat and BTB (POZ) domain containing 11 \\
33.181 & -2.0665 & 0.001 & 0 & ILMN_2778076 & $2210021 J 22 R i k$ & 72355 & 150383 & Cysteine-rich, DPF motif domain containing 1 \\
61.2262 & -2.0942 & 0.0029 & 0 & ILMN_2668333 & Prg4 & 96875 & NA & Proteoglycan 4 (megakaryocyte stimulating factor, \\
& & & & & & & articular superficial zone protein) \\
61.9241 & -2.1057 & 0.0033 & 0 & ILMN_2623983 & Egr2 & 13654 & 1959 & Early growth response 2 \\
18.8649 & -2.4826 & 0.0014 & 0 & ILMN_2652500 & Lrg1 & 76905 & 116844 & Leucine-rich alpha-2-glycoprotein 1 \\
13.3721 & -2.4851 & 0 & 0 & ILMN_2654906 & Mgat3 & 17309 & 4248 & Mannoside acetylglucosaminyltransferase 3 \\
25.6626 & -2.6212 & 0.0012 & 0 & ILMN_2710905 & S100a8 & 20201 & 6279 & S100 calcium binding protein A8 (calgranulin A) \\
6.5864 & -3.7552 & 0 & 0 & ILMN_2712075 & Lcn2 & 16819 & 3934 & Lipocalin 2 \\
4.4996 & -4.7574 & 0 & 0 & ILMN_1243615 & Gramd4 & 223752 & 23151 & GRAM domain containing 4 \\
3.677 & -5.3591 & 0 & 0 & ILMN_1223734 & Atf4 & 11911 & 468 & Activating transcription factor 4 \\
2.1886 & -7.3314 & 0 & 0 & ILMN_2507182 & Tomm22 & 223696 & 56993 & Translocase of outer mitochondrial membrane 22 homolog (yeast) \\
1 & -13.9276 & 0 & 0 & ILMN_1256369 & Lynx1 & 23936 & 66004 & Ly6/neurotoxin 1
\end{tabular}

V1 transcriptomes were profiled with microarray from $L y n \times 1^{-1-}$ mice (the plasticity brake Lynx1 is genetically deleted to allow experience-dependent plasticity even in adulthood) to generate the Lynx $1^{-1-}$ plasticity differential expression signature. Using RankProd differential expression (DE) analysis, V1 of adult Lynx $1^{-1-}$ male mice $>$ P60 was compared with adult wild-type mice (>P60; $n=3$ each group) to identify 132 DE probes, which mapped to 107 unique mouse Entrez IDs. For downstream analysis, mouse Entrez IDs were mapped to human orthologs using the Mouse Genome Informatics homology reference to yield a 98 gene $L y n \times 1^{-1-}$ plasticity signature. FC, fold change. RP, rank product. pfp, percent false positive (i.e. false discovery rate).

\section{References}

Atladóttir HO, Thorsen P, Schendel DE, Østergaard L, Lemcke S, Parner ET (2010) Association of hospitalization for infection in childhood with diagnosis of autism spectrum disorders: a Danish cohort study. Arch Pediatr Adolesc Med 164:470-477. CrossRef Medline

Aton SJ, Broussard C, Dumoulin M, Seibt J, Watson A, Coleman T, Frank MG (2013) Visual experience and subsequent sleep induce sequential plastic changes in putative inhibitory and excitatory cortical neurons. Proc Natl Acad Sci U S A 110:3101-3106. CrossRef

Banks WA, Robinson SM (2010) Minimal penetration of lipopolysaccharide across the murine blood-brain barrier. Brain Behav Immun 24:102-109. CrossRef Medline

Benjamini Y, Hochberg Y (1995) Controlling the false discovery rate: a practical and powerful approach to multiple testing. J R Stat Soc Series B Stat Methodol 57:289-300.

Benros ME, Sørensen HJ, Nielsen PR, Nordentoft M, Mortensen PB, Petersen $L$ (2015) The association between infections and general cognitive ability in young men-a nationwide study. PLoS One 10:e0124005. CrossRef Medline

Bona E, Andersson A-L, Blomgren K, Gilland E, Puka-Sundvall M, Gustafson K, Hagberg H (1999) Chemokine and inflammatory cell response to hypoxia-ischemia in immature rats. Pediatr Res 45: 500-509. CrossRef Medline

Bönn M (2016) hypergea: hypergeometric tests, version 1.2.3. R Foundation.

Bukhari N, Burman PN, Hussein A, Demars MP, Sadahiro M, Brady DM, Tsirka SE, Russo SJ, Morishita H (2015) Unmasking proteolytic activity for adult visual cortex plasticity by the removal of Lynx1. J Neurosci 35:12693-12702. CrossRef Medline

Centers for Disease Control and Prevention (2013) Incidence and trends of infection with pathogens transmitted commonly through food: Foodborne Diseases Active Surveillance Network, 10 U.S. sites, 1996-2012. MMWR Morb Mortal Wkly Rep 62:283-287.

Choi GB, Yim YS, Wong H, Kim S, Kim H, Kim SV, Hoeffer CA, Littman DR, Huh JR (2016) The maternal interleukin-17a pathway in mice promotes autism-like phenotypes in offspring. Science 351:933-939. CrossRef Medline

Dalman C, Allebeck P, Gunnell D, Harrison G, Kristensson K, Lewis G, Lofving S, Rasmussen F, Wicks S, Karlsson H (2008) Infections in the CNS during childhood and the risk of subsequent psychotic illness: a cohort study of more than one million Swedish subjects. Am J Psychiatry 165:59-65. CrossRef

Datwani A, McConnell MJ, Kanold PO, Micheva KD, Busse B, Shamloo M, Smith SJ, Shatz CJ (2009) Classical MHCl molecules regulate retinogeniculate refinement and limit ocular dominance plasticity. Neuron 64:463-470. CrossRef

Dawood FS, Fiore A, Kamimoto L, Bramley A, Reingold A, Gershman K, Meek J, Hadler J, Arnold KE, Ryan P, Lynfield R, Morin C, Mueller M, Baumbach J, Zansky S, Bennett NM, Thomas A, Schaffner W, Kirschke D, Finelli L (2010) Burden of seasonal influenza hospitalization in children, United States, 2003 to 2008. J Pediatr 157:808-814. CrossRef

De Simoni MG, Perego C, Ravizza T, Moneta D, Conti M, Marchesi F, De Luigi A, Garattini S, Vezzani A (2000) Inflammatory cytokines and related genes are induced in the rat hippocampus by limbic status epilepticus. Eur J Neurosci 12:2623-2633. Medline

Dudley JT, Tibshirani R, Deshpande T, Butte AJ (2009) Disease signatures are robust across tissues and experiments. Mol Syst Biol 5:307. CrossRef

Eklind S, Hagberg H, Wang X, Sävman K, Leverin A-L, Hedtjärn M, Mallard C (2006) Effect of lipopolysaccharide on global gene expression in the immature rat brain. Pediatr Res 60:161-168. CrossRef Medline

Fagerland MW, Lydersen S, Laake P (2015) Recommended confidence intervals for two independent binomial proportions. Stat Methods Med Res 24:224-254. CrossRef Medline

Failor S, Nguyen V, Darcy DP, Cang J, Wendland MF, Stryker MP, McQuillen PS (2010) Neonatal cerebral hypoxia-ischemia impairs plasticity in rat visual cortex. J Neurosci 30:81-92. CrossRef Medline

Fox SE, Levitt P, Nelson CA III (2010) How the timing and quality of early experiences influence the development of brain architecture. Child Dev 81:28-40. CrossRef Medline

Galic MA, Riazi K, Heida JG, Mouihate A, Fournier NM, Spencer SJ, Kalynchuk LE, Teskey GC, Pittman QJ (2008) Postnatal inflammation increases seizure susceptibility in adult rats. J Neurosci 28: 6904-6913. CrossRef Medline

Gordon JA, Stryker MP (1996) Experience-dependent plasticity of binocular responses in the primary visual cortex of the mouse. $J$ Neurosci 16:3274-3286. Medline

Greifzu F, Schmidt S, Schmidt K-F, Kreikemeier K, Witte OW, Löwel $S$ (2011) Global impairment and therapeutic restoration of visual plasticity mechanisms after a localized cortical stroke. Proc Natl Acad Sci U S A 108:15450-15455. CrossRef Medline

Guan Z, Fang J (2006) Peripheral immune activation by lipopolysaccharide decreases neurotrophins in the cortex and hippocampus in rats. Brain Behav Immun 20:64-71. CrossRef

Harlow EG, Till SM, Russell TA, Wijetunge LS, Kind P, Contractor A (2010) Critical period plasticity is disrupted in the barrel cortex of Fmr1 knockout mice. Neuron 65:385-398. CrossRef Medline 
Hodos RA, Kidd BA, Shameer K, Readhead BP, Dudley JT (2016) In silico methods for drug repurposing and pharmacology. Wiley Interdiscip Rev Syst Biol Med 8:186-210. CrossRef Medline

Hong F, Breitling R, McEntee CW, Wittner BS, Nemhauser JL, Chory J (2006) RankProd: a bioconductor package for detecting differentially expressed genes in meta-analysis. Bioinformatics 22: 2825-2827. CrossRef Medline

Huang ZJ, Kirkwood A, Pizzorusso T, Porciatti V, Morales B, Bear MF, Maffei L, Tonegawa S (1999) BDNF regulates the maturation of inhibition and the critical period of plasticity in mouse visual cortex. Cell 98:739-755. Medline

Jang E, Lee S, Kim J-H, Kim J-H, Seo J-W, Lee W-H, Mori K, Nakao K, Suk K (2013) Secreted protein lipocalin-2 promotes microglial M1 polarization. FASEB J 27:1176-1190. CrossRef Medline

Johnson JS, Newport EL (1989) Critical period effects in second language learning: the influence of maturational state on the acquisition of English as a second language. Cogn Psychol 21:6099. Medline

Kaneko M, Stellwagen D, Malenka RC, Stryker MP (2008) Tumor necrosis factor- $\alpha$ mediates one component of competitive, experience-dependent plasticity in developing visual cortex. Neuron 58:673-680. CrossRef

Khandaker GM, Pearson RM, Zammit S, Lewis G, Jones PB (2014) Association of serum interleukin 6 and c-reactive protein in childhood with depression and psychosis in young adult life: a population-based longitudinal study. JAMA Psychiatry 71:11211128. Medline

Knijnenburg TA, Wessels LFA, Reinders MJT, Shmulevich I (2009) Fewer permutations, more accurate P-values. Bioinformatics 25: i161-i168. CrossRef Medline

Kuhlman SJ, Olivas ND, Tring E, Ikrar T, Xu X, Trachtenberg JT (2013) A disinhibitory microcircuit initiates critical-period plasticity in the visual cortex. Nature 501:543-546. CrossRef

Layé S, Parnet P, Goujon E, Dantzer R (1994) Peripheral administration of lipopolysaccharide induces the expression of cytokine transcripts in the brain and pituitary of mice. Mol Brain Res 27: 157-162. Medline

LeBlanc JJ, Fagiolini M (2011) Autism: a "critical period" disorder? Neural Plast 2011:921680. CrossRef

Lee FS, Heimer H, Giedd JN, Lein ES, Šestan N, Weinberger DR, Casey BJ (2014) Adolescent mental health-opportunity and obligation. Science 346:547-549. CrossRef Medline

Levelt CN, Hübener M (2012) Critical-period plasticity in the visual cortex. Annu Rev Neurosci 35:309-330. CrossRef Medline

Lewis TL, Maurer D (2005) Multiple sensitive periods in human visual development: evidence from visually deprived children. Dev Psychobiol 46:163-183. CrossRef Medline

Marom T, Tan A, Wilkinson GS, Pierson KS, Freeman JL, Chonmaitree $T$ (2014) Trends in otitis media-related health care use in the United States, 2001-2011. JAMA Pediatr 168:68-75. CrossRef Medline

Mataga N, Nagai N, Hensch TK (2002) Permissive proteolytic activity for visual cortical plasticity. Proc Natl Acad Sci U S A 99:77177721. CrossRef Medline

Milnerwood AJ, Cummings DM, Dallérac GM, Brown JY, Vatsavayai SC, Hirst MC, Rezaie P, Murphy KP (2006) Early development of aberrant synaptic plasticity in a mouse model of Huntington's disease. Hum Mol Genet 15:1690-1703.

Miwa JM, Stevens TR, King SL, Caldarone BJ, Ibanez-Tallon I, Xiao C, Fitzsimonds RM, Pavlides C, Lester HA, Picciotto MR (2006) The prototoxin lynx1 acts on nicotinic acetylcholine receptors to balance neuronal activity and survival in vivo. Neuron 51:587-600. CrossRef Medline

Morishita H, Hensch TK (2008) Critical period revisited: impact on vision. Curr Opin Neurobiol 18:101-107. CrossRef Medline

Morishita H, Miwa JM, Heintz N, Hensch TK (2010) Lynx1, a cholinergic brake, limits plasticity in adult visual cortex. Science 330: 1238-1240. CrossRef Medline
Murphy KP, Carter RJ, Lione LA, Mangiarini L, Mahal A, Bates GP, Dunnett SB, Morton AJ (2000) Abnormal synaptic plasticity and impaired spatial cognition in mice transgenic for exon 1 of the human Huntington's disease mutation. J Neurosci 20:5115-5123.

Nabel EM, Morishita H (2013) Regulating critical period plasticity: insight from the visual system to fear circuitry for therapeutic interventions. Front Psychiatry 4:146. CrossRef

Nagakura I, Wart AV, Petravicz J, Tropea D, Sur M (2014) STAT1 regulates the homeostatic component of visual cortical plasticity via an AMPA receptor-mediated mechanism. J Neurosci 34: 10256-10263. CrossRef Medline

Nelson CA, Zeanah CH, Fox NA, Marshall PJ, Smyke AT, Guthrie D (2007) Cognitive recovery in socially deprived young children: the Bucharest Early Intervention Project. Science 318:1937-1940. CrossRef Medline

Nikolopoulos TP, O'Donoghue GM, Archbold S (1999) Age at implantation: its importance in pediatric cochlear implantation. Laryngoscope 109:595-599. CrossRef Medline

Reh R, Hensch TK (2014) Transient gamma power peaks upon monocular deprivation during critical period plasticity. Soc Neurosci Abstr 40:819.16. Washington, D.C.

Richwine AF, Sparkman NL, Dilger RN, Buchanan JB, Johnson RW (2009) Cognitive deficits in interleukin-10-deficient mice after peripheral injection of lipopolysaccharide. Brain Behav Immun 23: 794-802. CrossRef Medline

Sayyah M, Javad-Pour M, Ghazi-Khansari M (2003) The bacterial endotoxin lipopolysaccharide enhances seizure susceptibility in mice: involvement of proinflammatory factors nitric oxide and prostaglandins. Neuroscience 122:1073-1080. CrossRef

Schnydrig S, Korner L, Landweer S, Ernst B, Walker G, Otten U, Kunz D (2007) Peripheral lipopolysaccharide administration transiently affects expression of brain-derived neurotrophic factor, corticotropin and proopiomelanocortin in mouse brain. Neurosci Lett 429: 69-73. CrossRef

Schorr EA, Fox NA, Wassenhove V, Knudsen El (2005) Auditoryvisual fusion in speech perception in children with cochlear implants. Proc Natl Acad Sci U S A 102:18748-18750. CrossRef Medline

Schroeter M, Jander S, Stoll G (2002) Non-invasive induction of focal cerebral ischemia in mice by photothrombosis of cortical microvessels: characterization of inflammatory responses. J Neurosci Methods 117:43-49. CrossRef

Sipe GO, Lowery RL, Tremblay M-Ė, Kelly EA, Lamantia CE, Majewska AK (2016) Microglial P2Y12 is necessary for synaptic plasticity in mouse visual cortex. Nat Commun 7:10905. CrossRef Medline

Smyth GK (2005) limma: linear models for microarray data. In: Bioinformatics and computational biology solutions using $R$ and Bioconductor (Gentleman R, Huber W, Carey VJ, Irizarry RA, Dudoit S), pp 397-420 New York: Springer. New York: Springer, p 397420.

Steullet P, Cabungcal JH, Monin A, Dwir D, O'Donnell P, Cuenod M, Do KQ (2016) Redox dysregulation, neuroinflammation, and NMDA receptor hypofunction: a "central hub" in schizophrenia pathophysiology? Schizophr Res 176:41-51. CrossRef

Subramanian A, Tamayo P, Mootha VK, Mukherjee S, Ebert BL, Gillette MA, Paulovich A, Pomeroy SL, Golub TR, Lander ES, Mesirov JP (2005) Gene set enrichment analysis: a knowledgebased approach for interpreting genome-wide expression profiles. Proc Natl Acad Sci U S A 102:15545-15550. CrossRef Medline

Syken J, GrandPre T, Kanold PO, Shatz CJ (2006) PirB restricts ocular-dominance plasticity in visual cortex. Science 313:17951800. CrossRef Medline

Takesian AE, Hensch TK (2013) Balancing plasticity/stability across brain development. In: Changing brains: applying brain plasticity to advance and recover human ability, Chap 1 (Merzenich MM, Nahum M, Van Vleet TM, eds), pp 3-34. Amsterdam: Elsevier. Elsevier, p 3-34.

Tropea D, Giacometti E, Wilson NR, Beard C, McCurry C, Fu DD, Flannery R, Jaenisch R, Sur M (2009) Partial reversal of Rett 
syndrome-like symptoms in MeCP2 mutant mice. Proc Natl Acad Sci U S A 106:2029-2034. CrossRef Medline

Usdin MT, Shelbourne PF, Myers RM, Madison DV (1999) Impaired synaptic plasticity in mice carrying the Huntington's disease mutation. Hum Mol Genet 8:839-846. Medline

Vezzani A, Granata T (2005) Brain inflammation in epilepsy: experimental and clinical evidence. Epilepsia 46:1724-1743. CrossRef Medline

Wang B-S, Sarnaik R, Cang J (2010) Critical period plasticity matches binocular orientation preference in the visual cortex. Neuron 65:246-256. CrossRef Medline

Weber-Stadlbauer U, Richetto J, Labouesse MA, Bohacek J, Mansuy IM, Meyer U (2017) Transgenerational transmission and modification of pathological traits induced by prenatal immune activation. Mol Psychiatry 22:102-112.
Weinberger DR (1987) Implications of normal brain development for the pathogenesis of schizophrenia. Arch Gen Psychiatry 44:660669. Medline

Werker JF, Hensch TK (2015) Critical periods in speech perception: new directions. Annu Rev Psychol 66:173-196. CrossRef Medline

Wiesel TN, Hubel DH (1963) Single-cell responses in striate cortex of kittens deprived of vision in one eye. J Neurophysiol 26:10031017.

Yashiro K, Riday TT, Condon KH, Roberts AC, Bernardo DR, Prakash R, Weinberg RJ, Ehlers MD, Philpot BD (2009) Ube3a is required for experience-dependent maturation of the neocortex. Nat Neurosci 12:777-783. CrossRef Medline

Zhang S-D, Gant TW (2008) A simple and robust method for connecting small-molecule drugs using gene-expression signatures. BMC Bioinformatics 9:258. CrossRef 